\title{
Wipperfürth.
}

Von

\section{Leonard Korth.}

E in le i t u ng.

Ein geistvoller Rechtslehrer hat vor kurzem der Hoffnung Ausdruck gegeben, dass jetzt endlich der Schleier sich lüften werde, welcher die Anfänge des deutschen Städtewesens so lange den Augen der Forschung verborgen hat ${ }^{1}$. Und in Wahrheit sind gerade während der jüngsten Zeit die alten verfassungsgeschichtlichen Probleme in tiberraschender Weise ihrer Lösung näher geführt worden. Dabei ist aber das eine vor allem merkwïrdig, dass nicht etwa die Aufdeckung neuer Quellen für die Geschichte der grossen, in ibrer gesammten Entwicklung bisher als vorbildlich betrachteten Gemeinwesen den Anstoss zu solchen entseheidenden Fortschritten gegeben hat, dass vielmehr der grösste Theil aller Erfolge einer aufmerksamen Beschäftigung mit den alterthiimlichen Verfassungszuständen kleinerer Städte zu verdanken ist.

Es hat lange Zeit hindurch in den Kreisen der ziinftigen Geschichtsforscher zumeist als eine unfruchtbare Bethätigung beschränkter Heimathsliebe gegolten, den Schicksalen derjenigen Orte nachzugehen, welche zu politischer Bedeutung im Reiche niemals gelangt sind. Dieses geringschätzige Urtheil ist selbstredend vollkommen berechtigt, so lange die Betrachtung rein äusserlich anf Kriegsnöthe, Btirgerzwiste und Stadtbrände sich richtet, nicht minder auch, wenn die Formen des öffentlichen und rechtlichen Verkehrs obne Riicksicht auf verwandte Bildungen und auf das gesammte Verfassungsleben des Volkes fälschlich als eigenartige Einzelerscheinungen in's Auge gefasst werden. Allein es war bedenklich, von dem gleichen Standpunkte aus verfassungsgeschichtliche Arbeiten wie die eines G. L. von Maurer zu ibbersehen oder zu verwerfen, weil sie den Ursprung der deutschen Stadt und

1) R. Sohm, Die Entstehung des deutschen Städtewesens (Leipzig 1890), S. 9. 
ibres Rechtes durch die Erforschung und Vergleichung einfacher Gebilde aufzuhellen suchten ${ }^{1}$, und ebenso ungerecht ist es, wenn G. von Below, dessen scharfsinnigen und klaren Untersuchungen wir so viel verdanken, gerade deshalb getadelt wird, weil er in seiner Beweisführung auf kleine, spät zur Entfaltung: gekommene Flecken und Städtchen Bezug genommen habe?. Seit Aloys Schulte durch seinen glücklichen Urkundenfund und mehr noch durch die sachkundige Verwerthung dieser Entdeckung bescheidene Orte wie Radolfszell und gar Allensbach gewissermassen zu Urbildern städtischer Entwicklung erhoben hat ${ }^{3}$, darf die ernste Forschung getrost auch in Kleinstädten, welche die Hoffnungen und Absichten ihrer Begrïnder getäuscht haben, lehrreiche Beispiele bürgerlicher Anfangszustände erblicken.

Gemeinwesen solcher Art sind in den niederrheinischen Gegenden besonders zahlreich. Hier wurden geistliche und weltliche Landesherren durch den frïh belebten Handelsverkehr wie durch die Nothwendigkeit, in den bunt durcheinandergeschobenen Gebietstheilen feste Sammelpunkte zu schaffen, zur Städtegründung in hervorragendem Masse hingedrängt. An welche Vorbilder sie dabei sich angelehnt, wird eine genanere Untersuchung darthun müssen. Augenfällig ist eine gewisse Vielgestaltigkeit der Verfassungen, erzeugt durch die ungemeine Verschiedenheit örtlicher Zustände und Bedürfnisse, durch die Vertheilung des geistlichen Grundbesitzes, durch die Beweglichkeit der öffentlichen Rechtsformen in diesen Landen. Deshalb wird auch eine Sammlung der niederrheinischen Stadtrechtsurkunden, wie sie die Centraldirektion der Monumenta Germaniae beabsichtigt, ganz besonders erspriesslich und belehrend sein ${ }^{4}$. In gleicher Weise aber muss es einer wissenschaftlichen Erkenntniss unserer rbeinischen Vergangenheit immer wieder zu gute kommen, wenn die innere Geschichte

1) z. B. A. Heusler, Der Ursprung der deutschen Stadtverfassung S. $160 \mathrm{f}$.

2) C. Koehne, Der Ursprung der Stadtverfassung in Worms, Speier und Mainz (Breslau 1890), S. 376; dagegen G. ron Below, Deutsche Zeitschr. f. Geschichtswissenschaft Bd. 4 (1890), S. 114.

3) A. Schulte, Ueber Reichenauer Städtegründungen im 10. und 11. Jahrhundert, mit einem ungedruckten Stadtrecht von 1100, Zeitschr. f. d. Gesch. des Oberrbeins N. F. Bd. 5 (1890) S. $137 \mathrm{ff}$.

4) Vgl. F. Frensdorff, Reisebericht, Neues Archiv der Gesellschaft f. ält. deutsche Geschichtskunde Bd. 7 (1881), S. 11 ff.; reichbaltiger 
eines einzelnen Gemeinwesens aus den Quellen bergeleitet und in ibrem lebendigen Zusammenhange mit dem Verlaufe der allgemeinen Entwicklung untersucht wird.

Ich hebe aus der grossen Zahl niederrbeinischer Landstädte Wipperfuirth heraus, den alten Hauptort des Herzogthums Berg, um zunächst in möglichster Vollständigkeit die Urkunden darzubieten, welche die Schicksale dieser Stadt, insbesondere ihre bïrgerliche und kirchliche Verfassung, allseitig erläutern. Für die Wahl gerade dieses Ortes sind mancherlei Gründe bestimmend gewesen.

Wipperfürth war lange Jahrhunderte bindurch mit dem S. Apostelstifte zu Köln auf das engste verbunden. Nun hat aber unter allen kirchlichen Genossenschaften des Kölner Sprengels keine sich unausgesetzt einer so trefflichen Güterverwaltung erfreut wie diese. Die Sorge für den ausgedehnten Besitz und für die Rechte des Stiftes war meistens Männern von juristischer Bildung anvertraut, welche zudem nicht ohne geschichtlichen Sinn ibres Amtes walteten. Diesem Umstande verdanken wir die Erhaltung zahlreicher Urkunden, welche über das Verbältniss der Stadt Wipperfuirth zu den Herren von S. Aposteln einerseits, zum Landesfürsten andererseits Auskunft ertheilen. Es kommt binzu, dass auch das bergische Herrschergeschlecht von Anfang an dem Orte, als einem Vorwerke gegen Westfalen hin, ganz besondere Bedeutung beigemessen und $\mathbf{z u}$ wiederbolten Malen in ausfiibrlichen Gunstbriefen die Rechte der Bürgerschaft festgestellt und erweitert hat.

Allem Anscheine nach sind gerade diese urkundlichen Zeugnisse allgemeineren Werthes unvermindert anf uns gekommen. Die folgenden Blätter bieten für den Zeitraum von etwa zwei Jahrbunderten nahezu vierzig: Texte, deren Bedeutung über die

ist die Zusammenstellung bei G. v. Below, Die landständ. Verfassung in Jülich u. Berg Th. 1 (Düsseldorf 1885), S. 35 ff. Von den neuesten Bearbeitungen nenne ich F. Rein hold, Verfassungs-Geschichte Wesels im Mittelalter (Untersuchgn. z. deutsch. Staats- u. Rechtsgesch. 23, Breslau 1888); W. H a r les s, Z. Gesch. der Stadt Wesel, insbes. ihrer Schöffengeschlechter, Ztschr. des Berg. Gesch. - Ver. Bd. 24 (1888), S. 57 ff.; E. L i e s e g ang, Recht u. Verfassung von Rees, Westdeutsche Zeitschr. f. Gesch. u. Kunst, Ergänzungsheft 6 (Trier 1890); endlich J. K $u$ hl, Geschichte des früheren Gymnasiums zu Jülich. Zugleich ein Beitrag zur Ortsgeschichte (Jülich 1890). 
Grenzen der blossen ortsgeschichtlichen Forschung ersichtlich weit hinausragt.

Man wird wahrnehmen, wie klar in einer ganzen Folge von Aufzeichnungen das Verhältniss der Bürgerschaft zur landesherrlichen Gewalt sich darstellt. Willkommene Aufschlüsse erhalten wir sodann über Gerichtsverfassung und Steuerwesen, über die merkwürdigen Beziehungen zu den geistlichen Grundherren und iiber die Verwaltung der Seelsorge. Endlich geht auch die äussere Geschichte der Stadt nicht leer aus.

Ich schulde nunmehr noch ein Wort über meine handschriftlichen Quellen.

I. Das Königliche Staatsarchiv zu Düsseldorf bewahrt

1. die einundzwanzig Urkunden, welche ich hier aus den Originalen zum Abdrucke gebracht habe. Ihre Benutzung ist mir durch das liebenswiurdige Entgegenkommen des Herrn Gebeimrathes Dr. W. Harless ermöglicht worden. Ebenso habe ich durch seine Güte einsehen können

2. Liber albus des S. Apostelstiftes, Düsseldorf, königl. Staatsarchiv, B. $62^{2}$, 326 Blätter, Papier, fol. Dieser um -das Jahr 1380 angelegte Kopiar enthält 317 Urkundenabschriften, und zwar Bl. 1- $284^{\text {b }}$ nach Orten geordnet 242 Nummern von einer Hand, dann wechselnde Schreiber 14. und 15. Jhdts., Bl. $318^{\mathrm{b}} \mathrm{ff}$. Pachtordnung und Beschreibung der Stiftsgüter zu Lechenich.

3. Privilegien-Abschriften der Stadt Wipperfürth, ebenda, Jülich-Berg, Städte No. 15, beschrieben unten zu No. 12.

II. Aus dem Stadtarehiv zu Köln, welches zahlreiche Bestandtheile des ehemaligen Stiftsarchivs von S. Aposteln birgt, sind benutzt

1. Liber rubeus, ältester erhaltener Kopiar des S. Apostelstiftes, früher A X 50, jetzt: Kirchliches, S. Aposteln No. 1, 68 Blätter Perg., fol., angelegt Ende 13. Jabrh., fortgeführt bis zum 15. Jahrh., 157 sorgfältige Urkunden-Abschriften enthaltend.

2. Liber Luppelheim und Liber Loen, frïher $A X 64$, zwei in einem Bande vereinigte Sammlungen von Urkunden-Abschriften, Rentregistern, Kapitelsbeschlüssen u. s. w., angelegt durch die beiden Stiftsherren Winand Luppelheim (1440-96) und Dietrich von Loen (1494-1531), im ganzen 313 und 209 Seiten, Papier, fol., bearbeitet im Jahre 1664 durch den um das Archiv des Stiftes sehr verdienten Dekan Werner Francken. 
III. Das Archiv der katholischen Pfarrkirche zu Wipperfuirth, welches werthvolle Urkunden entbalten soll, ist mir zu meinem Bedauern unzugänglich geblieben ${ }^{1}$.

Gedruckt waren von den Texten, welche hier veröffentlicht werden, bisher nur zwölf, darunter schon im Jabre 1633 der Freibrief des Erzbischofs Engelbert in den Beilagen zu Gelen's Ausgabe der Vita. Dass ich auch diese Stikcke nochmals biete, wird niemand tadeln, der die älteren Drucke mit den gegenwärtigen vergleicht. Die beiden Privilegien für Euskirchen, das eine vorher nur in sehr unzulänglicher Weise, das andere in einer schwer erreichbaren Publikation mitgetheilt, glaubte ich des Vergleiches wie der Ergänzung wegen in den Anhang aufnehmen zu dürfen.

Die urkundlichen Nachrichten über Wipperfürth in monographischer Darstellung zu verwerthen, ist wiederbolt versucht worden. Zuerst, so viel ich weiss, hat vor fünfzig Jahren F. E. von M ering die äussere Geschichte der Stadt behandelt ${ }^{2}$. Weit verdienstlicher ist das jetzt sehr selten gewordene Büchlein des Lehrers $\mathrm{J}_{\text {. }} \mathrm{J}_{0 \mathrm{hn}}{ }^{3}$; es ist mit grosser Wärme geschrieben und erfreut ubberdies durch das Bestreben, den Zusammenhang mit der allgemeinen Landesgeschichte im Auge zu behalten. Eine kunstgeschichtliche Arbeit von Strauven ${ }^{4}$ bertibrt nur ganz kurz die städtischen Verhältnisse. Die jüngste Veröffentlichung endlich, aus der Feder eines Arztes hervorgegangen, erhebt nicht den Anspruch, den Forderungen der Wissenschaft zu genïgen, erfült aber sicher die Absicht des Verfassers, als anregende Heimathkunde zu dienen ${ }^{5}$.

1) Der Vikar Fr. K. L. Joesten, jetzt Pfarrer zu Leichlingen, hat mir trotz wiederholter schriftlicher und mündlicher Bitten den Zutritt zum Kirchenarchive mit dem Bemerken verweigert, dass er des gesammten vorhandenen Materials zu seinen eigenen Arbeiten bedürfe. Ich theile nicht die Befürchtung, dass meine Behandlungsweise des Gegenstandes die Forschungsergebnisse des Herrn $\mathbf{J}_{\text {oesten }}$ in ihrem Werthe irgendwie hätte beeinträchtigen köunen.

2) Geschichte der Burgen, Rittergüter, Abteien und Klöster in den Rheinlanden, 5. Heft (Köln 1840), S. 56-82.

3) Geschichte der Stadt Wipperfürth mit Hinweisung auf die Bergische Landesgeschichte (Gummersbach 1842), 178 SS.

4) Die Kirche des heil. Nikolaus zu Wipperfürth, Organ für christliche Kunst (1854), S. 2 ff.

5) Fr. Funcke, Beiträge zur alten Geschichte der ehemaligen bergischen Hauptstadt Wipperfürth, als Heimathkunde zusammengestellt (Crefeld, Selbstverlag [1888]). 
I.

Urkundenbuch.

1.

1222. - Erzbischof Engelbert I. von Köln beurkundet, dass er in Uebereinstimmung mit seinem verstorbenen Bruder, dem Grafen Adolf von Berg, die Bürger zu Wipperfürth von allen Abgaben und Lasten befreit habe, ohne jedoch die Verpflichtungen einzeIner gegen Herren und kirchliche Genossenschaften dadurch aufzuheben.

In nomine sancte et individue trinitatis. Engelbertus divina favente clementia sancte Coloniensis ecclesie archiepiscopus omnibus | ad quos presens scriptum pervenerit in perpetuum. Ne rei geste finem consumat oblivio litterarum solet indiciis eternari. Quapropter notum facimas universis | quod nos una cum fratre nostro Adolfo comite de Monte felicis recordationis, cum adhuc viveret, incommodum et necessitatem civium nostrorum in Wippervurde attendentes ipsos $a b$ omni exactionis onere exemimus et perpetuo liberos dimisimus ac solutos, hoc adiecto, quod singuli in memorato oppido degentes cuiuscumque conditionis dominis suis sive ecclesiis quibus pertinent debita servitia et iura exhibeant. Ut hoc autem factum nostrum ratum permaneat et inconvulsum presentem paginam exinde conscriptam sigilli nostri karactere fecimus communiri. Testes huius rei sunt: Sibodo dapifer. Engelḩertus de Bensbure. Riquinus de Zudendorp. Adolfus de Stamheim. Adolfus de Bernsowe. Theodericus et Henricus fratres sui et alii quam plures. Acta sunt hec anno dominice incarnationis M. CC.XXII.

Düsseldorf, Königl. Staatsarchiv, Köln, S, Aposteln no. 275. (Acc. G. 1.7/77.) - Original auf Pergament; das Siegel des Erzbischofs in weissem Wachs an grünen und roten Seidenfäden ist zerbrochen: es zeigt Engelbert auf der Kathedra mit Mitra und Stab, in der linken Hand das Evangelienbuch, Umschrift: ,Engelbertus dei gratia sancte Coloniensis ecclie. archiepiscop9'. Rückaufschrift 14.Jahrh.: ,Littera de libertate oppidi in Wuppervưrde. Von zwei verschiedenen Händen 15. Jahrh.: Scripta , in rubeo Iibro'. Alte Signatur N. I. 
Köln, Stadtarchiv, Abschrift a. d. Ende 13. Jahrh. ,de libertate quam habent oppidani in Wippervurde im Liber rubeus fol. 26 no. 85.

Verzeichnet: Köln, Stadtarchiv, Kirchl., S. Aposteln, Liber Luppelheim p. 228 .

Gedrucht: Aeg. Gelenius, Vita s. Engelberti (Köln 1633) p. 129 aus dem Archiv des Apostelstiftes; danach J. John, Gesch. der Stadt Wipperfürth (Gummersbach 1842) S. 60 f.; Lacomblet, Urkundenbuch Bd. 2 S. 59 no. 10\%, an allen drei Orten fehlerhaft; ferner: v. Mering, Gesch. der Burgen, Rittergüter etc. in den Rheinlanden, Heft 5 (Köln 1840) S. 60.

Verzeichnet: F'icker, Engelbert der Heilige $S .291$ no. 129 zwischen Oktober 1 und Dezember 26.

\section{2.}

1254 August 5, Köln. - Erzbischof Konrad von Köln verleibt die Pfarrkirchen zu Lechenich und Wipperfürth dem S. Apostelstifte ein, welches an beiden Orten bereits das Patronat besitzt, und verpflichtet es zum Unterhalte der Pfarrer.

De iure patronatus ecclesiarum in Legnich et in Wippervårdea

Conradus dei gracia sancte Coloniensis ecclesie archiepiscopus Italie archicancellarius dilectis in Christo .. preposito . . decano et capitulo ecclesie sanctorum Apostolorum Coloniensis salutem in domino. Nostri debitum exposcit officiib, ut ecclesiis et personis ecclesiasticis cure nostre commissis pia prospiciamus sollercia in hiis que utilitatis ipsarum respiciunt incrementum et honoris dei augmenta votiva tribuunt ac commodum ecclesiastice libertati. Eapropter vestre devocionis precibus favorabiliter inclinati ecclesias parrochiales in Leggenich et Wippervorde nostre dyocesis, in quibus ius habere noscimini patronatus, ad vestrarum melioracionem congruam prebendarum vestre unientes ecclesie vestris eas ita usibus perpetuis applicamus, ut, salvis per omnia dyocesani, archidiaconi ac decani locorum ipsorum iuribus, preficiatis in ipsis personas ydoneas ad regendum seu officiandum easdem; quibus rectoribus ad opus honeste sustentacionis ipsorum ac hospitalitatis servande tanta porcione relicta de bonis seu redditibus ecclesiarum ipsarum, quod ipsis sufficiat copiose et quod dictas ecclesias non contingat ex aliquo defectu debitis obsequiis defraudari, volumus et de gracia speciali concedimus, ut residuum applicetis vestrarum communibus usibus prebendarum. Nulli ergo omnino hominum liceat hanc paginam nostre concessionis infringere vel ei ausu temerario contraire. Siquis autem hoc attemptare presumpserit, indignacionem omnipotentis dei et beatorum Petri et Pauli apostolorum eius se noverit incursurum. Datum Colonie nonas augusti anno domini M.CC. quinquagesimo quarto.

Köln, Stadtarchiv, Abschrift a. d. Ende 13. Jahrh. im Liber rubeus fol. 15. no. 42 .

a) Diese Ueberschrift rot. Annalen des list. Vereins II. b) Ungestell aus ,officii exposcit'. 
Gedruckt: Lacomblet, Urkundenbuch Bd. 2 no. 402 aus Redinghovens Sammlungen Bd.2 Bl.372, unvollständig.

Verzeichnet: H. Cardauns, Regesten des Kölner Erzbischofs Konrad von Hostaden (Köln 1880) S. 45 no. 366, auch Annalen des hist. Ver. f. d. Niederrhein Heft 35 .

3.

1256 März. - Friedrich Dekan und das Kapitel von S. Aposteln beschliessen, die Pfarrkirche zu Lechenich oder zu Wipperfürth jedesmal nur einem geeigneten Kanoniker des Stiftes zu übertragen, welcher zu persönlicher Verwaltung und zur Residenz verpflichtet sein soll.

Quod in I egnich et in Wippervårde ecclesie cum vacaverint conferri debent alicui canonico ydoneo.

Fridericus dei gracia decanus totumque capitulum ecclesie sanctorum Apostolorum in Colonia universis hane litteram visuris eternam in domino salutem. Ad noticiam omnium volumus pervenire, quod cum ius patronatus ecclesiarum de Leggenich et Wippervorde ad nos pleno iure pertineat, nos pensata utilitate ecclesie ita ordinavimus, quod quandocunque contigerit vacare aliquam dictarum ecclesiarum ipsam conferamus alicui concanonico nostro si quis idoneus poterit inveniri et eam voluerit acceptare. Dictus itaque canonicus, quicunque erit, ipsam personaliter officiabit et in ea residebit et possessionem intrabit quam cito se facultas optulerit, ita quod per eum non stet, quominus possessionem intret; postquam autem adeptus fuerit possessionem illius ecclesie, fructus prebende sue ad nos pertinebunt et ad utilitatem nostram et idem nec electionibus nec tractatibus capituli intererit, et si forte interesset, suus consensus et suum factum pro non facto haberi debet. Quandocunque autem idem redire voluerit ad ecclesiam nostram, hoc facere poterit, sed ecclesie parrochiali in qua residet prius in manus decani vel eius vicem gerentis infra mensem post receptacionem sive acceptacionem a illius ecclesie parrochialis renunciabit et sic redibit et erit in pleno iure canonie sicut ante et sicut aliquis canonicorum ecclesie nostre; et si ipsum mori contigerit in ipsa ecclesia parrochiali quam per nos optinuit habebit annos defuncti sicut residens in ecelesia nostra; et si ipse, qui sic adeptus fuerit talem, forte pensionarius noster extiterat, ecclesie nostre de illa pensione, si voluerit eam optinere, sufficienter cavebit et si requisitus hoc nón fecerit cadet a iure quod habuit in dicta pensione. Actum et datum anno domini M . CC . L . V. mense marcio.

Köln, Stadtarchiv, Abschrift a. d. Ende 13. Jahrh. im Liber rubeus fol. 12 no. 31.

Erwähnt: v. Mering, Gesch. der Burgen etc. Heft 5, S. 61.

a) Verbessert aus, accepcionems. 
4.

1263. - Ritter Hartlev von Dromere verpflichtet sich, von einem Grundstïcke am "Szevelinc" zu Wipperfürth dem S. Apostelstifte jährlich 12 sol. Zins zu zahlen.

De quibusdam bonis apud Wippervurde solventibus 12 denarios.

Universis has litteras visuris Hartlevus miles de Dromere, uxor eius et Iiberi de Wippervurde notum facimus, quod de terra que iacet ex illa parte Wippervurde que Szevelinc vocatur, quam a decano et capitulo ecclesie sanctorum Apostolorum Coloniensis iure hereditario possidemus, annuatim in festo beati Martini 12 denarios persolvemus et persolvet ille quicumque fuerit illius terre possessor. Et hec presenti littera sigillo mei Hartlevi sigillata confitemur. Datum anno domini M. CC. sexagesimo tercio.

Köln, Stadtarchiv, Abschrift aus dem Ende 13. Jahrh. im Liber rubeus fol. 26 no. 86 .

5.

1267 November 21. - Graf Adolf von Berg, Margareta seine Mutter und Elisabeth seine Gemahlin einerseits, Propst, Dekan und Kapitel von S. Aposteln andererseits ernennen den Propst Werner von S. Gereon und den Dekan Friedrich von S. Aposteln zu Schiedsrichtern in ihrem Streite über eine Mühle, das Grundstück Stadelhof, die Fischereigerechtigkeit des Stiftes und den Zoll zu Wipperfürth.

Compromissio facta inter comitem de Monte et ecclesiam sanctorum A postolorum in Colonia.

Noverint universi ad quos presentes littere pervenerint, quod nos Adolphus comes de Monte, nos Margareta mater eius et nos Elyzabet uxor ipsius comitis pro nobis et successoribus nostris ex una parte, et nos .. prepositus.. decanus et.. capitulum ecclesie sanctorum Apostolorum Coloniensis ex altera super molendino quodam, area quadam que dicitur Stadelhoif, ipsius ecclesie piscatura, theolonio et quibusdam aliis rebus et iuribus de oppido Wippelvurde, de quibus inter nos iamdudum questio movebatur, compromisimus hinc inde simpliciter et de plano in viros honestos et discretos Wernerum prepositum ecclesie sancti Gereonis et Fredericum decanum ecclesie sanctorum Apostolorum supradicte, ut quidquid prefati arbitri super premissis ordinarent, statuerent sive diffinirent inter nos, quod ratum et firmum habere debeamus et teneamur fideliter adimplere sine contradictione qualibet et difficultate; et hoc promisimus fide hinc inde prestita corporali. Eligimus nichilominus, quod ab archiepiscopo qui pro tempore fuerit in partem contra predictum arbitrium venientem monicione premissa excommunicacionis sentencia proferatur sine mora. Preterea nos comes, Margareta mater eius et Elyzabet uxor ipsius comitis pro nobis et successoribus nostris eligimus, quod 
si nos contra predictum arbitrium venire contigerit et moniti non satisfecerimus competenter, quod capitulum predictum crucem suam sine nostra contradictione, si voluerit, humiliet et reponet 1 . Ut autem premissa robur firmitatis obtineant presentem litteram formam compromissi continentem communiter conscribi fecimus et sigillis predictorum arbitrorum in testimonium communiri. Actum et datum feria secunda ante festum beate Cecilie virginis anno domini M. CC. sexagesimo septimo.

Köln, Stadtarchiv, Abschrift aus dem Ende 13. Jahrh. im Liber rubeus fol. 26 no. 87 .

6.

1267 November 22. - Werner Propst von S. Gereon und Friedrich Dekan von S. Aposteln entscheiden zwischeu dem Grafen Adolf von. Berg und dem S. Apostelstifte über genannte Besitzungen und Rechte. zu Wipperfürth.

Universis presentes litteras audituris nos Wernerus prepositus ecclesie sancti Gereonis in Colonia et Fredericus decanus ecclesie sanctorum Apostolorum Coloniensis arbitri assumpti a viro nobili | Adolpho comite de Monte, Margareta matre eius et Elizabeth uxore ipsius comitis ex nna parte, .. preposito, .. decano et capitulo ecclesie sanctorum Apostolorum Coloniensis ex altera, presentibus litteris I intimamus, quod de questionibus, iniuriis et dampnis, videlicet molendino, area que dicitur Stadelhoif, piscatura, theolonio in Wippelvurde et rebus aliis diligenti deliberacione prehabita, volentes predictam ecclesiam in iure suo indempnem conservare, de voluntate et consensu parcium predictarum et oppidanorum in Wippelvurde in nomine domini pronunciamus et statuimus: ( $\$ 1$. Abgaben. von den beiden Mülblen zu Wipperfürth an das Stift zum Ersatz für dessen ehemaligen Mühlenbesitz.) Quod de cetero in perpetuum de duobus molendinis apud Wippelvurde constitutis solventur predicto capitulo in festo purificacionis beate virginis decem maldra tritici et quindecim maldra siliginis in recompensacionem molendini, quod olim prefata ecclesia ibidem possidebat, hoc adiecto, quod si prefata duo molendina destruantur vel incendio consumantur vel quocunque modo alienentur, quod prefatus comes et eius successores nichilominus memoratam. annonam suis terminis solvere tenebuntur. ( $(2$. Abgaben von dem Grund-

1 Hierzu hat eine Hand 16. Jahrhunderts am Rande bemerkt: ,., Nota $\dagger$, cine andere aus gleicher Zeit hat hinzugefügt: ,Iste abusus reprobatus in concilio Lugdunensi. Vide c. ,Si canonici“ de offic. ordinaria lib. 6. G. M. Sch.' Das Konzil von Lyon verordnete thatsächlich im Jahre 1273: ,Ceterum detestabilem abusum horrendae indevotionis illorum, qui crucis, beatae Mariae virginis aliorumque sanctorum imagines seu statuas irreverenti ausu tractantes eas in aggravationem cessationis.. (scil. divinorum) prosternunt in terram et urticis spinisque supponunt. . de caetero districtius prohibemus.6 c. 2. Si canonici lib. 6. tit. 16. 
stücke Stadelhof, auf dem das städtische Kaufhaus errichtet ist.) Ordinamus eciam sive statuimus, quod de area, que olim fuit Stadelhoif ecclesie predicte, ubi nunc domus per oppidanos de Wippelvurde est constructa, in qua panni, pisces et alie res venduntur, decem et. octo solidi in perpetuum per oppidanos sine contradictione qualibet aut diminucione persolvantur ecclesie memorate similiter in festo purificacionis beate Marie supradicto. (§ 3. Holzgerechtigkeit ohne Einspruch des Grafen.) Item ordinamus, quod ligna sua quecumque vendere aut succidere valeant quandocumque ipsi ecclesie placuerit et videbitur expedire sine contradictione comitis vel sui officialis. (\$ 4. Fischereigerechtiglieit des Stiftes in den Stadtgräben.) Item ordinamus, cum.. prepositus aut.. decanus ecclesie prenotate Wippelvurde venerint, quod piscari valeant in fossatis circa Wippelvurde existentibus si ipsis piacuerit. (\$ 5. Recht der, volscherich-Leute.) Item ordinamus de hominibus qui dicuntur, ,volscherich ${ }^{6}$ infra oppidum commorantibus quod pleno iure gaudeant sicut extra. (\$6. Gerichtliche Eintreibung der Gefälle für das Stift.) Item ordinamus, quod census et debita quecumque sive per iudicium seculare sive per indicium ecclesiasticum, prout capitulo memorato videbitur expedire, sine contradictione comitis requirantur, si iusticia sine mora eis facta non fuerit expedita. (\$ 7. Erhebung des Zolles und Einsetzung des Schultheissen.) Item de theolonio recipiendo et sculteto ponendo ac aliis iuribus ad scultetum pertinentibus requirendis volumusa quod libere possideant et quiete, sicut hactenus consueverunt et nullum super hiis sustineant impedimentum. $(\S \S$. Stiftung eines Jahrgedächtnisses für das gräfliche Haus aus einem Theile der. Mühlengefälle.). De annona autem predicta volumusa, quod quinque maldra cedant ad memoriam predictorum comitis, patris, matris et uxoris eiusdem et eorum anniversarius sicut canonicorum sepedicte ecclesie solempniter peragatur. Predicta vero omnia et singula volumusa inviolabiliter observari. In cuius rei testimonium et firmitatem perpetuam presens littera est conscripta, sigillis nostris predictarum parcium, ecclesie Coloniensis et oppidanorum Wippelvurdensium communita. Pronunciatum et actum in die beate Cecilie virginis anno domini millesimo ducentesimo sexagesimo septimo.

Düsseldorf, Königl. Stautsarchiv, Köln, S. Aposteln no. 48. Original auf Pergament mit 7 Siegeln in rotem Wachs an grünen, roten und gelben Seidenfäden: 1) Graf Adolf von Berg, bergischer Löwenschild auf rautenförmig gegittertem, mit Lilien bestreutem Grunde, Umschrift: Sigillum Adolphi de Monte; Rüclisiegel: Löwenschild auf gegittertem Grunde, Umschrift: Secretum comitis de Monte. 2) Gräfin Margareta, Reiterin mit Falken und Windspiel, Umschrift: S. Margarete comitisse de Monte; Rücksiegel: Turm mit Umschrift: ,Secretum meum." 3) Gräfin Elisabeth, Reiterin mit Falken und zwei Windspielen, Umschrift: Sigillum Elyzabeth comitisse de Monte; Rücksiegel: dreitürmige Burg, Unischrift: Sigillum secreti mei. 4) Propst Werner von S. Gereon, sitzender Priester mit Buch und Palme, Umschrift: ,Wernerus dei gra. ppositg sci. Gereonis $\overline{\mathrm{i}}$ Colonia'; Rücksiegel:

a) volimus. 
Brustbild des h. Petrus, Umschrift: ... [patro]nus Coloni.. 5) Dekan Friedrich von S. Aposteln, Brustbild Christi auf gestirntem Grunde, darunter . knieender Priester, Umschrift: S. Frederici decani scor. aplor. in Col. 6) Domkapitel, altes Kapitelsiegel. 7) Stadt Wipperfürth, dreitürmige romanische Kirche, darïber das bergische Wappen, darunter Stadtmauer, Umschrift: ,S. burgensium opidi in Wippervurde.', sehr schön erhalten. Von einem 8. Siegel sind nur noch die Seidenfäden vorhanden. Rückaufschrift 1壬. Jahrh.: ,Littera pronunciacionis inter nos et comitem de Monte de molendinis et bonis in Wůppervůrde." Vermerke 15. Jahrh.: ,Scripta est.' ,Registrata in rubro libro." Alte Signaturen: N. III., ferner I. K. 218. no. 35, endlich: Sanctorum Apostolorum caps. A. no. 53, nebst kurzen Inhaltsangaben.

Köln, Stadtarchiv, Abschrift a. d. Ende 13. Jahrh. im Liber rubeus fol. 26. no. 88 .

Gedruckt: Lacomblet, Urkundenbuch 2 S. 335 no. 575.

7.

$12 \% 5$ März 26, Mainz. - König Rudolf gestattet dem Grafen Adolf von Berg die Verlegung seiner Münzstätte von Velberg nach Wipperfürth.

Rudolfus dei gracia Romanorum rex semper augustus. Universis sacri imperii Romani fidelibus presen|tes litteras inspecturis graciam suam et omne bonum. Volentes nobilem virum Adolfum comitem de / Monte dilectum fidelem nostrum suis claris exigentibus meritis prerogativa favoris et gratie prosequi singularis, quod monetam suam que in Weleberch cudi consuevit hactenus ab antiquo ex nunc in Wippilvord cudi perpetuo possit et debeat, comiti prenotato ex regia liberalitate concedimus presencium testimonio litterarum. Datum Maguncie VII. kalendas aprilis indictione tertia reg|ni nostri anno secundo.

Düsseldorf, Königl. Staatsarchiv A I no. 68. - Original auf Pergament, das venig verletzte Majestätssiegel in weissen Wachs hängt an einem Pergamentstreifen. Lateinische und deutsche Inhaltsangaben 17. Jh. auf der Rückseite. Alte Signaturen: „num. 1mo. ad caps. 17."“

Gedruckt: Lacomblet, Urkundenbuch Bd. 2 no. 665 .

8.

1276 Juli 10. - Bürgermeister und Einwohnerschaft zu Wipperfürth erklären, vom S. Apostelstifte eine bisher vergeblich geforderte Beisteuer zur baulichen Unterhaltung der Pfarrkirche und der S. Peterskapelle für die Folge nicht mehr verlangen zu wollen.

Quod ecclesia sanctorum Apostolorum non tenetur nec obligata est dare aliquid ad edificia ecclesie in Wippervurde et capelle sancti Petri.

Universis ad quos presentes littere pervenerint magistri civium acuniversi opidani in Wippervurde notum facimus presentis scripti testimonio 
declarantes, quod licet multis temporibus requisiverimus a venerabilibus viris decano et capitulo ecclesie sanctorum Apostolorum Coloniensis pro iure quodam triginta solidos coloniensium denariorum in adiutorium edificii ecclesie in Wippervurde et capelle sancti Petri, tamen quia numquam soluti fuerunt de quo memoria aliqua habeatur, a tali requisicione predictos dominos .. decanum et capitulum dimittimus absolutos et dicimus eos ad solucionem de iure de cetero non teneri. In cuius rei testimonium presentem litteram conseribi fecimus et eandem sigillo opidi nostri cum sigillo plebani nostri predictis dominis decano et capitulo tradidimus communitam. Actum et datum anno domini M. CC.LXX.VI feria VI a ante festum beate Margarete proxima.

Köln, Stadtarchiv, Abschrift aus dem Ende 13. Jahrh., im Liber rubeus fol. 28 no. 97 .

Fehlevhafter Druck bei v. Mering, Geschichte der Burgen etc., Heft 5, S. 63 .

9.

1279 December 3. - Erzbischof Siegfried von Köln und Graf Adolf von Berg ernennen Scbiedsrichter zur Schlichtung ihres Streites über das bergische Münzrecht zu Wipperfürth, Velberg und an anderen Orten.

Nos Sifridus dei gracia sancte Coloniensis ecclesie archiepiscopus sacri imperii per Italiam archicancellarius et nos Adolphus comes de Monte notum facimus $\mid$ universis et tenore presencium publice protestamur, quod cum inter nos hinc inde exorta fuisset materia questionis super eo, quod nos archiepiscopus | asseruimus et asserimus, ipsum comitem de Monte nullam monetam cudere posse, cudi permittere vel etiam habere debere in Wippelvirde, Weileberg et alias in terra sua, ipso comite contrarium asserente, tandem super dicta discordia et questione sedanda nos archiepiscopus pro nobis et ecclesia nostra Coloniensi in dilectos in Christo Conradum prepositum et Theodericum decanum ecclesie Coloniensis, et nos comes pro nobis et successoribus nostris in eosdem prepositum et decanum compromisimus et compromittimus, promittentes bona fide, quod quicquid predicti prepositus et decanus super dicta questione et discordia ordinaverint, statuerint, pronunciaverint per viam iuris, pacis sive amicabilis compositionis, iuris ordine servato vel non servato, hoc inviolabiliter observabimus nec contra veniemus quoquo modo. In cuius rei testimonium nos archiepiscopus Coloniensis et nos Adolphus comes de Monte predicti sigilla nostra presentibus duximus apponenda. Actum et datum III. nonas decembris anno domini M.CC.LXX . nono.

Düsseldorf, Königl. Staatsarchiv A III. Churcöln no. 275. Original auf Pergament mit anhängendem Bruchstücke des Bergischen Reitersiegels nebst Seliret und mit einem Siegeleinschnitte. Gleichzeitige Rülchaufschrift: Compromissum super moneta in Wippervurde. Inhaltsangabe 17. Jh. Alte Signatur No. 114 lit. C. 
Köln, Stadtarchiv, Abschrift aus dem Ende 13. Jahrh., Kopiar des Erabischofs Siegfried fol. 15 no. 40.

Verzeichnet: Mittheilungen a. d. Stadtarchiv v. Köln Heft 12 S. 49 no. 63.

10.

1279 December 9, Deutz. - Konrad von Berg Dompropst und Dietrich [von Büren] Domdekan entscheiden zwischen Erzbischof Siegfried und Graf Adolf von Berg, dass letzterer zwar widerrechtlich in Wipperfürth und Velberg gemünzt habe, dass er jedoch fortan eine jährliche Erbrente von 12 Mark aus der Kölner Münze beziehen solle.

Nos Conradus dei gracia maior in Colonia prepositus frater nobilis viri Adolphi comitis de Monte et Theodericus decanus Coloniensis | notum facimus universis, quod cum inter reverendum patrem et dominum nostrum Syfridum archiepiscepum Coloniensem ex una parte et nobilem virum | Adolphum comitem de Monte ex altera super moneta quam predictus comes cudi fecit apud Wippelvurde et Weleberg in nos sit compromissum sub hac forma:

\section{[Folgt die Urlunde von 1279 December 3, obens no. 9.]}

nos compromisso huiusmodi et ordinacione in nos susceptis diligenti inquisicione et inquisita veritate prehabitis invento et cognito, quod predictus . . comes in locis predictis aut alias in terra sua nullam monetam de cetero cudi faciet nec cudi permittet et quod denarii monete coloniensis in terra ipsius current sicut in civitate Coloniensi; sed quia idem . . comes in predictis locis seu eorum altero monetam aliquando fieri fecit de facto, ipso domino archiepiscopo et predecessoribus suis contradicentibus, ut in amicicia deinceps permaneant et quod de iure cessare debet cesset in amicicia, dicimus, pronunciamus et ordinamus, quod ... comes predictus et heredes sui in moneta Coloniensi singulis annis in festo purificacionis beate Marie virginis recipient duodecim marcas coloniensium denariorum in recognicionem premissorum et in augmentum feodi, a domino archiepiscopo, suis successoribus et ecclesia Coloniensi obtinendas. In cuius rei testimonium et perpetui roboris firmitatem nos Conradus prepositus et Theodericus decanus Coloniensis sigilla nostra presentibus litteris duximus apponenda. Pronunciatum et actum Tuicii sabbato post Nicolai anno domini millesimo CC.LXX.nono.

Düsseldorf, Königl. Staatsarchiv A III. Churcöln no. 275. Original auf Pergament, mehrfach durchlöchert, mit anhängendem Siegel des Propstes Konrad an gelben Seidenfäden und mit Einschnitten für ein zweites Siegel. Alte Signatur no. 12 lit. SS.

Köln, Stadtarchiv, Abschrift a.d. Ende 13. Jahrh. im Siegfried'schen Kopiar fol. 15 no. 41.

Gedr.: Lacomblet, Urkundenbuch Bd. 2 no. 733 , unvollständig.

Verz.: Mittheilungen a. d. Stadtarchiv v. Köln Heft 12, S. 49 no. 64. 
11.

1281 Juni 30. - Gottfried von Stouphon, Viceprior des Johanniterordens in Deutschland, nimmt von dem Wipperfürther Bürger Gerhard Plumph und dessen Mutter L. die Schenkung eines steinernen Hauses zu Wipperfürth mit Zubehör an Acker, Weide, Wiese und Wald nebst 12 Mark Einkünften unter der Verpflichtung entgegen, daselbst so oft der Schenkgeber es verlangt, durch Ordensmitglieder Gottesdienst abhalten zu lassen. (1281 in crastino bb. apostolorum Petri et Pauli.)

Düsseldorf, Königl. Staatsarchiv, Johanniter-Commende Herrenstrunden no. 32. - Original auf Pergament mit geringem Reste eines abhängenden Siegels; es felllen die Siegel der Komture Anselm von Heimbach, Erwin von Burg (in Castro) und Arnold von Köln. Rückaufschrift 15. Jahrh. ,De bonis in Wippervurde6. Aufschriften 1\%. Jahrhunderts: „Littere [de bonis in W.] et ea ratione prestandis officiis. Anno 1281. Num. 23. Burg".

Gedruckt: Lacomblet, Urkundenbuch Bd. 2 no. T52. $^{2}$.

12.

1283 Janmar 25. - Graf Adolf von Berg bestätigt und erweitert in Gemeinschaft mit seiner Gemahlin Elisabeth die Rechte und Freiheiten, welche sein Oheim Heinrich Herzog von Limburg Graf von Berg und sein Vater Graf Adolf der Stadt Wipperfürth verliehen hatten.

In dem namen der heylger dreyvoldigheit des vader, des sones inde des heylgen geistes amen. Wir Aylff greve inde Elizabeth grevinne van den Berge. So der edele man onse herre die hertoge Heinrich van Limborg inde greve van dem Berge onse aynche deym got genedig sy zo synen zyden onse statt zo Wipperforde inde de borgere die do da waren inde nach sint na stede rechte gerryet have an live ind an gude, inde onse her onse vader die greve Ailff die greve van deme Berge, deme gott genedigh sy; dat selve dede in synen zyden, so doin wir kont allen den genen die nu sint inde noch herna koment unde die dese hantvestene angesient inde gehorent, dat wy mit onsen goden vryen willen inde mit rade inde gehencknisse der erwirdiger luide heren Conrades des domprovestes van Kolne, heren Engelbertus van sunte Kuneberte, heren Walravens van sunte Marien van den Greden der proveste van Kolne, des edelen mannes heren Henricks des herren van Wintegge, Wilhelms des canonickes van dem dome unser leven broeder inde mit rade onser getruwen manne, burchmanne ind unser vrunde alle die recht die genade die de vorgesagede heren onse aynche de hertoge Henrich van Limborgh inde greve van deme Berge in synen tyden unde de greve Ailff van deme Berge unse vader in synen tyden der statt van Wipperforde inde den 
borgeren gegeven havent inde gelenet an liven ind a an gude, die stedegen wy der statt zo Wipperforde, den borgeren de da nu sint inde noch dair na komen sullen vor uns inde unse nachkomeling inde sullen se in ewilicken stede holden in goden truwen sonder argelist inde gunnen un des wall, dat sy alle de recht haven ind holden in allen stucken da burgere ir reicht genieten sullen; ind bengen und willen woll (\$. 1. Alljährliche Wahl des Bürgermeisters und der zwölf Ratmannen mit Genehmigung des Landesherrn.), dat die gemeine burgere van Wipperforde ricke und armen aller jerlickes under in keesen eenen burgermester und twelff raitman mit rade der herschap van den Berge; die sullen sweren to den heilgen, dat sie die herschap van den Berge in alle irme reichte to Wipperforde sollen holden, die statt inde de borgere arme inde rycke in yrme reichte sullen huden und holden, der stede ere und vromen und alle iren borgeren na all erer macht vort keren sullen in guden truwen sonder argelist. (\$. 2. Verlüngerung der Amt.dauer einzelner Ratsmitglieder durch die Bürgerschaft.) Iss oich, dat die raidtluiden ind burgermesteren off er einch den burgeren und der statt woll bevellet und nutte iss, de mogen bliven sonder iemantz widderedie na der stede willen und der burgere. (\$. 3. Ernennung des obersten Richters aus dem städtischen Rate durch den Landesherrn.) Vort so beholden wy onss ind onsen nakomelingen de greven sint toe dem Berge, dat wy off onse nakomelinge under den twelff raidtmannen und anders nergent einen richter nemen mugen die unsse recht halde ind vorder van unsenthalven ind uns ind unsen nakomelingen den graven van den Bergen daraff andtworden sullen; ind boven den richter ensall niemant syn dan wir selven off onse nakomelingen die die herschap hant van den Berge. (§. 4. Befugniss der dreizehn Ratmannen, über falsches Mass und Gewicht zu richten; von der Busse erhält der Landesherr 5 Schillinge, die Stadt 20 Pfenninge.) Dese vursagede ${ }^{b}$ druittein raitman sullen mogen richten van allen unreichten maten dar ${ }^{\mathrm{C}}$ men mit mitet to Wipperforde we de sint genant, behalden unss ind onsen nakomelingen unses alden rechtens mit den vorwarden, so wie brecke mit falscher mate ind dess verwonnen worde vorme rade, de sall also dicke also he bricht unss off onsen nakomelingen viff schillinge gelden ind der statt ind dem rade twintig pennonge. ( $(5$. Baupolizeiliche Befugnisse der Ratmannen.) Ever wilch man boven d overtimmer mackede to Wippirforde op eymans hindernisse off andere steyde rurt sonder orloff ind gehenckenisse der e druittein gesworene ind sy et eme vorbeden, den moge wy off unse nakomelingen anesprecken van gewalde alss recht iss. (\$. 6. Busse für offene Wunden: 5 Mark dem Landesherm, 5 Schillinge der Stadt.) So wie oich open wonden sloge off desgelichenisse dede, die sall unss off unsen nakomelingen viff marck schuildigh syn ind der stede viff schillinge ind dem kleger allererst beteren, also dat hy dem gerichte ind der stede dancke. (\$. 7. Gericht ïber T'otschlag etc. hegt der Landesherr nach städtischem Recht auch ohne Kläger.) Den doitschlagh, heimsuckinge, noitocht, valck ind dergelicke muge wy ind unse nakomelinge richten na gemeinen stede rechte an den geinen die die daet
a) in.
b) vursagende.
c) aat.
d) bove.
e) $d r$. 
gedaen havent so die missedaet kenlich off apenbar sy; nochtans a dair nemanne klaget ind men sall niemanne untschuldigen umb geinge missedaet ${ }^{b}$, id en sy he en muge sich ontschuildigen na stede rechte. (§. 8. Busse für Rauferei: 1 Mark dem Landesherrn, 5 Schillinge der Stadt.) So we backschlach schleit, horropen deit ind desgelichenisse ind des wirt overgangen mit twen manne den to gelovene is, de sall uns off onsen nakomelingen gelden enen marck kolscher pennonge und der stede viff schillinge. (§. 9. Busse für Scheltworte: 5 Schillinge dem Landesherrn, 20 Pfennige der Stadt.) Ende id sy man off vrawe die den anderen anevertiget mit bosen scheltworden ind des overgangen wirt als recht is de sall uns viff schillinge ind der stede twintig pennonge gelden; so wie aver dess nicht gelden en magh, die sall die stat een halff jair versweren ind ruymen aff einen maent in dem stocke sitten to Wipperforde so wilcher he will, ind wie dafur biddet, die sall denselven kuren gelden ane widertalle. (\$.10. Ius de non evocando.) Ende geven wie sunderlicken den burgeren van Wipperforde unsen getruwen holden vur unss ind unsen nakomelingen die gnade, dat sy nieman en moge laden, eischen offte dagen ute Wipperforde vor einig werlich gerichte, id en were dat ir einigh openbare ind kenliche missedaen hedde in eenen anderen gerichte, mer en ewelich ${ }^{c}$ man sall recht nemen ind geven dem anderen in der stat to Wipperforde ind id en sall niemandt den anderen mugen vertugen mit getuigen die van buten sint inbinnen Wipperforde na stede rechte. (§. 11. Verbot der Schenkung an die tote Hand ohne die Einwilligung des Landesherrn und der Frben.) Ende setten inde willen wy, dat en geyn burger van Wipperforde syn erffnisse dat binnen der stat gelegen sy einigerhande begeven luide verkopen, besetten offte geven muge sonder onsen orloff off unser nakomelinge off der wetlichen erffnoten die daerto gehorent. (§. 12. Verbot, ohne landesherrliche Evlaubniss Hörige als Bürger aufzunehmen.) Ende setten wy ende willen, dat die borgere van Wipperforde noch einigen onsen unschuldigen man off unsen vogetman to burger e entfain sonder unsen orloff ind unser nakomelingen. (\$. 13 Richterliche Befugnisse des Landesherrn.) Were aver, dat einigerhandef undat to Wipperforde geschege, nochtans s dat neman en clagede doch sall man uns die ind unsen nakomelingen wrogen inde die muge wy richten na scheffen urdele. (\$. 14. Schöffen und Rat zu Siegburg bilden den Oberhof für Wipperfürth.) Ende setten wy ind gunnen unsen borgeren to Wipperforde sunderlicke dess, off yn eviges rechtes entbrecke dair man ane twyfelde, dat se dat recht soeken sullen to Syburgh an den schepenen ind an dem raide. (\$. 15. Verpflichtung zum Gehorsam gegen den Rat.) Were ever eyman die sich vervrevelde ind der raitluide ind der stede rait to Wipperforde nicht halden en wolde, den sullen wie off unse nakomelingen off onse richter alsulch halden, dat hy gehorsam sy ind wy ind unse nakomelingen sullen die gewalt aflegen dem raide ind der stede van Wipperforde. (\$.16. Widerrufliche Ueberlassung landesherrlicher (vogteilicher) Güter an die Stadt.) Ende

a) noch von.

Ba. 9 S. 278 liest, inwendig'. g) nach dan. b) mandat.

d) dat dat. c) ewelich $=$ jeglich; Rit $z$ in v. Leiteburs Archiv

e) burgen.

f) geiniger. 
gunnen wy unsen burgeren van Wipperforde sunderlingen der gnade, dat sy der burge gueden, die ons togehort, die sy van unsen gnaden noch bit her hebbent gehalden, vort op unse gnade ind unser nakomelingen besitten ind behalden, also as se die gut her heblet gebracht, behalden uns ind unsen nakomelingen all unses alden rechtens up gnade, so se unser voget gude sonder unse orloff ind unser nakomelinge neman ensullen gelden noch sich underwinden. - Ind umbe dat dese vorwart der stat van Wipperforde ind den burgeren de da nu sint off herna komen sullen ewelicke stede geholden werde van uns ind van unsen nakomelingen, so hebben wy dese vurwarden doin beschriven in dese hantvestene den burgeren van Wipperforde gegeven, besegelt met onsen segelen inde unse vorgenanter broder ingesegelen, der wy uns ind unse nakomelinge mit verbunden zo allen desen vurwarden ewelichen stede to beholden den burgeren van Wipperforde ind iren nakomelingen. Ind wy de genante Conrade doemproveste van Kolne, Engelbert van sinte Kunibertus ind Walraven van sinte Marien Greden proveste van Kolne, wy Henrich van Windeggen der her ind Wilhelm die kanonich van deme doeme to Collne broder des greven Ailff van dem Berge in ein urkunde des, dat alle dese vurwarden die hir vur geschreven sint mit unsen willen, unsen raide ind unseme gehenkenisse gescheit syn, so hebben wy unse ingesegele an dese hantvestene gehangen da wy uns verbinden vor uns ind unse nakomelingh, alle dese vurwarden ewelich stede to holdene sunder argelist der stat ind den burgeren van Wipperfurde. Dit is geschiet in orkunde unsers alle ind mit orkunde der erwirdiger luide her Werners des provestes van sint Gereone ${ }^{b}$, heren Henrickes van Virnenborgh des greven unses omen, broders Everwines des kommendures van sinte Johanne to der Burgh, heren Werners des cappelains; Engelbertus Ruselpaffen des ridders, Johannes des scrivers, Diederickes Mecken des drusseten van dem Berge; Peters Plumpens, Tillmans Winniges ind Hartlevis der burgeren to Wipperforde. Dit is gescheit na godes geborte duisent jair twehondert jair inde twe ind achtzigh jair up den dagh dat sunte Paulus bekert wart.

Das Original der Urkunde scheint verloren gegangen zu sein. Dem gegenwärtigen Abdrucke liegen zwei Kopieen 17. Jahrhunderts zu Grunde, welche in einem Altenhefte des Königl. Staatsarchivs zu Düsseldorf, JülichBerg, Städte des Herzogthums Berg no. 15 Blatt 5-7b und Bl. 19-21 enthalten sind; an letaterer Stelle ist die Urkunde einev Bestätigung vom 8. August 1340 inserirt, s. unten no. 17. Vielleicht beruht auf dieser Abschrift des Transsumpts die sehv ungenaue Veröffentlichung von W. Ritz in I. v. Ledeburs Archiv f. d. Geschichtskunde des Preuss. Staats Bd. 9 (1832) S. 2r5 ff.

a) Die andere Kopie hat die voget guede. Vgl. jedoch unter no. 30 und 31 .

b) Torher durch Punkte getilgt: Henrickes van Virnenborgh. 
13.

1328 Juli 27, Rom. - Kaiser Ludwig gewährt dem Grafen Adolf von Berg die Erlaubniss, in seiner Münze zu Wipperfürth, die ihm vom Reiche bewilligt ist, fortan auch silberne Turnosgroschen prägen: zu lassen.

Düsseldorf, Königl. Staatsarchiv A I no. 330. - Original auf Pergament; das gut erhaltene Majestätssiegel hängt an grün- und roten Seidenfäden, rïckwärts aufgedrücht ist das Sekret : ein Adler mit der Umschrift „Iuste iudicate filii hominum'. Lateinische und deutsche Inhaltsangaben 17. Jh. auf der Rückseite. Alte Signatur: ad caps. 13. num. 2.

Gedruckt: Lacomblet, Urkundenbuch Bd. 3 no. 234 .

Verzeichnet: Lamprecht, Deutsches Wirtschaftsleben in Mittelalter Bd. 2 S. 432 no. 21. Vgl. Kruse, Kölnische Geldgeschichte bis 1386 (4. Ergänzungsheft der. Westdeutschen Ztschr., Trier 18s8) S. $40 \mathrm{ff}$.

\section{4.}

1329 März 29. - Das Kapitel von S. Aposteln verpachtet dem Adolf von Lüdenscheid auf die Dauer von zehn Jahren gegen näher bezeichnete Leistungen das Schultheissenamt zu Wipperfürth.

Universis presentes litteras visuris et audituris nos . . capitulum ecclesie sanctorum Apostolorum Coloniensis notum facimus tenore presencium confitentes, quod concessimus | et concedimus iusto titulo locacionis et concessionis discreto viro Adolfo de Ludyscheyt opidano in Wyppilvirde officium sculteti nostri | ibidem cum omnibus suis iuribus et attinenciis ad idem officium spectantibus ad decem annos continuos qui currere incipient anno domini 1rv. 25. millesimo ccc $^{\text {mo }}$ vicesimo nono in annunciacione beate Marie virginis ad habendum et pacifice possidendum pro annua pensione viginti marcarum et quatuor denariorum pagamenti coloniensis et pro quindecim maldris siliginis et pro decem maldris tritici nobis solvendis nomine nobilis viri domini comitis de Monte de molendino sito apud Wippilvurde et pro decem maldris avene et pro tribus maldris salis et pro decem et octo solidis pagamenti predicti racione theolonii solvendis et ceteris iuribus ab eodem officio nobis competentibus persolvendis ecclesie nostre predicte singulis annis terminis infrascriptis sub hac forma videlicet: quinque marcas et unum denarium ort. 1. Solvet in festo beati Remigii proximo profuturo, item in festo nativitatis Dez. 25. Christi subsequente quinque marcas et unum denarium eiusdem pagamenti, Feir.z. item in festo purificacionis beate Marie virginis quinque marcas et unum denarium, item in festo ascensionis domini quinque marcas et unum denarium eiusdem monete; bladum vero predictum et decem et octo solidos solvet $F_{e b r}$.2. singulis annis predictis in festo purificacionis beate Marie virginis, item tria $x_{n}$. 11. maldra salis solvet in festo beati Martini hyemalis; item solvet omnia iura et faciet que sibi incumbunt racione predicti officii facienda. Et nos . . ca- 
pitulum predictum recognoscimus per presentes, quod Adolfus predictus mutuavit, tradidit et in parata pecunia nobis assignavit centum marcas denariorum pagamenti coloniensis, quas eidem aut suis heredibus bona fide solvere promisimus immediate post decem annos predictos finitos et elapsos; quod si non fecerimus, ipse Adolfus et sui heredes stabunt et perdurabunt in dicto officio sub condicionibus predictis donec ipsi et suis heredibus de dictis marcis per... nos plenarie fuerit satisfactum, hoc adiecto, quod postquam Adolfo a vel suis heredibus predictis per nos annis predictis elapsis integre satisfactum fuerit de marcis predictis, extune nos . . capitulum prefatum de huiusmodi officio nostram utilitatem ordinare et facere poterimus, predicti Adolfi aut suorum heredum contradiccione in aliquo non obstante, dolo et fraude exclusis et excepcione pecunie non numerate non tradite non assignate et omnibus defensionibus iuris et facti tam canonici quam civilis, que nobis contra premissa possent aut deberent quavis arte vel ingenio quomodolibet suffragari. In cuius rei testimonium et maiorem firmitatem premissorum sigillum ecclesie nostre ad causas una cum sigillo predicti Adolfi de Ludischeyt presentibus est appensum. Et ego Adolfus predictus fateor sigillum meum appendisse presentibus in testimonium premissorum. Datum anno domini M.CCC . vicesimo nono post festum annunciacionis beate Marie virginis feria quarta proxima subsequente.

Düsseldorf, Königl. Staatsarchiv, Köln, S. Aposteln no. 123. Original auf Pergament mit einer Pressel, einem Siegeleinschnitt. Rückaufschrift 14. Jahrhunderts 1. Hälfte: ,Littera quod concessimus Adolfo de Ludischeyt officium scultetatus in Wuppervurde', Vermerk 18. Jahrinunderts : ,Nominatio sculteti in Wipperfürdt a. 1329; est valde notabilis'. Alte Signatur: N. VI.

Abschrift a. d. Ende 14. Jahrh. ebenda, Liber albus fol. $279^{b}$ no. 236 .

15.

1333 August 20. - Bürgermeister und Schöffen zu Wipperfürth beurkunden, dass der Bürger Tilmann Lebart 16 Mark Zins von seinem Hause Rodenhus dem Frühmessaltar [in der S. Peterskapelle] ${ }^{1}$ zugewandt habe.

.. Univer[sis presencia] b visuris et audituris innotescat, qued coram nobis .. magistrocivium / et.. sca[binis de] Wipperevůrde Telemannus Lebart noster coopidanus dat et dedit / sufficien[ter] rectori altaris prime misse in Wipperevurde celebrande ex domo sua dic[ta R]odenhus cum suis appendiciis sedecim marcas brabantinas tribus [hallensibus] pro uno denario computatis semper in festo sancti Martini episcopi persolven[das. In] cuius rei Nov. 11. testimonium nostrum sigillum presentibus est appensum. Datum anno [domini] $m^{\circ} . \operatorname{ccc}^{m o}$. tricesimo tercio feria sexta proxima post assumpcionem domine nostre.

a) Im Originat zloeimal Adolfo.

b) Die Urzunde ist durchlöchert.

1) Vgl. no. 16 . 
Düsseldorf, Königl. Staatsarchiv, Köln, S. Aposteln no. 129. Original auf Pergament mit Pressel. Rückaufschrift 14. Jahrh. ,Littera de dotacione altaris prime misse in Wuppervîrdec. Alte Signatur: N. VII. nebst Vermert von der Hand des Dekans Francken: ,Amno 1333 in augusto'.

16.

1333 [nach Angust 20.] - Erzbischof Walram von Köln bestätigt die Schenkung des Tilmann Lebart an den Frühmessaltar in der S. Peterskapelle zu Wipperfürth, behält jedoch die dargebrachten Opfergaben der Pfarrkirche vor, verpflichtet den jedesmaligen Rektor zum Treueide gegen den Pfarrer und sichert dem Stifter auf die Dauer seines Lebens das Präsentationsrecht zu, während später die Besetzung des Rektorats durch den Pfarrer erfolgen soll; hierzu geben der zeitige Pfarrer Dietrich von Xanten und das Kapitel von S. Aposteln ihre Einwilligung.

Walramus dei gracia sancte Coloniensis ecclesie archiepiscopus sacri imperii per Italiam archicancellarius universis presentes litteras inspecturis salutem cum noticia veritatis. / Ex parte dilecti familiaris nostri Thilmanni dicti Lebart de Wipperenvơrde nobis est humiliter supplicatum, quatinus, cum ipse in remedium anime sue et progenitorum suorum desi|deret unum altare infra capellam beati Petri apostoli in Wipperenvi̊rde de suis bonis propriis sufficienter dotare, nos ipsia dotato de eodem altari perpetuum creare beneficium diguaremur, cui rector ${ }^{b}$ preficeretur, qui summo mane cottidie missam in eodem celebraret altari et de eisdem redditibus se posset sine plebani eiusdem ecclesie ac ecclesie sue gravamine et preiudicio commode sustentare, premissaque de consensu et beneplacito dilectorum nobis . . decani et . . capituli ecclesie sanctorum Apostolorum Coloniensis ecclesie in Wipperenvürde patronorum necnon plebani eiusdem ecclesie procedere dinoscatur. Nos itaque volentes ipsius Thilmanni pio satisfacere proposito, ut tenemur, recepta resignacione et dotacione bonorum infrascriptorum, scilicet sedecim marcarum brabantinorum denariorum pensionis annue, tribus hallensibus pro uno denario computatis, solvendarum quolibet anno rectori ipsius altaris pro temNov. 11. pore existenti in festo beati Martini episcopi de domo ipsius Thilmanni dictac Rodenhus cum suis appendiciis sicut in litteris sigillo oppidi Wipperenvurdensis sigillatis vidimus contineri ${ }^{1}$, ita quod rector ipsius beneficii pro tempore de hiis redditibus et obvencionibus se poterit commode sustentare et onera ipsi beneficio incumbencia supportare, cum quibus idem Thilmannus exnunc, intercedente nostra auctoritate, perpetuo dotat altare prefatum, predictam pensionem ipsi altari, ut ad ipsum perpetuo pertineat, exnune appli-
a) ipso.
b) rectori.
c) dicti.

1) S. no. 15 . 
camus et designamus, ipsum altare sic dotatum perpetuum esse debere bene- 1333 [nach ficium reputari tenore presencium decernentes. Ne tamen ius ipsius par- $\Delta u g .20]$ rochialis ecclesie pretextu huius beneficii ledatur in aliquo, volumus et ordinamus, ut oblationes que huius altaris infra missarum suarum celebracionem rectori pro tempore obvenerint, sine diminucione aliqua quolibet die quo obvenerint rectori parrochialis ecclesie integre presententur, quas eciam oblaciones ad eundem rectorem parrochialis ecclesie volumus pertinere debere. Volumus eciam, quod quicunque rector pro tempore existens postquam admissus fuerit ad predictum altare, prestet iuramentum, quod matricem ecclesiam nequaquam impediet, immo pro posse promovebit in licitis et honestis et pro eo, quod oblaciones ad altare suum provenientes sibi cedere non debebunt aliqualem fraudem, scilicet hominibus persuadendo, ut, quod ad altare offerre volent, extra missam sibi assignent vel quocunque alio modo tacite vel expresse, quominus tales oblaciones minores in altari fiant et sibi de hoc emolumentum proveniat, adhibere aliqualiter non presumet et quod ipșas oblaciones rectori parrochialis ecclesie integraliter assignabit nec in dampnum ecclesie aliqua sibi dari seu legari procurabit seu faciet per se seu per alium fraudulenter. Ordinamus eciam, quod ipse Thilmannus deinceps quo ad dies vite sue ad huiusmodi beneficium habeat ins presentandi personam habilem et ydoneam actu sacerdotem seu qui ydoneus sit, ut infra annum a tempore quo admissus fụerit ad ipsum beneficium numeranduma valeat in presbiterum promoveri, plebano predicte ecclesie in Wipperenvürde pro tempore existenti, qui eundem presentatum per predictum Thilmannum, dum tamen alias sit habilis et ydoneus, admittere teneatur; verum si aliquem non actu sacerdotem presentari contingat, qui infra annum postquam eiusclem beneficii pacificam adeptus fuerit possessionem cessante legitimo impedimento ad ordinem sacerdocii promotus non fuerit, decernimus eo ipso nulla eciam monicione premissa talem iure, quod in eodem beneficio habuit, fore privatum. Post mortem vero ipsius Thilmanni rector parrochialis ecclesie in Wipperenvůrde prefate pro tempore existens deinceps inperpetuum predictun altare conferet pleno iure persone actu sacerdoti seu alias habili et ydoneo infra annum post pacificam adeptam ipsius altaris possessionem in presbiterum promovendo sub. modis et penis superius prenotatis. Et quia hec nostra ordinacio et omnia que superius sunt narrata de consensu expresso predictorum . . decani et capituli ac Theoderici de Xanctis plebani ecclesie parrochialis prefate processerunt, in perpetuum eorum testimonium presentes litteras nostro sigillo fecimus communiri. Datum Colonie in crastino beati Bartholomei apostoli anno domini millesimo cce mo tricesimo tercio.

Et ${ }^{b}$ nos .. decanus et .. capitulum ecclesie sanctorum Apostolorum Coloniensis predicti, patroni ecclesie parrochialis in Wipperenvi̊rde, recognoscimus omnia et singula premissa per reverendum patrem et dominum nostrum dominum Walramum Coloniensem archiepiscopum supradictum de nostro expresso consensu ordinata esse, eo quod deliberacione super hoc habita repu-

a) numerandum ouf Rasur.

b) Die folgenden beiden Absïtre sinit rom schueiber des Vrhunlentextes gleichzeitig hinzugefïgt. 
tavimus et reputamus utilitatem et bonum ecclesie parrochialis predicte in hoc fieri et procurari hiis litteris in signum nostri consensus sigillum ecclesie nostre prefate duximus apponendum.

Et ego Thilmannus dictus Lebart opidanus in Wipperenvo̊rde predictus recognosco me pensiones sedecim marcarum brabantinorum denariorum prefatas renunciasse (et) superportasse ad manus reverendi patris et domini mei domini Walrami Coloniensis archiepiscopi predicti ad hoc, quod predicto altari appropriarentur et incorporarentur et unirentur a et ad ius et proprietatem eius cederent in perpetuum et quod de eis disponeretur sicutidem dominus meus archiepiscopus de eis statuit, disposuit et ordinavit, et quod premissa omnia et singula de meo consensu et voluntate acta sunt, unde in eorum testimonium sigillum meum hiis litteris duxi apponendum. Datum ut supra.

Düsseldorf, Königl. Staatsarchiv, Köln, S. Aposteln no. 130. Original auf Pergament mit anhängendem verletztem Siegel des Erzbischofs Walram, das den Kirchenfürsten auf der Kathedra zeigt mit Mitra und Stab, segnend, rechts das kölnische, links das jülichsche Wappen, in einem Bogen unter der Kathedra ein ruhender Löwe; ferner mit einem Bruchstiicke des Stiftssiegels, welches noch die thronende Jungfrau mit dem Kinde, umgeben von einigen Apostelköpfen, erkennen lässt; von dem dritten Siegel ist nur noch eine Pressel erhalten. Rückaufschrift 14. Jahrhunderts: ,Littera de erectione altaris in capella beati Petri in Wuppervi̊rde', ferner aus den 17. Jahrh. ,Fundatio altaris seu vicariae s. Petri in Wipperfürde anno 1333 in crastino Bartholomaei. Signaturen 17. und 18. Jahrhunderts: N. VIII und Caps. B. no. 150, zu letztever der Vermerk: ,NB. copiam huius fundationis vide in capitulatione d. Averhausen pastoris 9 a decembris 1693 , item ibidem sententiam domini officialis contra decanum et capitulum sanctorum Apostolorum in causa huius vicariae؛.

Ebenda, Abschrift 14. Jahrth. im Liber albus fol. $277^{\circ}$ no. 235.

Evwähnt: v. Mering, Gesch. der Burgen, Heft 5, S. 63 .

17.

1340 Angust 8. - Graf Adolf von Berg und seine Gemahlin Agnes bestätigen der Stadt Wipperfürth das Privilegium vom 25. Januar 1283 und bestimmen zugleich den Verlauf der städtischen Bannmeile.

In goitz namen amen. Wir Ailff greve inde Nesa grevinne van dem Berge doin kondt alle den genen die diesen brieff ane sien inde horen lesen, na deme dat onse vorvaren aynchge inde oymen, den gott genedigh sy, greiven van deme Berge unser stat inde burgeren van Wipperforde genade, vryheit, reicht, hantvestingen gegeven, geleindt, gestedicht inde in darup brieve gegeven havent, die von worde zo worde byegent inde luident als herna geschreven steit:

[Folgt die Urkunde vom 25. Januar 1283, oben no. 12.]

a), unierentur.

Annalen des hist. Vereins LI. 
Want a nun die stat ind burgere vorgemelt uns dienstlichen gebedden haint ind biddent, dat wir in dese vorgemelte genade, vryheit, recht ind hantvestingen sementlichen mit irren banmilen, die geyt umbe die stat van den zwen linden vor der Siberscher portzen an der Vesten, van der Vesten in der Hamere, van dannen neder in de Wippere, van danne an die linde vur sent Anthonius brugge, vort up dem hoisten des Wolfsberges, aldair da die Warsype velt in die Wippere, von danne an den Hoenstein up dissyde de Wetsagebrugge, dair vort an den lackstein dair men vert zo Stillinckhusen, ron dannen in die Goll tuischen de zwa lomoillen da die eich stondt, von dannen an die vorgemelte zwa linden, lenen, geven ind stedigen van unser herschap wegen vur uns ind unse nakomelingen ewelicken inde mit unsem brieve vernuwen willen; herombe want unse vurvaren dese gnade der vorgemelter stat ind burgeren gedaen haint ind ouch de an ons ind unses lantz beste versinnen, so haven wy dese vorgenante gnade, vrybeit, reicht, hantvestinge inde banmile mit raide unser vrunde, manne inde burgmanne gestedigt ind stedigen sy in al der wyse ast vurgeschreven is. Hyby sint gewest die eydell inde beyrve luide: her Johan van Nuwenair. Heinrich van Graischaff. Arnolt inde Diederich van Elren. Engelbrecht van Uphoven. Bode van Budlenberg. Ailff (ind) Huneikin van Beinsbuirb. Wilhelm der Quade inde Wilhelm van Kalbeim ritter. Gerdt van Waldenbergh unse ambtman. Henrich van dem Voerste inde Didtwein van der Weyden burger zo Wipperforde, alle argelist uissbescheiden in desen dingen. Ind diss zo eynrec urkunde ind ewiger stedicheit so haint wyr der vorgenanter stat inde burgeren gegeven desen brieff besiegelt mit unser beider ingesiegelen vur ons ind onse nakomelingen in dem jair ons herren as man schreiff duisent driehondert in deme vierzigsten jaire up sent Ciriacks dagh des hyligen martelars.

Dïsseldorf, Königl. Staatsarchiv, Abschrift 1\%. Jahrhunderts in dem oben zu no. 12 beschriebenen Aktenhefte, $B l .21^{b}$ mit folgender Beglaubigung von anderer Hand versehen: "Dass gegenwerthige copey der abschrifft so under Johannes Krigen gewesenen gerichtschreibers der stadt Wipperfurdt handt in prothocollo privilegiorum der stadt Wipperfurdt erfindlich, darab mihr das original mitt sechs ahnhangenden gantzen siegelen vorbracht worden nach fleissiger collationirungh gleichlautendt befunden, bezeuge ich Paulus Linden offenbarer in furstlicher Guillich- und Bergischer cantzeley zu Dusseldorff approbirt- und immatriculirter notarius; subscripsi."

Gedruckt: W. Ritz in v. Ledebur's Archiv Bd.9, S.275-281.

18.

1347 März 1, Bensberg. - Graf Adolf von Berg beschliesst, an Stelle der beiden landesherrlichen Richter zu Wipperfürth künftighin nur eínen Richter aus den zwölf städtischen Schöffen zu ernennen.

Nos Adolphus comes de Monte notum facimus ad universorum noticiam deducendo, quod cum hactenus ex parte nostra duo iudices in oppido Wipper-
a) Unndt.
b) Hungern von Bainswir.
c) $\operatorname{esm}$. 
furde iudiciis ibidem prefuerint, unus quidem, qui de debitis et ceteris causis ea contingentibus, alter vero de potestate et causis superius iudicium contin. gentibus habebant iudicium, nos una cum amicis nostris, commodo et utilitate nostris ac nostrorum successorum necnon oppidanorum nostrorum oppidi nostri prescripti ac eorum ibidem successorum in hoc pensatis, huiusmodi iudicia in oppido nostro prescripto coniungimus et connectimus in hiis scriptis et eadem iudicia ibidem pro nobis et nostris successoribus coniuncta et connexa perpetuo remanebunt, ita videlicet, quod de cetero perpetuis temporibus more solito ex duodecim scabinis per oppidanos nostros predicti nostri oppidi annuatim eligendis eligere debebimus et nostri successores similiter eligere debebunt unum iudicem seu iusticiarium qui ex parte nostra et successorum nostrorum predictis iudiciis ex nunc, ut antea ${ }^{\mathrm{a}}$, coniunctim presit et nobis, successoribus nostris ac oppido nostro prius dicta sua iura teneat et conservet. Idem eciam iudex seu iusticiarius nobis et nostris successoribus seu commissariis nostris de prescriptis indiciis, ut premittitur, connexis et emergenciis sive obvencionibus eorundem computacionem debitam faciet et prestabit. Privilegia tamen quecunque oppido nostro prius dicto a nobis et progenitoribus nostris felicis recordacionis de libertatibus eiusdem concessa et indulta (sunt) salva nichilominus et illibata $b$ volumus permanere. Hec quidem predictorum iudiciorum coniunctio seu connectio acta est in presencia et mediante consilio strenuorum ${ }^{c}$ et discretorum virorum Heinrici de Graschaff militis. Wilhelmi vamme Haen dapiferi et Arnoldi de Holthusen camerarii nec non $\mathrm{D} D$. (!) notarii nostri. In cuius rei testimonium ac robur perpetuum et ut omnia et singula premissa oppidanis nostris predictis et eorum successoribus per nos et successores nostros sine fraude et dolo inviolabiliter observentur eisdem presentem litteram nostro sigillo tradidimus sigillatam. Datum Bensbure anno domini M.CCC.XL septimo feria quinta die prima mensis marcii.

Düsseldorf, Königl. Staatsarchiv, Abschrift 1\%. Jh. in dem unter no. 12 beschriebenen Alktenhefte $B$ l. 16.

\section{9.}

1353 November 28. - Johannes vom Broich und Philipp Brůser von Düren verkaufen dem S. Apostelstifte eine Rente von 4 Mark, Thirus von Wald eine solche von 2 Mark.

Noverint universi presentes litteras visuri et audituri, quod nos Johannes de Broeke et Philippus Brůser / de Důren ac Alheydis coniuges legitimi recognoscimus publice in hiis scriptis protestando, quod cum con/sensu et bona voluntate nostrorum heredum et amicorum vendidimus ac vendimus rite et racionabiliter discretis ac honestis dominis et viris . . decano et capitulo ecclesie sanctorum Apostolorum Coloniensis redditus annuales quatuor marcarum coloniensis pagamenti pro tempore (currentis), quondam nobis a Gotscalco dicto

a) Vielleicht in antea? träglich eingeschoben. b) ilibeta.

c) strenui.

d) , sánctorum" ist nach- 
Mrre pie memorie devolutos pro quodam pecunie summa nobis ab eisdem dominis benivole et integre persoluta. Quos quidem redditus predictos nobis officiatus curtis in Wippervo̊rde singulis annis in festo epiphanie domini ex Jan. 6 . parte.. dominorum sepedictorum finaliter et benivole persolvebat. Ceterum ego Thirus de Walde recognosco in hiis scriptis publice protestando, me vendidisse sepedictis dominis . . decano et capitulo ecclesie sanctorum a Apostolorum Coloniensis annuos redditus duarum marcarum eiusdem pagamenti suprascripti pro quadam pecunie summa michi a predictis..dominis finaliter persoluta. De quibus redditibus pretactis nos.. Johannes.. Philippus et. Thirus prenominati renunciamus et effestucacionem facimus in hiis scriptis ore, manu et calamo simpliciter et de plano omni fraude et dolo in hiis exclusis penitus et ammotis. Acta sunt hec coram viris providis et discretis .. Henrico de Vorst iudice in Wippervůrde .. Hermanno de Celario magistro civium. Telemanno Andenberge . . Telemanno Pistore . Gerlaco de Engellerskerken .. Gerardo de Wippera .. Hilbrando Lijf . . Everwino Vogel . . Heynemanno de Neyden .. Hartlevo de Borbeke . . Johanne de Quicke.. Johanne de Valle. . Henrico Pulmenti consulibus et scabinis in Wippervirde, quos rogavimus ex utraque parte, quod presens scriptum sigillo opidi confirmarent. Unde nos .. iudex . . magister civium et . . scabini prenarrati ad preces utriusque partis sigillum opidi presentibus apponi fecimus in testimonium omnium premissorum. Insuper nos Johannes et Philippus, quia premissam vendicionem recognoscimus esse veram, sigilla nostra presentibus duximus apponenda. Et ego Adolfus Hünoldi ex parte Tyri sepedicti sigillum meum presentibus duxi apponendum in testimonium veritatis. Anno domini M.mo CCC.mo LIII. ${ }^{\circ}$ feria quinta post festum Katherine virginis et martyris gloriose.

Düsseldorf, Königl. Staatsarchiv, Köln, S. Aposteln no. 160. Original auf Pergament mit 3 anhangenden Siegeln und 1 Pressel: 1 . Siegel der Stadt Wipperfürth (vgl. oben no. 6). 2. S. Johanns v. Broich, quergeteilter Schild, im oberen Felde 3 Sterne, Umschrift: ,S. Jo[hannes] vanme Broiche. 3. S. Philipp Brusers, Schild mit 3 Seeblättern (2:1) dazwischen ein laufender Hund, Umschrift . . Bru . . . - Rïckaufschrift 14. Jahrh.: ,Littera super empcione reddituum quatuor marcarum in Wuppervurde contra Johannem de Broke et Philippum Bruser.' Alte Signatur: N. IX, nebst entsprechender Inhaltsangabe.

Ebenda, Abschrift a. d. Ende 14. Jahrh. Liber albus fol. $280^{b}$ no. 236.

20.

1388 Juli 10. Wipperfïrth. - Johannes vom Pfau, Stiftsherr zu S. Aposteln, wird an Stelle Wilhelms von Monsteghe zum Pfarrer in Wipperfürth ernannt.

(Notariatsinstrument.) In nomine domini amen. Per hoc presens publicum instrumentum cunctis ipsum | inspecturis pateat universis, quod anno

a) ,sanctorum' ist nuchtrüglich eingeschoben. 
Juli 10. a nativitate eiusdem domini millesimo / cccmo lxxxvijo indiccione undecima die decima mensis iulii hora nona vel quasi, pontificatus sanctissimi in Christo patris ac domini nostri domini Urbani divina providencia pape VIti anno decimo in mei notarii publici infrascripti et testium subscriptorum ad hoc specialiter vocatorum et rogatorum presencia personaliter constitutus venerabilis ac discretus vir dominus Iohannes de Pavone canonicus prebendatus ecclesie sanctorum Apostolorum Coloniensis habens et tenens in manibus suis certi tenoris litteras patentes emanatas ab auditorio venerabilis viri domini officialis prepositi (et) archidyaconi Coloniensis cuius vices ad presens gerunt et supplent venerabiles viri domini decanus et capitulum ipsius ecclesie Coloniensis propter mortem ultimi prepositi viam universe carnis sicut domino placuit ingressi, quemadmodum id in dictis litteris inferius inserendis latius continetur. Quasquidema litteras tam investiture quam presentacionis a decano et capitulo sanctorum Apostolorum hincinde emanatas, tradidit domino Henrico rectori ${ }^{b}$ capelle in Wippervurde ad exequendum easdem litteras et se petendum investiri de ecclesia supradicta; quasquidem litteras predictas idem dominus Henricus ad se, reverencia qua decuit, receptas ut et tamquam obediens ${ }^{\circ}$ filius reverenter fuit executus, prefatum dominum Iohannem de Pavone de prelibata ecclesia sollempniter investiendo et in || possessionem corporalem eiusdem canonice mittendo iuxta predictarum litterarum continenciam et tenorem. Quarum litterarum tenores sequuntur verbotinus sub hac forma:

(Verleihungsurliunde des stellvertretenden Archidiakons:) In nomine domini amen. Nos Gerardus officialis decani et capituli esclesie Coloniensis prepositura vacante dicte ecclesie Coloniensis et ad infrascripta comnissarius ab eisdem specialiter deputatus . . decano christianitatis capitulid Tuiciensis ac universis et singulis ecclesiarum parrochialium, altariume rectoribus et presbiteris ${ }^{f}$ nobis subiectis ad quos presentes littere pervenerint salutem in domino. Presentato eisdem dominis . . decano et capitulo seu robis vices eorum in hac parte gerentibus discreto viro domino Iohanneg de Pavone canonico prebendato ecclesie sanctorum A postolorum Coloniensis per venerabiles viros . . dominos .. decanum et capitulum eiusdem ecclesie sanctorum Apostolorum ac supposito dictis dominis nostris seu nobis eorum nomine, quod cum ecclesia parrochialis in Wippervůrde infra limites archidyaconatus dicte prepositure consistens, que ad mensam capituli eiusdem ecclesie sanctorum Apostolorum eidem canonice incorporata et unita spectare dinoscitur, per concanonicum dumtaxat prebendatum eiusdem ecclesie, quem decanus et capitulum ipsius (ecclesie) sanctorum Apostolorum ad id deputare consueverunt et ad votum revocare, solita gubernari per cessum seu dimissionem domini Wilhelmi de Monsteghe dicte ecclesie sanctorum Apostolorum canonici prebendati hactenus et ultimo regentis eandem et ipsius revocacionem ad presens huiusmodi gubernatore et rectore, qui eam vice èt nomine capituli eiusdem ecclesie regat et gubernet, careat et sit destituta, quatinus dicto domino Iohanni exercicium cure dicte ecclesie parrochialis vice et nomine \| dicti capituli agendum et pro

b) rectore.

c) obediencie.

d) capittuli.

e) altareum.

f) presbitris.

g) Johanni. 
ipsis quoad populum et parrochianos a ipsius, prout hactenus fieri et obtineri $1388 J_{u l i}$ consuevit et ad dictos dominos nostros . . decanum et capitulum prepositura vacante pertinet et consuevit hactenus pertinere, exercendum per dictum dominum Iohannem et dicte ecclesie vice et commissione dicti capituli presidente committere curaremus; cuius presentacionis tenor sequitur in hec verba:

(Präsentationsbrief des Kapitels.) „Decanus et capitulum ecclesie sanctorum Apostolorum Coloniensis dilecto nobis domino Iobanni de Pavone (con)canonico nostro salutem et sincere caritatis affectum. Cum parrochialis ecclesia in Wippervi̊rde Coloniensis dyocesis infra limites archidyaconatus venerabilis domini prepositi et archidyaconi ecclesie Coloniensis consistens que ad mensam capituli nostri eidem canonice incorporata et unita cum suis iuribus, fructibus et pertinenciis universis in usus et sustentacionem fratrum ecclesie nostre convertendis spectare dinoscitur et a tempore, cuius contrarii hominum memoria non existit eciam a nobis sit possessa, consuevit pertinere per concanonicum ${ }^{b}$ dumtaxat eiusdem ecclesie nostre prebendatum, quem ad id specialiter curavimus et consuevimus, quociens opus extitit, deputare donec eum ducimus revocandum, solita gubernari, presentandum prefato domino archidiacono et preposito, et prepositura vacante decano et capitulo dicte ecclesie Coloniensis seu officiali eorundem pro cure exercicio dicte ecclesie ab eodem obtinendo quoad populum et parrochianos eiusdem, vice et nomine nostro illud donec eidem ecclesie prefuerit exequendum, prout ad eundem dominum prepositum et archidyaconum pro tempore, et prepositura vacante ad .. decanum et capitulum dicte ecclesie Coloniensis pertinere dinoscitur et hactenus de consuetudine fieri est consuetum, huiusmodi persona, que eandem ecclesiam vice nostra regat et gubernet $c$, sit ad presens destituta per revocacionem, cessum seu dimissionem domini Wilhelmi de Monsteghen dicte ecclesie nostre canonici prebendati hactenus et ultimo eciam ex commissione nostra seu capituli nostri regentis eandem, uos de vestri, domini Iohannis de Pavone, in ecclesia nostra sanctorum Apostolorum predicti concanonici circumspeccionis industria confisi, personam vestram ad regimen et gubernacionem dicte ecclesie et ad ipsam ecclesiam regendam et gubernandam vice nostra, ut premittitur, iuxta morem et consuetudinem hactenus observatos duximus deputandum ipsumque vobis iuxta morem premissum committendum, presentantes venerabilibus viris dominis decano et capitulo ecclesie Coloniensis seu eorum in hac parte vicegerenti seu officiali eorum, dicta prepositura vacante, ipsisque cum instancia debita supplicantes, quatinus vobis, domino Iohanni de Pavone nostro concanonico curam et regimen ac exercicium cure dicte ecclesie parrochialis pro nobis et vice nostra, proutd hactenus fieri est consuetum, et id ad ipsum dominum prepositum e et arclidyaconum et ad . . decanum et capitulum predictos, vacante prepositura, de consuetudine pertinet supradicta, quoad parrochianos et populum ipsius ecclesie parrochialis exequendum quamdiu vos, domine Iohannes, eidem prefueritis ecclesie et eidem vos preesse contingat, dignetur committere et mandare. In quorum testimonium presentes litteras
a) perrochianos
b) concanonicatum.
c) gubersat.
d) pro.

e) Vorkher durchstrichen: Iohannem. 
sigillo capituli nostri ad causas duximus sigillandas. Datum et actum in loco capitulari ecclesie nostre predicte capitulo ad hoc specialiter indicto anno 1388 Juli 1. domini millesimo trecentesimo lxxxvilj ${ }^{\circ}$ mensis iulii die prima. ${ }^{*}$

Nos vero officialis commissarius predictus receptis huiusmodi presentacionis litteris, ut prefertur, quia contenta in eisdem per informaciones a sufficientes desuper nobis factas veritate $\|$ reperimus fulciri ${ }^{b}$, supplicacionem dominorum .. decani et capituli sanctorum Apostolorum racioni consonam reputantes de dicto domino lohanne per dominos decanum et capitulum predictos factam, ut prefertur, duximus admittendum, curam plebis ac regimen et exercicium cure dicte ecclesie parrochialis in Wippervurde, quoad populum et parrochianos ipsius ecclesie, eidem domino Iohanni quamdiu ipsi ecclesie ex commissione dicti capituli prefuerit, per eum vice dicti capituli, prout moris est, exercendi et custodiam reliquiarum ${ }^{c}$ ipsius ecclesie in domino committendum duximus et committimus in biis scriptis, recepto ab eodem domino Iohanne de obediendo reverendo in Christo patri domino nostro archiepiscopo Coloniensi et domino archidyacono predicto eorumque officialibus pro tempore existentibus in licitis et honestis, de bonis et iuribus dicte parrochialis ecclesie inventis conservandis et non alienandis ac de perditis a et alienatis pro posse recuperandis solito iuramento, mandamus vobis universis et singulis et cuilibet vestrum, qui super hoc fueritis requisiti seu fuerit requisitus, quatinus accedentes ad e dictam ecclesiam in Wippervurde et ibidem presentes nostras litteras parrochianis ipsius ecclesie insinnari et publicarif curetis, prefatum dominum Iohannem seu eius procuratorem pro eo in dictam ecclesiam et eius possessionem tenendam et possidendam vice et nomine dicti capitulig nostra auctoritate introducatis corporalem sibique de fructibus ${ }^{\mathbf{h}}$, proventibus, iuribus et obvencionibus ipsius ecclesie, ut moris est, absque preiudicio capituli supradicti responderi faciatis et mandetis temporibus debitis et consuetis. In quorum testimonium sigillum officialitatis nostre presentibus duximus appendendum, sub 1388 Juli 8 anno domini millesimo ecemo ${ }^{\mathrm{mxx}}$ anII ${ }^{\circ}$ mensis iulii die octava."

(Einführung des neuen Pfarrers.) Quibus omnibus sic ut prefertur' in presencia parrochianorum ipsius ecclesie tunc per pulsum campane \|ibidem congregatorum ${ }^{i}$ peractis aliquo ex eis nomine ipsorum id ratificante, humiliter et instancia, qua decuit, iusi domino Iohanni, eorum, ut premittitur, pastori, supplicarunt, ut ipsos in eorum antiquo et vetusto iure conservaret et foveret. Quo audito et intellecto prenominatus dominus Iohannes idipsum pro se et ecclesia sua sanctorum Apostolorum ab eisdem parrochianis se et ecclesiam predictam petivit et rogavit illese $k$ et illibate conservari secundum ipsius ecclesie sanctorum Apostolorum consuetudinem longevam et diaturnam. Et peciit predictus dominus Iohannes de Pavone super premissis sibi fieri a me, notario publico infrascripto, in meliori forma publicum seu publica instrumentum seu instrumenta. Acta fuerunt hec in ecclesia parrochiali de Wippervurde supradicta, anno, indiccione, die, mense, hora et loco quibus supra, presentibus discretis viris ${ }^{1}$ et
a) informacionis.
b) fulsiri.
d) predictis vor her durchstrichen.
c) Vorther relinquarum attrchstriches.
g) Wowher ecclesie duwlistrichen.
h) frucibus
f) insynuare et publicare.
tion ist hier ganz besonders verwir't.
k) ille.
i) congregatio; die Konstruk-
1) Vorkier vm durchstrichen. 
honestis videlicet Thoma burgimagistro pro tempore, Gobelino Jungen, Hartlevo de Keymeringen, Sybelone de Cellario et Iohanne de Ravenstrasen scabinis in Wippervurde ac pluribus alïs fidedignis testibus ad premissa vocatis specialiter et rogatis.

Et ego Wernerus de Elfke clericus Coloniensis dyocesis publicus imperiali auctoritate et in curia Coloniensi iuratus notarius, quia premissis omnibus et singulis, dum sic, ut premittitur, agerentur et fierent una cum prenominatis testibus presens interfui eaque sic fieri vidi et audivi in hanc publicam formam redegi, quod propria manu mea scripsi et signo meo solito et consueto signavi vocatus et requisitus in testimonium omnium et singulorum premissorum.

Düsseldorf, Königl. Staatsarchiv, Abschrift 14. Jahrh. im Liber. albus $275-277^{b}$ no. 234 .

21.

1398 Februar 7, Achen. - König Wenzel belohnt die Dienste des Herzogs Adolf von Berg durch die Erlaubniss, in Lennep (Lympe) und Wipperfürth (Wepilfurde, Wepelfurde) fünf Jahre lang und länger bis zum Widerruf von jedem Fuder Wein 4 Turnosen, von jedem mit Kaufmannsgut beladenen Pferde 1 Turnos als Zoll erheben zu lassen.

Düsseldorf, Königl. Staatsarchiv, A. I no. 1358. - Original auf Pergament, das Siegel, das an schwarz-queisser Seidentordel hing, abgeschnitten. Kanzleivermerke, rechts auf dem Bug: Per d. W. patriarch. Anth. cancell. | Wlachnico de Weitemmule., auf der Rückseite oben: R. Petrus de Wischow. Inhaltsangaben 17.Jh. auf der Rïckseite. Alte Signatur: ad caps. 18. num. 16.

Gedruckt: Lacomblet, Urkundenbuch Bd. 3 no. 1041.

22.

1421 September 26, Köln. - Vertrag des Johannes von Linnich genannt van der Buntervederen mit dem S. Apostelstifte über die Verwaltung der durch den 'Tod des Johannes von Balve erledigten Pfarrstelle zu Wipperfürth.

In nomine domini amen. Per hoc presens publicum instrumentum cunctis pateat evidenter, quod anno nativitatis eiusdem millesimo quadrin|gentesimo vicesimo primo indictione quartadecima mensis septembris die vicesima sexta, hora primarum vel quasi, pontificatus sanctissimi in | Christo patris et domini domini nostri Martini divina providencia pape quinti anno quarto, in mei, notarii publici et testium infrascriptorum ad hoc vocatorum specialiter et rogatorum presencia personaliter constituti venerabiles et circumspecti viri domini de capitulo ecclesie sanctorum Apostolorum Coloniensis per pulsum campane 
in domo capitulari dicte ecclesie capitulariter congregati ex una parte et honorabilis vir dominus lohannes Lynnich alias dictus van der Buntervederen canonicus prebendatus eiusdem ecclesie sanctorum Apostolorum ex altera convenerunt et inter eos amicabiliter necnon fraternaliter concordati sunt de et super regimine ecclesie in Wippervoirde Coloniensis diocesis ad mensam dominorum decani et capituli ipsius ecclesie sanctorum Apostolorum prenominate spectantis et pertinentis, ut asseruerunt iidem domini, in modum et formam subsequentes in quadam cedula papirea diligenter conscriptos. Cuius tenor de verbo ad verbum sequitur et est talis: "Sciendum est, quod dominus Iohannes Lynnich alias dictus van der Buntervéderen canonicus prebendatus ecclesie sanctorum Apostolorum Coloniensis loco prebende sue a venerabilibus viris dominis decano et capitulo eiusdem ecclesie acceptavit ecclesiam parrochialem in Wippervoirde diocesis Coloniensis regendam et preessendam forma, modis et condicionibus infrascriptis, videlicet, quod idem dominus Iohannes debeat preesse dicte ecclesie et eam honorifice ac laudabiliter regere per se et honestos capellanum seu capellanos sic et taliter, quod dominis decano et capitulo predictis nulle querele saltem pregnantes ab opidanis opidi Wippervoerde sive aliis parrochianis dicte parrochie exinde proveniant. Et anni regiminis sui quibus ipsam ecclesiam regere debeat et teneatur inceperunt die 1421 Juri24. nativitatis beati Iohannis baptiste iam ultimo elapso et continue durare debeant quinque annis nullo medio interveniente sequentibus. Et quicquid proventum seu levatum fuerit de dicta ecclesia post mortem sive decessum quondam domini Iohannis de Balve rectoris eiusdem ecclesie dum vixerat, quod dicto domino Iohanni de Lynnich de iure aut consuetudine debeatur, hoc debeat sibi cedere in utilitatem suam propriam, et tenetur ac promisit se concordare cum capellano qui dictam ecclesiam rexerat post mortem Iohannis Balve pro laboribus suis, quod domini decanus et capitulum predicti ab ipso nullas impeticiones debeant pati sive audire. Eciam domini de capitulo expensis suis dabunt dicto domino Iohanni de Lynnich investituram ad dictam ecclesiam expeditam. Et habebit idem dominus Iohannes emolimentum et fructus prebende sue integraliter nil dempto a data presentis instrumenti ac si presens esset et chorum continuaret sicut aliis canonicis chorum continuantibus per integrum istum primum annum et non amplius hac de causa. Condicionatum est eciam, quod dominus Iohannes predictus non possit neque debeat ex causa sui aut propter suam commoditatem dimittere regimen dicte ecclesie, iam per ipsum sponte acceptatum, infra quinque annos prenarratos. Et si post hos annos voluntatem dimittendi haberet, de hoc certificare deberet dominos decanum et capitulum predictos per integrum annum ante, ut sibi de hoc de oportuno remedio providere possent. Eciam si notabiles defectus fierent, quod absit, super hiis capitulum posset et deberet de oportuno remedio providere, eciam ipso domino Iohanne invito et sine sui contradiccione 1." Qua quidem cedula per me notarium publicum subscriptum alta et intelli-

1) Hierzu hat eine andere Hand in flüchtiger Schrift am Rande bemerkt: Eciam debet ipsam ecclesiam ipsemet regere cum emolumentis honoribus et oneribus sicut sui predecessores dicte ecclesie fecerunt dolo et fraude exclusis. 
gibili voce integraliter perlecta prefatus dominus Iohannes Lynnich contenta ipsius cedule michi notario publico infrascripto stipulanti et recipienti promisit bona fide inviolabiliter observare. Super quibus omnibus et singulis supradictis prefate partes hincinde pecierunt a me notario publico subscripto unum vel plura publicum aut publica sibi fieri instrumentum seu instrumenta ad dictamen sapientis, facti tamen substancia non mutata. Acta sunt hec Colonie sub anno, indictione, mense, die, hora, pontificatu et loco quibus supra, presentibus ibidem discretis viris Iohanne dicto Schalsteler de Hornberg clerico Moguntinensis diocesis et Iohanne de Ubaich custode domus capitularis dicte ecclesie sanctorum Apostolorum incolis Coloniensibus, testibus fidedignis ad premissa vocatis pariter et rogatis.

[Notariatszeichen.] Et ego Everhardus Snelle de Lippia clericus Coloniensis diocesis publicus imperiali auctoritate notarius approbatus, quia convencioni et concordacioni aliisque omnibus et singulis prememoratis dum sic ut premittitur agerentur et fierent unacum prenominatis testibus presens interfui eaque taliter fieri vidi et audivi ideoque hoc presens publicum instrumentum manu mea scriptum exemplavi, confeci, signavi, subscripsi et in hane publicam formam redegi signoque et nomine meis solitis et consuetis signavi ad hoc vocatus, rogatus et requisitus in fidem et testimonium omnium et singulorum premissorum.

Düsseldorf, Königl. Staatsarchiv, Köln, S. Aposteln no. 227. Original auf Pergament mit Umfaltung, jedoch ohne Spuren von Besiegelung; Rückaufschrift 15. Jh.: „Instrumentum contractus inter capitulum et Iohannem Bonteveder super regimine ecclesie in Wippervoerde." Alte Signatur: N. X. Inhaltsangabe 17. Jh.

23.

1428 Juni 6. - Thijs Smet in der Hamer nimmt von Jobann von Linnich genannt van der Buntenvederen, Pfarrer zu Wipperfürth, und vom S. Apostelstifte ein Grundstück in der Hamer "dar der Sybelenborn dor lopet" gegen 5 Mark jährlich zunächst auf 24 Jahre in Pacht, um darauf ein Wohnhans zu errichten.

Ich Thijs Smet in der Hamer bekenne ind bezuge overmitz dyssem breyve vor mich ind myn rechten erven, dat ich hebbe gewunnen ind gemet| van heren Johan van Lynge geheissen van der Buntenvederen pastor der kerspelskerchen van Wipperfurde ind vord van den ersamen heren $\mid$ dechens ind kapittels der hilliger Apostelenkirchen bynnen Colne erve in gued, as myt namen eyn stucke landes gelegen in der Hamer dar der Sybelenborn dor lopet, as dat gelegen is bynnen synen tůnen, schessende an Kerstians wese in den Wynhơs selige, borger to Wipperfurde, veyrindtwyntich jar lanck nest an eynanderen volgende ${ }^{a}$ na datum dysses breyves vor eyne jarlinx gulde ind pacht, as myt namen vyff ${ }^{a}$ marck colcz pagementes, welche vurschreven

a) wolgende, wsff. 
gulde ind pacht ich Thijs vurschreven off myn rechten erven off behelder des principals breyffs betalen ind verrichten sollen alle jar deme pastor to der tijd der vurschreven kerspelskyrohen to Wipperfurde to halffvasten eyn jar dem anderen ervolgende. Item so sal ich Thijs vurschreven off myn rechten erven op dat vurschreven guet ind erve eyn gewontlich wonhis don tymmeren ind vord ander ghehutte as my gedelich ind not is ind dat in guden bauwe halden. Ind vord so is gevorwerd, so wan dey veyrindtwyntich jâr omber syn, so mach ich Thijs vurschreven off myn rechten erven komen ind gesynnen des vurschreven erves ind gudes an dem pastor to der tijd der egenanten kyrchen to Wipperfurde ind an dey erberen ${ }^{2}$ heren dechen ind capittels to sente Apostolen vurschreven ind solen sey my offte myn rechten erven dat vurschreven erve veyrindtwyntich jar wederomber don in alle der wijs as ich dat in vorjaren gehät hebbe ind my Thys vorschreven offte myn rechten erven des nicht wegeren, so vere as ich Thys off myn rechte erven off behelder des breyffs dey egenante pacht ind gulde van allen jareu wol betale ind dat vurschreven gued in sime gebaůwe behalde as ich dat gevůnden hebbe ind ock den vurschreven tymmer in guden bowe to behalden. Ock so is gevorwert, offt sake were dat dat vorgenante erve nicht betymmert en worde myt huse ind gehuchte ind in tine as vurschreven is ind ock gebroclich worde in der betalinge, so dat sick eyn jar deme anderen ervolgede as op den vurschreven termyn, so, sal dat vurschreven gued ind erve wederomber vellich syn an dey vurschreven egenante kerspelskyrchen to Wipperfurde sunder enigerhande wederredde dey gescheya mochte van myr Thijs wegen off myn rechten erven offte behelder des principals breyffs wegen. Ock off ick Thijs, myn rechten erven off behelder des breyffs gevunden worde in versetter gulde ind pacht, as vurschreven is, dey sole wy betalen ind overreken dem pastor der egenanten kyrspelskyrchen to Wipperfurde to der tyd ind vorder enigerhande recht an dat vurschreven erve to hebben. Item so is gevorwert b, off enigerhande overlast op dat vurschreven erve gedrungen worde as van schattes wegen offte van enigen saken, dat sal ich Thijs, myn rechten erven off behelder des breyffs allegader affdôn sunder enige wederrede, alle argelist, nuwe ind alde vünde ind quade beheyndicheyt in allen pünten dys breyffs genslich ind to male uissgescheden. Ind vord to merre sicherheit alle vurschreven půnte so hebbe ich Thijs vurschreven vor mich ind myn rechten erven gebeden den ersamen berven lude borgemester, richter, scheffen ind råt der stat to Wipperfurde, dat sey er stat ingesegel hebbent gehangen beneden an dysen breyff. Des wyr borgemester, scheffen, richter ind rat der vurschreven stat bekennen omber bede ind vruntschop willen Thijs vurschreven. Datum anno domini millesimo quadringentesimo vicesimo ${ }^{c}$ octavo in octava trinitatis.

Dïsseldorf, Königl. Staatsarchiv, Köln, S. Aposteln no. 231. Original auf Pergament mit anhängendem, stark verletztem kleinerem Sieget der Stadt Wipperfürth in grünem Wachs; es scheint eine genaue Wieder-
a) eberen.
b) gevorwet.
c) vicessimo. 
gabe des grösseren Siegels zu sein. Alte Signatur: N. XI nebst zwei kurzen Inhaltsangaben 16. u. 17. Jahrh.

24.

1429 Juni 13. - Erzbischof Dietrich von Köln erteilt dem Gerhard de Bercka die Erlaubniss zur Uebernahme der Pfarrerstelle in Wipperfürth trotzdem er im S. Apostelstifte bereits eine Priesterpfründe besitzt.

Theodericus dei gracia sancte Coloniensis ecclesie archiepiscopus sacri imperii per Italiam archicancellarius apostolice sedis legatus. | Nuper decanus et capitulum ecclesie sanctorum Apostolorum Coloniensis nobis exposuerunt, quod licet ipsi volentes ecclesie parrochiali in Wypper|vorde nostre diocesis, per canonicum dicte ecclesie sanctorum Apostolorum ab antiquo gubernari consuete, de utili et ydonea persona providere, devotum nostrum Gerardum de Bercka dicte ecclesie sanctorum Apostolorum canonicum pro utraque ecclesiarum evidenti utilitate in rectorem dicte ecclesie parochialis elegerint, tamen idem Gerardusa, qui prebenda presbiterali in dicta ecclesia sanctorum Apostolorum extitit prebendatus, quodam statuto per ipsum in primordio assumpcionis sue, ut asserit, eciam iurato, quo inter alia cavetur, ne canonici huiusmodi prebendis presbiteralibus prebendati ab eadem ecclesia ultra tempus in eo expressum se absentent, sibi obviante, dubitaret, se preter formam et tenorem dicti statuti non posse a dicta ecclesia absentare, et propterea nobis supplicarunt, ut ipsis et dicto Gerardob, qui eciam debitum suum racione dicte prebende sue in buiusmodi absencia, ut accepimus, ex convencione prehabita per alium fieri procurabit, super premissis de optimo remedio quatinus expediret providere curaremus, Nos igitur ex pastoralis officii nostri debito providere attendentes huiusmodi ecclesiarum necessitatem et utilitatem et considerantes, quod, qui ecclesie utilitate abest, iuris interpretacione residere videatur, dictum statutum quoad personam dicti Gerardi, quamdiu ipsum regimini dicte parrochialis ecclesie preesse contigerit, ad cautelam relaxamus et huiusmodi iuramentum propter necessitatem et utilitatem predictas in melius commutantes, eidem Gerardo taliter et ex causa predicta abessendi et dictam ecclesiam parrochialem in salutem animarum parrochianorum eiusdem fideliter gubernandi tenore presencium auctoritate nostra ordinaria concedimus facultatem. Datum Colonie nostro sub sigillo feria secunda post beati Barnabe apostoli anno domini millesimo quadringentesimo vicesimo nono.

Per dominum . . Coloniensem

H. prepositus ${ }^{\mathrm{c}}$.

Düsseldorf, Königl. Staatsarchiv, Köln, S. Aposteln no. 232. Original auf Pergament mit kleinem Bruchstück des abhängenden Siegels. Fast erloschene Rückaufschrift 15. Jahrh. ohne besondere Bedeutung.

a) Zuischen jdem und Gerardus ein Strich auf Rasu*.

b) Zuischen dicto $u$. Gerardo Strich auf Rasur; ebenso zuvischen dicti nund Gerardi.

c) Diese Untev'schrift von anderev Hand. 
25.

1429 Juni 30. - Der Official des Dompropstes und Archidiakons zu Köln überträgt nach dem freiwilligen Verzicht des Johanues von Linnich genannt Buntefeder die Pfarrei Wipperfürth dem vom $\mathrm{S}$. Apostelstifte präsentirten Stiftsherrn Gerhard de Bercka.

Officialis prepositi et archidiaconi Coloniensis universis et singulis ecclesiarum parrochialium, capellarum et altarium rectoribus ceterisque presbiteris curatis et non curatis, clericis et notariis | publicis quibuscumque salutem in domino cum plena veritatis noticia subscriptorum. Presentato nobis discreto viro domino Gerardo de Bercka canonico ecclesie sanctorum / ApostoIorum Coloniensis ad parochialem ecclesiam in Wypperfurde Coloniensis diocesis nostri archidiaconatus vacantem ad presens per liberam resignacionem domini Johannis de Lynghe alias Buntefeder novissimi rectoris eiusdem ecclesie per venerabiles dominos decanum et capitulum ecclesie sanctorum Apostolorum, ad quos dicte ecclesie presentacio, quociens eam vacare contingit, ex quo ad mensam capituli ibidem canonice incorporata et unita existit, cum suis iuribus, fructibus et pertinenciis universis in usus et sustentacionem fratrum dicte ecclesie sanctorum Apostolorum convertendis spectare dinoscitur, supplicantes nobis, quatinus eundem presentatum concanonicum suum ad dictam ecclesiam admittere ac de eadem investire dignaremur. Nos itaque officialis, supplicacioni huiusmodi in iusticia annuentes ac tribus proclamacionibus in talibus fieri consuetis ex certis et racionabilibus causis pretermissis, maxime cum dicta ecclesia in Wypperfurde per unum de canonicis ecclesie sanctorum Apostolorum quem predicti domini decanus et capitulum ad hoc duxerint eljgendum et deputandum duntaxat regi et gubernari consuevit, memoratum dominum Gerardum de Bercka personaliter coram nobis in figura judicii in ambitu ecclesie Coloniensis constitutum ad eandem ecclesiam parrochialem in Wypperfurde admisimus et admittimus per presentes, ipsumque per libri tradicionem in nomine patris et filii et spiritus sancti investivimus et investimus, curam anymarum et custodiam reliquiarum eiusdem ecclesie sibi in animam suam committendo, recepto tamen prius ab eodem domino Gerardo corporali ad sancta dei ewangelia et per eum tactis ymagine crucifixi et scripturis sacrosanctis prestito fidelitatis iuramento consueto, videlicet, quod ex nunc in antea erit fidelis et obediens reverendissimo domino nostro archiepiscopo Coloniensi nec non domino nostro preposito et archidiacono ecclesie Coloniensis et eorum officialibus pro tempore existentibus in licitis et honestis, et quod inventa dicte ecclesie in Wypperfurde conservabit ac deperdita recuperabit pro posse et nosse. Quocirca vobis omnibus et singulis supradictis et cuilibet vestrum in solidum precipiendo mandamus, quatinus dictum dominum Gerarduum cum desuper requisiti fueritis seu aliquis vestrum fuerit requisitus in et ad corporalem eiusdem ecclesie possessionem immittatis et inducatis cum sollempnitatibus debitis et consuetis. In- 
super moneatis auctoritate nostra omnes et singulos utriusque sexus homines ad quos fructuum et redditnum ac aliorum iurium quorumcumque eiusdem ecclesie assignacio seu exhibicio spectat et pertinet, quatinus prefato domino Gerardo tanquam vero et canonico rectori eiusdem ecclesie de huiusmodi fructibus et redditibus, prout consuetum est, respondeant et satisfaciant suis loco et tempore debitis et consuetis, alioquin contrarium facientes, sex dierum canonica monicione premissa, quorum duos pro primo duos pro secundo et reliquos duos dies pro tercio et peremptorio termino ipsis et eorum cuilibet prefigimus et assignamus, quos nos ex tunc propter hoc in hiis scriptis excommunicamus, excommunicatos publice nuncietis et teneatis, nisi medio tempore causam coram nobis pretendant racionabilem, quare ad premissa minime teneantur parte altera ad hoc legitime vocata. In quorum omnium fidem et testimonium premissorum sigillum officialitatis curie nostre maius presentibus est appensum. Actum et datum anno domini millesimo quadringentesimo vicesimo nono die iovis ultima mensis iunii hora causarum de mane consueta.

Scriptum per me Wilhelmum de Gher. notarium communem.

Düsseldorf, Königl. Staatsarchiv, Köln, S. Aposteln no. 232. Original auf Pergament mit Pressel, Siegel ab. Rückaufschrift 15. Ja7rh.: ,Littere domini Gerardi super ecclesia in Wippervorde videlicet presentacio et institucio'; Signatue 17. Jahrh.: N. XIV.

26.

1429 Juli 7. - Das Kapitel von S. Aposteln schljesst mit dem Stiftsherrn Gerhard de Bercka einen Vertrag über die Verwaltung, der Pfarrstelle zu Wipperfürth.

In nomine domini amen. Anno a nativitate eiusdem millesimo quadringentesimo vicesimo nono indiccione septima die vero septima mensis iulii hora terciarum vel quasi, pontificatus | sanctissimi in Christo patris et domini nostri domini Martini divina providencia pape quinti anno duodecimo in mei notarii publici et testium infrascriptorum ad hoc vocatorum specialiter et rojgatorum presencia personaliter constituti, domino decano pro tunc absente, venerabiles viri domini Heynmannus de Smalenberg, Conradus de Ulma, Giso Utenwerde, Wilhelmus de Stipite, Iohannes Deghen, Henricus de Vynhusen, Iohannes de Molendino, Anthonius Peregrini de Susato, Iohannes de Stummel et Godfridus Scholer de Tytz canonici ecclesie sanctorum Apostolorum CoJoniensis in loco seu domo capitulari eiusdem ecclesie capitulariter congregati et capitulum dicte ecclesie facientes et, ut asseruerunt, representantes ex una, et dominus Gerardus de Bercka canonicus prebendatus eiusdem ecclesie ac regens parrochialem ecclesiam in Wippervoerde Coloniensis diocesis nomine decani et capituli prefati; quibus sic constitutis prefati domini de capitulo quasdam convencionem et concordiam amicabiles inter dominos decanum et capitulum et Gerardum de Bercka canonicos dicte ecclesie sanctorum Apostolorum prefatos de et super regimine prefate ecclesie parrochialis in Wipper- 
voerde factas et ordinatas atque conceptas iuxta tenorem cuiusdam papiri 1429.Juli \% cedule conscripte et per dominum Godfridum Scholer supradictum de verbo ad verbum ibidem alta et intelligibili voce in presencia dicti domini Gerardi et eo ad infrascripta consenciente perlecte, non vi, dolo neque metu intervenientibus set sponte et libere, ut asseruerunt, inierunt. Cuius quidem cedule tenor sequitur de verbo ad verbum et est talis: „Hec est convencio inter dominos decanum et capitulum ecclesie sanctorum Apostolorum Coloniensis ex una et dominum Gerardum de Bercka canonicum prebendatum eiusdem ecclesie ex alia partibus de et super regimine ecclesie parrochialis in Wippervoerde Coloniensis diocesis facta. ( $\$$ 1. Verpflichtung des Pfarrers zur Wahrung des Besitzstandes und zur Tragung aller Lasten.) In primis prestito per supradictum dominum Gerardum de Bercka iuramento in talibus prestari solito et consueto iuxta tenorem iuramenti in libro ewangeliorum dicte ecclesie sanctorum Apostolorum descripti ${ }^{1}$ concorditer convenerunt, in hunc modum videliset, quod prefatus dominus Gerardus tenebit dictam ecclesiam tamquam incorporatam prefatis dominis decano et capitulo ad eorum mensam cum omnibus et singulis suis consuetis emolumentis et supportabit omnia et singula onera prefate ecclesie parrochialis tam in decimis quam procuracionibus incumbencia. (\$ 2. Uebernahme der Seelsorge auf' neun Jahre mit Residenzpflicht.) Item prefatus dominus Gerardus in prefata parrochiali ecclesia personaliter residebit, curam animarum et custodiam reliquiarum, pront sibi ab archidiacono loci commissum extitit, geret ad novem annos continuos incipientes 1129 Juni25. currere in crastino nativitatis beati Iohannis Baptiste proxime ante datam presentis instrumenti publici transacto. (\$ 3. Geldzahlung des Kapitels an den Pfarrer.) Preterea dicti domini decanus et capitulum dabunt prefato domino Gerardo distinctis vicibus infrascriptis triginta duos florenos renenses, quolibet floreno pro tribus marcis et quinque solidis monete coloniensis communiter currentis computando; quorum quidem triginta duorum florenorum dabunt sibi sedecim quamprimum idem dominus Gerardus venerit ad residenciam personalem dicte ecclesie in Wippervoerde et deinceps alios sedecim florenos infra dimidium annum extunc immediate sequentem, tali condicione adiecta, quod si prefatus dominus Gerardus ante completum elapsum prefatorum novem annorum decederet, extunc pro rata temporis vite sue dictorum novem annorum debitam porcionem predictorum triginta duorum florenorum obtinebit et aliam residuam porcionem pro rata temporis similiter competentem eo de medio sublato per dictos novem annos manufideles ipsius domini Gerardi refundent et restituent dominis de capitulo supradictis. (\$ 4. Investitur auf Kosten des Kapitels.) Item condicionatum extitit, quod supradicti domini decanus et capitulum procurabunt domino Gerardo supradicto investituram de dicta ecclesia parrochiali libere et absolute eorum expensis. (§5. Erzbischöfliche Dispens von der Verpflichtung, als Pricsterkanonikus in Köln zu residiren, auf Kosten des Kapitels. ${ }^{2}$ Item iidem domini decanus et capitulum procurabunt et ordinabunt suis eciam expensis supradicto domino Gerardo

1) S. unten no. 38 .

2) Eine solche Dispensurkunde s. oben no. 24. 
dispensacionem a reverendissimo in Christo patre et domino domino archiepiscopo Coloniensi super iuramento de residendo apud dictam ecclesiam. sanctorum Apostolorum occasione prebende sue sacerdotalis prestito. Item debitum huiusmodi prebende sacerdotalis dicto domino Gerardo incumbens dicti domini decanus et capitulum ad se recipient et eorum expensis fieri procurabunt. (§. 6. Herstellung des baufälligen Pfarrhauses auf Kosten des Stiftes und des letzten Pfarrers.) Item quia domus dicte parrochialis ecclesie in Wippervoerde tecto et parietibus ruinosa extitit, propterea condicionatum est, quod dicti domini decanus et capitulum una cum domino Iohanne Buntefeder, qui eiusdem ecclesie parrochialis novissimus rector extitit, ordinabunt et disponent inter se taliter quantocicins fieri poterit, quod dicta domus dotis ad debitam structuram quoad tectum et parietes ponatur, et in tali vel consimili structura antedictus dominus Gerardus eandem conservabit et tempore dimissionis ecclesie relinquet. (\$. 7. Absetzbarkeit des Pfarrers bei Pflichtverletzung.) Item dicti domini decanus et capitulum poterunt dictum dominum Gerardum demeritis ipsius, quod absit, exigentibus de regimine dicte ecclesie ad eorum beneplacitum revocare. - Super quibus omnibus et singulis prenarratis supradicte partes hincinde videlicet tam dominus Gerardus quam dicti domini de capitulo pecierunt a me notario publico infraseripto unum vel plura publicum seu publica sibi in meliori forma fieri instrumentum aut instrumenta ad dictamen cuiuslibet sapientis, facti tamen substancia non mutata. Acta sunt hec Colonie sub anno, indiccione, mense, die, hora, pontificatu et loco quibus supra presentibus ibidem honorabilibus viris dominis Syfrido Hunen predicte ecclesie sanctorum Apostolorum vicario et Winando de Ubach monasterii ad Vivarium extra muros Colonienses officiante presbiteris, testibus fidedignis ad premissa vocatis pariter et rogatis.

[Notariatszeichen] a Et ego Everhardus Snelle de Lippia [etc. wie unten in no. 27.]

Düsseldorf, Königl. Staatsarchiv, Köln, S. Aposteln no. 232. Original auf.Pergament mit Rückaufschrift 15. Jahrh.: In Wyppervorde. Instrumentum super concordia inter decanum et capitulum ecclesie sanctorum Apostolorum Coloniensis et dominum Gerardum de Bercka canonicum eiusdem ecclesie super regimine ecclesie parrochialis in Wippervorde." Signatur 17. Jahrh. ,N. XV.

\section{7.}

1437 November 9. - Das Kapitel von S. Aposteln schliesst mit dem Priester Volmar von Hilden aus Attendorn einen Vertrag über die Verwaltung der Pfarrstelle zu Wipperfürth.

In nomine domini amen. Per hoc presens publicum instrumentum cunctis pateat evidenter, quod anno a nativitate eiusdem domini millesimo quadringentesimo / tricesimo septimo indiccione prima secundum stilum et

a) Die folgende Beglaubigung von gleicher Sohrift wie der Text. 
1437 xov. 9. consuetudinem scribendi civitatis et diocesis Coloniensis mensis novembris die nona de mane hora decima / vel quasi, pontificatus sanctissimi in Christo patris ac domini nostri domini Eugenii divina providencia pape quarti anno septimo, in mei notarii publici et testium infrascriptorum ad hoc vocatorum specialiter et rogatorum presencia personaliter constituti venerabiles et honorabiles domini Conradus Ludekynck decanus, Conradus de Ulma, Thomas Vrede de Kempen, Wilhelmus de Stipite, Iohannes de Sibergh, Wilhelmus Wall, Iohannes de Arwilre, Iohannes Degen, Henricus Vynhusen, Petrus de Stralen, Iohannes de Molendino, Iohannes de Stummel, Anthonius Peregrini de Susato, Iohannes Cabebe de Urdingen, Iohannes de Wydenvelt, Gotfridus Scholer de Tijtz. Petrus Bau, Iacobus van der Straten, Iacobus de Horst scolasticus et Gobelinus Mey canonici ecclesie sanctorum Apostolorum Coloniensis in domo capitulari dicte ecclesie ad sonum campane propter ea congregati et capitulum eiusdem ecclesie facientes ex una, et discretus vir dominus Wolmarus de Helden de Attendarn presbiter Coloniensis diocesis de et super arrenda sive regimine parrochialis ecclesie in Wyppervorde dicte diocesis partibus ex altera; quibus taliter constitutis decanus et domini de capitulo antedicto quasdam convencionem et concordiam amicabiles inter dominos decanum et capitulum necnon dominum Volmarum antefatos de et super regimine dicte parrochialis ecclesie in Wippervorde factas, ordinatas atque conceptas iuxta tenorem cuiusdam papiri cedule conscripte ac ibidem exhibite, necnon de verbo ad verbum alta et intelligibili voce in presencia dicti domini Volmari et eo ad infrascripta consenciente perlecte, non vi, dolo neque metu interveniente sed sponte ac libere, ut asseruerunt, mutuo inierunt. Cuius quidem cedule tenor de verbo ad verbum sequitur et est talis: ,Contractus initus per et inter venerabilem et honorabiles viros dominos decanum et capitulum ecclesie sanctorum Apostolorum Coloniensis ex una et discretum virum dominum Volmarum de Helden de Attendarn presbiterum Coloniensis diocesis de et super arrenda sive regimine parrochialis ecclesie in Wyppervorde dicte diocesis partibus ex altera. (\$. 1. Allgemeine Pflichten des Pfarrers.) Primo enim prefatus dominus Volmarus dictam ecclesiam parrochialem reget et gubernabit eique in divinis laudabiliter deserviet sic et taliter, quod dicti domini decanus et capitulum propterea a parrochianis dicte ecclesie nullas penitus habeant sive audiant querelas aut aliqua dampna, incommoda et detrimenta inde paciantur aut sustineant. (§. 2. Abgaben und Leistungen an das Stift.) Item dictus dominus Volmarus omnes et singulos fructus, redditus, proventus, obvenciones et emolumenta dicte ecclesie percipiet et propterea dictus dominus Volmarus singulis annis prefatis dominis decano et capitulo in festo nativitatis beati Johannis baptiste aut infra quindenam expost immediate sequentem realiter persolvet, tradet et assignabit vigintiquinque florenos renenses quolibet floreno pro tribus marcis et quinque solidis pagamenti coloniensis computato. (§. 3. Verpflichtung des Pfarvers zur Tragung aller Zehnten und Lasten olne Beihilfe des Stiftes.) Item idem dominus Volmarus se solo quascunque decimas impositas seu imposterum imponendas racione dicte ecclesie parrochialis persolvet et cum hoc omnia et singula alia onera dicte ecclesie quandocunque et qualitercunque incumbencia solus sup- 
1437 Nov. 9. portabit, nullum subsidium a capitulo predicto propter premissa petendo. (\$. 4. Lebenslängliche Amtsdauer bei tadelloser Verwaltung.) Preterea condicionatum existit inter dictas partes, quod memorati domini decanus et capitulum dictum dominum Volmarum in regimine a dicte ecclesie ad dies vite sue tolerabunt nec eundem ab huiusmodi regimine quoquomodo ammovebunt aut revocabunt, nisi in regimine dicte ecclesie defectuosus repertus fuerit et eius demerita quoad exercicium cure dicte ecclesie id exegerint. (\$. 5. Verpflichtung zur Wiedererwerbung einer dem Stifte vorenthaltenen Kornrente aus der Mühle zu Wipperfürth.) Item dictus dominus Volmarus bona et sincera fide, dolo et fraude penitus cessantibus, promisit dictis dominis decano et capitulo ecclesie predicte et michi notario publico infrascripto stipulantibus et recipientibus, novem maldra siliginis que dicta parrochialis ecclesia in Wippervorde a molendino ibidem habere consuevit, iam aliquamdiu ab eadem per dominos terre et eorum officiatos alienata, velle totis viribus et conatibus suis efficere et procurare, quod huiusmodi novem maldra ad dictam ecclesiam parrochialem realiter et effectualiter revertantur; et in casu, quo dictus dominus Volmarus hoe modo premisso procuraverit, extunc idem dominus Volmarus habebit singulis annis quibus dicte ecclesie prefuerit et eam in divinis rexerit de dictis novem maldris tria maldra, residua sex malda siliginis antedictus dominus Volmarus singulis annis una cum vigintiquinque florenis renensibus aut eorum verum valorem pro eisdem realiter et effectualiter infra civitatem Coloniensem suis periculo, laboribus et expensis dictis dominis presentabit. (\$. 6. Verpflichtungen des Pfarrers nach Erlangung einer Pfründe im S. Apostelstifte.) Item condicionatum existit in casum et eventum quo prefati domini decanus et capitulum ullo umquam tempore antedicto domino Volmaro prebendam dicte ecclesie sanctorum Apostolorum Coloniensis contulerint, quod extunc post huinsmodi prebende collacionem et annorum expectancie expiracionem sepedictus dominus Volmarus ab huiusmodi sex maldris siliginis et vigintiquinque florenis renensibus predictis erit absolutus et apud supradictam ecclesiam parrochialem ad dies vite sue residebit eam gubernando et regendo ut supra premittitur, salvo tamen, quod idem dominus Volmarus extunc deinceps singulis annis viginti maldra avene ad preseneias dominorum canonicorum predictorum infra civitatem Coloniensem presentabit aut eorum verum valorem persolvet pro eisdem. (§. 7. Verpflichtung zur Instandhaltung der Kirchengebäude und der Ländereien.) Item edificia dicte parrochialis ecelesie in bona structura ac agros atque prata eiusdem in bona ac debita cultura conservabit et sic eciam tempore dimissionis relinquet. (\$. 8. Investitur auf gemeinschaftliche Kosten des Kapitels und des Pfarrers.) Item, quod si contigeritb, dictum dominum Volmarum per supradictos dominum decanum et capitulum archidiacono ecclesie Coloniensis ad prefatam parrochialem ecclesiam in Wippervorde pro investitura presentari, quod tunc littere huiusmodi investiture communibus expensis ipsorum dominorum decani et capituli et Volmari expedientur. (\$. 9. Der Vertiag tritt am 24. Juni 1438 in Kraft.) Item annus arrendacionis huiusmodi incipiet anno domini mille-

a) regimen.

b) Vervessert aus, contingerit. 
simo quadringentesimo $\mathrm{xxx}$ octavo in festo nativitatis beati Iohannis baptiste. - Promiserunt insuper partes prefate hincinde ad manus mei notarii solempniter stipulantis et recipientis vice et nomine omnium et singulorum quorum interesse poterit, contenta et narrata in suprainserta convencionis cedula firmiter et inviolabiliter observari. Super quibus omnibus et singulis prenarratis supradicte partes hincinde pecierunt a me notario publico unum vel plura publicum seu publica sibi fieri instrumentum seu instrumenta in meliori forma ad cuiuscumque dictamen sapientis, facti tamen substancia non mutata. Acta sunt hec Colonie sub anno, indiccione, mense, die, hora, loco et pontificatu quibus supra, presentibus ibidem honorabilibus viris dominis Conrado Roide et Amplonio de Bercka vicariis in predicta ecclesia sanctorum Apostostolorum, testibus ad premissa vocatis pariter et rogatis fidedignis.

[Notariatszeichen.] a Et ego Everbardus Snelle de Lippia clericus Coloniensis diocesis publicus imperiali auctoritate et approbatus notarius quia premissis omnibus et singulis dum sic, ut prefertur, agerentur et fierent una cum prenominatis testibus presens interfui eaque realiter fieri vidi et andivi ideoque hoc presens publicum instrumentum manu aliena fideliter ingrossatum exinde confeci et in hanc publicam formam redegi signoque et nomine meis solitis et consuetis signavi atque subscripsi ad hoc vocatus, rogatus et requisitus in fidem et testimonium premissorum omnium et singulorum.

Düsseldorf, Königl. Staatsarchiv, Köln, S. Aposteln no. 237. Original auf Pergament mit Notariatszeichon; auf dèr Rückseite gleichzeitige Aufschrift: ,Pro capitulo', von einer späteren Hand 15. Jahrh.: ,Instrumen. tum concordie super regimine ecclesie parrochialis in Wippervorde inter dominos decanum et capitulum ecclesie sanctorum Apostolorum et dominum Volmarum de Helden de Attendorn'. Archiv-Sigraturen 1\%. Jahrh.: ,Wipperfurdt. N. XVI. - Ein zweites Exemplar der Urkunde ist von anderer Hand geschrieben, auch stimmen darin die Schriftzüge der notariellen Beglaubigung nicht nit denen des Textes überein, andere Abweichungen jedoch beschräntien sich auf orthographische Besonderheiten.

28.

1439 December 2, Köln, S. Aposteln. - Das Kapitel von S. Aposteln überträgt dem Priester Volmar von Helden aus Attendorn das durch den Tod Heinrichs von Vynhusen erledigte Kanonikat und ermächtigt ihn zugleich, sich durch den Archidiakon mit der Pfarrstelle zu Wipperfürth investiren zu lassen.

In nomine domini amen. Per hoc presens publicum instrumentum cunctis pateat evidenter, quod anno a nativitate domini eiusdem millesimo quadringentesimo tricesimo nono indiccione tercia secundum | stilum et con-

a) Die folgende Beglandignng stimmt mit aler Handschrift des Textes Hberein. 
1439 Dec. 2. suetudinem scribendi civitatis et diocesis Coloniensis, die vero mercurii secunda mensis decembris de mane hora terciarum vel quasi, pontificatus sanctissimi in Christo patris et domini nostri domini Eugenii divina / providencia pape quarti anno suo nono, in loco seu domo capitulari ecclesie sanctorum Apostolorum Coloniensis venerabilibus et circumspectis viris dominis Conrado Ludekingk decano, Conrado de Ulma, Iohanne de Siberg, Iohanne de Arwilre, Iohanne Deghen, Wernero Vyncke, Iohanne Kirdorp, Anthonio Peregrini, Iohanne Cabebe, Iohanne de Wydenvelt, Gotfrido Scholer, Petro Bau, Iacobo de Strata, Petro (de) Prumia, Gobelino Mey, Iacobo de Horst scolastico, Petro Waldorp, Henrico Vrijdach, Theoderico Randenrode et Iordano de Mallant canonicis dicte ecclesie capitulariter congregatis ipsisque ibidem ex causis infrascriptis ex una et honorabili viro domino Volmaro de Hielden de Attendarn presbitero Coloniensis diocesis partibus ex alia in mei, notarii publici et testium infrascriptorum insimul constitutus presencia dictus dominus Volmarus inter alia exposuit, se intellexisse, quod prefati domini decanus et capitulum noviter, videlicet die iovis proxime preterita que erat vicesima sexta novembris quosdam canonicatum et prebendam ipsius ecclesie per obitum quondam Henrici de Vynhusen dum vixit eiusdem ecclesie canonici tunc vacantes sibi, licet absenti, auctoritate ordinaria contulissent et de eisdem sibi providissent, quas collacionem et provisionem ipse dominus Volmarus expresse ratificavit et approbavit ac peciit, se ad possessionem corporalem, realem et actualem eorundem canonicatus et prebende secundum consuetudinem dicte ecclesie admitti et, quatinus oportunum foret, eosdem sibi denuo conferri te de eisdem provideri. Super quibus prefati domini decanus et capitulum, prehabita aliquali deliberacione, dicte peticioni annuentes, dictos canonicatum et prebendam sic, ut premittitur, per obitum ipsius quondam Henrici vel alio quovismodo aut ex alterius cuiuscumque persona vacantes eidem domino Volmaro hoc humiliter petenti denuo contulerunt et de eisdem per ipsum dominum decanum per birreti capitis sui imposicionem melioribus modo et forma quibus potuerunt dicta auctoritate providerunt et recepto ab eo iuramento per canonicos eiusdem ecclesie in recepcione et admissione suis iurari consueto, in libro ewangelii dicte ecclesie descripto ${ }^{1}$, quod ipse dominus Volmarus alta voce de verbo ad verbum recitavit et iuravit, ipsum dominum Volmarum ad possessionem eorundem canonicatus et prebende, salvis statutis et consuetudinibus ipsius ecclesie et iure alterius cuiuscumque, receperunt et admiserunt, stallum sibi in choro et locum in capitulo per prefatum dominum Henricum Vrijdach eorum concanonicum in latere prepositi assignarunt et assignari fecerunt. Et continuo eisdem decano et capitulo asserentibus, quod ecclesia parrochialis in Wippervoerdea ${ }^{a}$, ipsis et dicte eorum ecclesie

a) Dwch Umstellungszeichen aus ecclesia in W. parrochialis.

1) Dieses Evangelienbuch befindet sich 'jetzt im Stadtarchiv zu Köln, Handschriften $A B$ no. 244. Es ist ein Codex von 250 Blättern Perg. in $4^{0}$, angelegt in Anfange des 13. Jahrh., mit vielen später'en Zusätżen. Die Eidesformeln mit den Evangelienanfängen sind Blatt 236 ff. von einer Hand 15. Jahrh. nachgetragen. 
1939 Dec. 2.dudum incorporata, ab antiquo regi et gubernari consueverit per canonicum prebendatum dicte ecclesie in et ad eandem per ipsos presentatum et institutum, et propterea ipsi domini decanus et capitulum, volentes dicte ecclesie parrochiali in Wippervoerde, que noviter per obitum quondam Gerardi de Bercka, eciam dum vixit dicte ecclesie canonici, vacabat, providere, eidem domino Volmaro presentacionem tunc debito tempore de persona sua tamquam habili et ydonea factam sub eorum sigillo sigillatam tradiderunt ad a effectum, ut ipse se ad eandem per loci archidiaconum institui et investiri faceret et procuraret. Et nichilominus ipsum eciam de novo ibidem ex habundanti cautela ad dictam ecclesiam parrochialem, sive per obitum dicti quondam Gerardi vel alio quovis modo aut ex alterius cuiuscumque persona vacaret, per dictum loci ordinarium instituendum presentarunt, offerentes, se sibi desuper tradere litteras oportunas; quas eciam presentaciones idem dominus Volmarus ratas habens et gratas earum vigore sic quantocicius fieri posset, se in et ad dictam parrochialem ecclesiam institui et investiri facere, premissis proclamacionibus et aliis iuris solempnitatibus promisit et habita institucione dictam ecclesiam, apud eandem personaliter residendo, iuxta formam contractus alias (inter) dictos dominos decanum et capitulum ac ipsum de anno domini millesimo quadringentesimo tricesimo septimo die nona mensis novembris ${ }^{1}$ super regimine et gubernacione dicte ecclesie et quibusdam aliis ibidem expressis (initi) fideliter et legaliter regere et gubernare, sic quod ipsi domini decanus (et) capitulum exinde nullas querelas a parrochianis sive aliis perciperent 2. Et sic apportato huiusmodi ewangelii libro idem dominus Volmarus iuramentum solitum et consuetum per pastores dicte ecclesie in Wippervoerde iurari in fine dicti libri descriptum ${ }^{3} \mathrm{de}^{\mathrm{b}}$ verbo ad verbum in presencia huiusmodi capituli publice et alta voce recitavit et tactis sacrosanctis ewangeliis omnia et singula in dicto iuramento descripta pro posse et nosse facere et adimplere promisit et iuravit. Promisit eciam idem dominus Volmarus et iuravit, dictos suos canonicatum et prebendam ac ecclesiam parrochialem predictam sine voluntate et consensu expressis dictorum dominorum decani et capituli ac contra eorum volıntatem non permutare sive in dampnum dicte ecclesie sanctorum Apostolorum quovis quesito colore alienare neque simpliciter vel ex causa huiusmodi permutacionis resignare et hoc sub pena mille florenorum renensium pro una rererendissimo domino archiepiscopo Coloniensi et pro reliqua hedietatibus dictis dominis decano et capitulo applicandorum. Et si, quod absit, ipse dominus Volmarus forsan in futurum propter senium vel aliam sui corporis debilitatem aut alias supervenientes causas jpsum legitime excusantes ad regimen et gubernacionem ipsius parrochialis ecclesie inutilis redderetur, placuit ipsis dominis decano et capitulo, quod tunc huiusmodi parrochiali ecclesie in manibus eorum de simili eorum consensu et voluntate expressis renunciare posset, dolo et fraude cessantibus. Dicte eciam partes dictum contractum, sic, ut prefertur, initum
a) ad ad.
b) de de.

1) Vgl. oben no. 27 .

2) Vgl. \$. 1 des Vertrages vom 9. November $143 \%$

3) Die Eidesformel ist unten no. 38 mitgetheilt. 
hincinde innovarunt et observare promiserunt. Super quibus omnibus et singulis prenarratis suprascripte partes hincinde pecierunt a me notario publico infrascripto sibi in meliori forma fieri unum publicum instrumentum ant plura publica instrumenta ad dictamen sapientis cuiuslibet, facti tamen substancia non mutata. Acta fuerunt hec Colonie sub anno, indiccione, mense, die, hora, loco et pontificatu quibus supra, presentibus ibidem discretis viris Hermanno Lippoldesbergh clerico Padeburnensis diocesis et Sandero Konynxhoven clerico Coloniensi testibus fidedignis ad premissa vocatis pariter et rogatis.

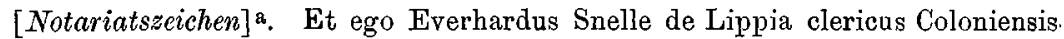
diocesis publicus sacra imperiali auctoritate et approbatus notarius, quia premissis omnibus et singulis dum sic, ut prefertur, agerentur et fierent una cum prenominatis testibus presens interfui eaque taliter fieri vidi et audivi ideoque hoc presens publicum instrumentum manu aliena, me aliis interim legitime occupato negociis, fideliter scriptum exinde confeci et in hanc publicam formam redegi signoque et nomine meis solitis et consuetis signavi atque subscripsi in fidem et testimonium premissorum omnium et singulorum rogatus et requisitus.

Düsselalorf, Königl. Staatsarchiv, Köln, S. Aposteln no. 23\%. Original auf Pergament mit Notariatszeichen; auf dev Rückseite von einer Hand 15. Jahrh.: ,Super ecclesia in Wyppervorde qualiter dominus Volmarus de Hielden collata sibi prebenda per obitum quondam H. Vynhuß ipsam ecclesiam ad presentacionem capituli accepturus iuravit et sub pena promisit eam non permutare etc.' Signatur 17. Jahrh.: ,N. XVII'.

29.

1449 Juli 24. - Herzog Gerhard von Jülich und Berg Graf zu Ravensberg bestätigt der Stadt Wipperfürth auf ewige Zeiten die Schenkung der gesammten Accise, welche ihr sein Oheim Herzog Adolf zur Aufbesserung nach erlittenem Brandschaden überlassen hatte.

Wir Gerhardt von gotz gnaden hertzouge zu Gulich zo dem Berge und greve zo Ravensbergh doen kundt, as unse leve ohme hertzoge Adolph wilne hertzoge zo Guilge zo dem Berge, dem got gnade, in vorzyden unserstadt Wipperfurde umb verderfflichs brandts ind schadens willen van vee$d_{\text {en }} \mathrm{b}$ wegen, oich suiss geleden hadde und nedergegangen was, de weder zu bouwen und zo vestenen gegeven, gegunt und erlassen hat und wir ouch bis. an dese zytc unse assyse in der vurschreven unser stat, des so bekennen wir offentlich mit diesem brieve vor uns und unse erven und nakomelingen, das. wir angesehen und bedacht hain kenliche noitbaue und andere gebreche und noitsachen der vurschreven unser stadt Wipperfurdt, da die noch mit bela-

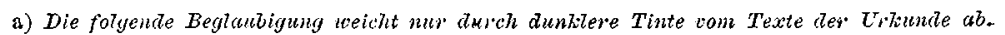
b) veclen. c) zeit. 
Jt7i2f. den ind beschwert is ind haven darumb ror uns, unse erven und nakomen unsen leven getruwen burgermeistern, raede ind burgeren gemeintlichen derselver unser stadt die vurschreven unse alinge assyse van nu vortan na datum diss brieffs vort erfflichen zo den ewigen dagen zo nutze, baue, urber, vestungen ind besten wille unser vurschreven stadt, daran sy die keren sollen, da dat dan beste und nutzlichste syn wirdt, gegunt, gegeven ind bewyst, gunnen, geven ind bewysen vestiglichen in krafft diss brieffs. Ind wir Gerhardt hertzoge etc. vurschreven haint geloifft ind geloven in guden truwen by unser furstlicher eren vor uns, unse erven ind nakomen, die vurschreven burgermeistere, scheffen, raedt ind burgere unser stadt vurschreven by der alinger assysen, as vurschreven is, nu vortan erfflichen ind zo den ewigen (dagen) zo ungehindert zo laessen, zo halden ind gehalden zo werden ind daer weder neyta anders zo doen noch zo soechen doin, doin off schaffen gedhaen werden noch zo geschehen lassen in einigerlei wyse sunder alle geverde ind argelist. Ind deser vurschreven unser gnaden ind gifft haven wir hertzoge vurschreven zo urkunde der warheit und gantzer, vaster, ewiger stedigkeit vur uns, unse erven ind nakomen unse ingezegel an desen brieff doen hangen ind haven vort geheischen ind befohlen unsen besonderen leven reeden ind getruwen her Wilhelm van Nesselrode herre zom Steyne zor zyt unsen lantdrosten unses landes van dem Bergh, her Johan Quaden rittere ind Lamberten van Bevessen unsen hovemeister zor zyt, want die by deser unser gifft, sachen ind verschryvongen van unsen wegen gewest synt ind hant helpen dadingen, dat sy darumb yre segele by dat unse zo vorderem gezuige ind erkentnuss deser selver vurschreven sachen an desen brieff hant gehangen; des wir Wilhelm van Nesselrode, Johann Quade rittere ind Lambert van Bevessen vurschreven erkennen, dat yd waer is ind van begerden, geheische ind bevelnisse unss gnedigen leven hern hertzogen zo Gulich, zo dem Berge etc. vurschreven gerne gedhain hain. Gegeven in den jaren unsers herren dusent vierhundert neun ind viertzigh uff sint Jacobs avent des hilligen apostels.

Abschrift 17. Jahrhunderts in dem oben unter no. 12 beschriebenen Aktenhefte des Königl. Staatsarchivs zu Düsseldorf Bl. $16^{b}-17^{b}$, am Schlusse mit der nachstehenden, auch auf no. 18 bezüglichen Beglaubigung versehen: "Das gegenwerttige copeyen mit den wharen ahn schrifft und insiegelen unradirt, uncancellirt und zumhalen unarghwonlichen originalen nach fleissiger collationirungh gleicblautendt befunden bezeuge ich Paulus Linden, offenbarer in furstlicher Gullig- und Bergischer cantzeley zu Dusseldorff approbirtund immatriculirter notarius."

30.

1449 Juli 24. - Herzog Gerhard von Jülich und Berg, Graf zu Ravensberg überträgt der Bürgerschaft von Wipperfürth zum Dank für die Dienste, die sie ihm im Beginne seiner Regierung erwiesen hat

a) niet neyt. 

auf ewige Zeiten die ,burgergude ${ }^{6}$ im Umkreise der Stadt unter Torbehalt einer jährlichen, burgersomme von 16 rhein. gl.

Wir Gerhart von gotz gnaden hertzouge zo Guylge, zo dem Berge etc. ind greve zo Ravensberge doin kunt ind bekennen offentlich mit desem brieve vur uns, unse erven und nakomen|, dat wir angesehen haven truwen treffligen und dancknemen dienst, willen ind gehoirsamcheit den unse stat und burgerschaft van Wypperfurde unse lieve frunde ind getruwen, do wir / erst zo unsen landen quamen, die innaemen ind ouch besonder seder der zijt in unsen noeden, veden und kregen mit diensten, hulpen, bystande, gyfft und gaven unss sere truweligen und willentlichen gedayn ind bewijst haint und ouch noch vurbas furder doin ind bewisen moigen, sulchs uns bedechtlichen beweget hait ind haven daromb vail unser sunderlinger gunst und gnaden mit unsem vurbedachten vryen moitwillen unser stat ind burgerschaft van Wypperfurde vurschreven sich damit zu besseren erfflichen zo den ewigen dagen loss, ledich und vry gegeven und geven in kraft disselven briefs alie alsulche burgergude die vurgenante unse stadt ind burgerschaft van aldem herkommen by unsen alden und vorfaren seliger gedechtnussen lange jaren her und ouch by ons bis an dese zyt in iren henden gehadt, an sy gekommen ind gegeven haven umb gross verderflichs nedderfals, brantz ind schadens willen den die ehegemelte onse stat hiebevorentz zo viell zeyten van vheden ind krygen aengekommen ist gewest, bey sulcher gifft wyr sie bisher gevryet ind gelaissen haint gehadt ind nu vorbass zo den ewigen dagen erfflich ind ewentlich, wir onse erven ind nakomelingen doin willen ind sullen mit alle alsulchen hoeven, erven ind guideren as sy die vor an bis nu up dat leste by unsen gezyden zo dienste ind gebode gehadt haint, wa die gelegen synt, boven der stat, dair beneden undt zo byden syden wie die gnantt synt, niet dayrine uisgescheiden in berge, in daele, in nassen, in druigen, dat sy gross off cleyne, up dat dieselve onse stat rurschreven dess de bas gebouwet ind gebessert werde, as ons ind onsen landen des oich trefflich noit is, sunderlingen nadem dat deselve onse stat an dem exde unses landes van dem Berge ligt; ind sullen dese vurschreven guider und die luide die dairuppe wonen geniessen ind gebruchen alle alsulcher handtvestingen ind verschrivongen, vort by allen olden herkommen syn ind bliven, in massen unse vorfaren, greven ind hertzougen van dem Berge, den gott allen barmhertzig syn wille, und wir der vorgenanter onser statt in vorziden ror und na gegeven, confirmirt, bestedigt, bewilligt ind belifft haven; ind sullen herup auch alle die luide van mannespersonen die up desen guideren sitzendt unser vurschreven stat verbunden syna mit eyden und geloffden, yrre burgerschafft treuwelich zo halden ind derselver onser stat gehorsam syn und darin diemen und zo doin as sich geburt, ind (sal) anders niemandt van onsentwegen an den selven die up deu vurschreven guideren sitzen, geyn gebot haven noch doin dan burgermeister, scheffen und raidt unser stat vurschreven. Wir hertzoge etc. vurgenant haint 
Juli 24. vort me angesehen treulichen dienst den uns die ehegenante unse stat ind burgerschaft by onsen zyden gedain haint ind vortain doin moigen und hain sy besonder begifftigt mit den burgersommen die up etzlichen a den vorgerorten yren gude staint, as die van onsen wegen bisher gehaven synt worden, dat dieselve onse stat ind borger die nu vortan erfflich ind zo den ewigen dagen an sich heven, haven ind boeren sullen, doch ons dairinne ausgescheiden ind behalden, dat onse stat ind burgerschafft vorschreven zo allen jaren ons ind onsen eligen lyffierven geven ind leveren sullen in wat hant wir dat wysen ind stellen sesszien rynsche guilden as dry marck ind vunff schillinge colsch vor iglichen der gulden zo rechenen ind der sullen sy geven alle jair zo lichtmissen vunff gulden, zo meye vunff gulden und zo herveste sess sulcher guilden, dat macht jairs zosamen die vurschreven seesszien gulden. Vort haven wir Gerhart hertzouge etc. vurschreven der vurschreven unser stat ind burgerschaft van Wipperforde birinne sulliche gnade inde gunst. vurder mit gedain ind gegeven vur uns, unse erven ind nakomen vestlich in krafft diss brieffs, off sach were dat idt unse herre gott also voegende worde, dat wir doitz halven affgiengen sunder elige lyffsgeburt van unsen lyffe geschaffen, damit unse herre gott uns im besten versien wille, dat alsclan darachter die vurschreven unse stat ind burgerschafft van der vurschreven unser behalden burgersommen, mit namen sesszien der vurschreven gulden, alsdan vortan erfflich ind zo den ewigen dagen gentzlich ind all fry, quyt und entledigt syn ind bliven sullen zo besseringe ind bouwe $b$ der vurschreven unser stadt ind burgerschaft, sich desdefurder zo bevestenen ind zo versorgen; ind off wir na onsem affgange elige lyffserven liessen van unsem lyve geschaffen, mans off frauwen personen, ind die oich sonder elige lyffsgeburt van yrem lyve geschaffen affgingen van dodes wegen, so soll ouch giychewale diese vurschreven onse gifft ind verschryvonge gentzlich macht and moege haven, vallen ind komen an vurschreven onse stat ind burgerschaft in aller maissen wir in dat alhyr verschreven ind gegeven hain. Ind wir hertzoge etc. vurschreven hain geloefft ind geloeven in guden treuwen bey unser furstlicher èhren vur uns, unse erven ind nakomen, dat unse stat ind burgerschaft van Wipperforde vurschreven by alle desen sachen ind puncten in maissen as vurschreven is, erfflich ind zo den ewigen gentzlich bliven, gelaissen ind gehalden werden sullen ungehindert, ind darwider noch tgain enwillen noch ensullen wir noch onse erven ind nakomen niet doin, suchen, vornemen doin, doyne off schaffen gedain ${ }^{c}$ werden mit einigerkunned behulpe noch sachen, wie man die erdencken, uisseren, doin off vornemen mochte mit geistlichen off werentlichen gerichten ind reichten off mit einigen anderen sachen oder wederstandt in einigerley wyse, sonder alle geferde ind argelist, ind bevelen uch allen onsen amptluden, oversten ind understen ind ouch besonder onsen ambtluiden unser vesten ind amptz van Steinbach de nun synt off hernamals werden mogen vestlich overmitz desen selven brieve, die vurschreven unse stat ind burgerschafft van Wipperforde deser onser gyfft, gnaden ind verschryvongen na innehalde diss brieffs gentz-
a) spetzlichen.
b) rowe.
c) gadain.
d) kummer. 
lich laissen .zu gebruchen und sy darby helpen zo behalden, in treuwlich behulpigh ind bystendigh zo syn aen einige indracht. Ind alle deser vurschreven onser gyfft, gnaden und sachen haven wir hertzouge vorschreven zo urkunde ind gezuige der warheit ind gantzer, faster, ewiger stedigheit vur uns, unse erven ind nakomen unse insiegell mit unser rechter wist ind willen an diesen brieff doin hangen ind haven vort geheischen ind bevolen unsen besondern leven reden ind getreuwen hern Wilhelm von Nesselrade hern zome Steine zor zyt onsen lantdrosten unss lantz vame Berge, hern Johan Quaiden ritter und Lamberte van Bevessen onsen hoffmeister zur zeit, want de by deser onser gyfft, sachen ind verschryvongen van unsen wegen gewest synt ind haint helpen dadingen, dat sy dairombe yre siegele by dat onse zo vorderem gezuige ind erkentnisse alre vurschreven sachen an desen brieff haint gebangen; dess wir Willem van Nesselrode, Johan Quade ritter ind Lambert. von Bevessem etc. vurschreven erkennen, dat id wair is und van begerten, geheische ind bevelnisse unsers gnedigen lieven herren hertzogen zo Guilge, zo dem Berge etc. vurschreven gerne gedain haven. Gegeven in den jairen onsers herren dusendt vierhondert nuyn und viertzig up sente Jacobs avent des heylgen apostels.

Abschrift 17. Jahrhunderts in dem oben unter no. 12 beschriebenen Aletenhefte des Königl. Staatsarchivs zu. Düsseldorf Bl.23-24b, mit notarieller Beglaubigung wie no. 29 .

31.

1449 November 10. - Herzog Gerhard von Jülich und Berg Graf zu Ravensberg überträgt der Bürgerschaft von Wipperfürth zum Danke für ihre treuen Dienste im Beginne seiner Regierung bedingungsweise seine Vogteigüter oberhalb der Stadt zwischen Wipper und Bever.

Wir Gerhart van gotz gnaden hertzouge zo Guylge, zo dem Berge etc., ind greve zo Ravensberge doin kunt ind bekennen offentlich mit desem brieve vur uns, unse erven ind nakomen / dat wir angesehen haven truwen, treffligen und dancknemen dienst, willen ind gehoirsamcheit den unse stat und burgerschafft van Wypperfurde unse lieve frunde und getruwen, do wir I erst zo unsen landen quamen die innaemen ind ouch besonder seder der zijt in unsen noeden, veden und kregen mit diensten, hulpen, bystande, gijfft und gaven uns sere truweligen und willentlichen gedain und bewijst haint und ouch noch vurbas furder doin ind bewisen moigen, sulchs uns bedechtlichen beweget hait ind haven daromb van unser sunderlinger gunst und gnaden mit unsem guden vurbedachten vryen moitwillen unser stat ind burgerschafft van Wijpperfurde vurschreven sich damit zo besseren erfflichen zo den ewigen dagen loss, ledich und vry gegeven und geven in crafft dis brieffs in sulcher maissen: off sache were, dat id unse herre got also fuegende wurde, dat wir doitzhalven affgiengen sunder elige lijffsgeburt van unsem lijve geschuffen, damit unse herre got uns in dem besten versien wille, alle unse vaygtgueder 
10.1449 enboeven unser stat Wijpperfurde tusschen der Wypper und der Bever in unser vesten ind ampte van Steynbach gelegen ind gehorende in unse kirspell van Wijpperfurde mit luyden, erffschafft und alre gulden, renten, schetzongen, sommen, hervestbeden, assysen, tzijnsen, peichten, diensten, upkomsten und vervall, gerichte, geboede und verboede, vort alle yren rechten, zo- und ingehoeren, so wie die geleigen synt in berge, yn daele, in nassen ind drugen neit daynne uyssgescheiden, gross off cleyne in eyncherwys, up dat die vurschreven unse stat die vurder gebuwet und bevestent werde, as uns ind unsen landen des ouch trefflich noit is, sunderlingen na dem dieselve unse stat an dem ende uns lantz vamme Berge lijgt, beheltniss doch uns unser bruchten; ind sullen dese vurschreven vaydtgueder und die luede da uppe woenende genyessen und gebruychen alle alsulche hantfestungen und verschryvongen, vort by allen alden herkomen ind gewoenden sijn und blijven in maissen unse vurfaeren greven und hertzougen van dem Berge, den unse herre got alle samen barmhertzich sijn wille, und wir vurtzijtz vur ind na der vurschreven unser stat Wijpperfurde gegeven, confirmeirt, bestediget, bewillicht und beliefft haven, ind sullen herup ouch alle die lude von mannespersoenen up desen vurschreven unsen vaytzgueden woenende unser vurschreven stat verbunden syn mit eyden ind geloeffden yre burgersehaff truwelich zo halden und derselver unser stat gehoirsam syn und daryn dienen und zo doin as sich geburt. Were aver sache dat wir na unsem affgange elige lyffsgeburt van unsem lyve geschaffen na uns liessen, mannes off frauwen persoenen, und die ouch sonder elige lyffserven van yren lyven geschaffen affgiengen van doedes wegen, so sall ouch gelychewaill alle dese vurschreven gijfft und verschryvonge gentzlich macht ind moege haven, vallen ind komen an unse vurschreven stat in alre maessen wir yn dat alhie verschreven ind gegeven hain. Ind wir hertzonge etc. vurschreven hain geloefft ind geloeven in guden truwen by unser furstlicher eren vur uns, unse erven ind nakomen, dat die vurschreven unse stat, burgerschaft und ingesessen van Wijpperfurde na unsen doide, off wir sunder elige lijffs geburt affgaen as vurschreven is, by alle deser vurschreven unser gifft erfflich und zo den ewigen dagen fredelich ungehijndert blijven und gehalden sullen werden ind darweder neit zo doin noch zo soechen doin, doyn off schaffen gedain werden mit eyncherkonne behulpe noch sachen wie man die erdencken, uiseren, doin off vurnemen mochte mit geistlichen off werentlichen gerichten und rechten off mit eynchen anderen sachen ader wederstande in eyncherleyewys, sunder alle geverde und argeliste, ind bevelen uch allen unsen amptluden oeversten ind understen ind ouch besunder unsen amptluden unser vesten ind amptz van Steynbach die nu synt off hernamails werden moigen vestlich oevermitz desen selven brieff die vurschreven unse stat ind burgerschafft van Wipperfurde deser unser gifft ind gnaden na unsem doide in maissen wir yn die alhie in diesem brieve, off wir sunder elige lyffsgeburt affgaen, as vurschreven steyt, gegeven ind verschreven hain, laissen zo gebruychen und sy daby helpen zo behalden, in truwelich bystendich und behulpen zo syn aen eynche indracht. Ind alle deser vurschreven unser gifft und gnaden haven wir hertzong etc. vurschre. ven zo urkunde ind getzuyge der wairheit und gantzer vaster ewiger ste- 
1449 Nor. 10. dicheit vur uns, unse erven ind nakomen unse ingesegell mit unser rechter wist und willen an desen brieff doin hangen ind haven vort geheysschen ind bevoelen unsen besunderen lieven reeden ind getruwen herren Wilhelm van Nesselroede herren zom Steyne zor zijt unsen lantdrosten unss lantz vamme Berge, her Johan Quaiden rittere und Lambert van Bevessen unsen hoevemeister zer zijt, want die by deser unser gifft und verschrivongen van unsen weygen geweist synt und hant helpen dedingen, dat sy daromb yre segele by dat unse zo vurderem getzuyge und erkentnisse alre vurschreven sachen an desen brieff gehangen haint; des wir Wilhem, Johan und Lambert vurschreven erkennen, dat id wair is und van begerden, geheyssche ind beveilnisse unss gnedigen lieven herren hertzougen zo Guylghe, zo dem Berge etc. vurschreven gerne gedain haven. Gegeven in den jaeren unss herren duysent vierhondert nuyn und viertzich up sente Mertins avent des heilgen busschoffs.

Düsseldorf, Königl. Staatsarchiv, A I, 2454. - Original auf Pergament, stockfleckig, mit anhängendem Siegel Lamberts von Bevessen, Wappen: Trichter, dasunter ein Jagdhorn, in der Helmzier Horn, darüber wachsender Baum, ausserdem drei Siegeleinschnitte. Auf der Rückseite Inhaltsangabe 1\%. Jahrhunderts. Alte Signatur: No. 38. ad caps. 99.

32.

1451 März 18. -- Notariatsinstrument über die Verlesung des Erbvertrages zwischen Herzog Gerhard von Jülich-Berg und Erzbischof Dietrich von Köln vom 12. März 1451 auf dem Marktplatze zu Wipperfürth und über die Huldigung der Bürgerschaft daselbst in Gegenwart des Erzbischofs, der Vertreter des kölner Domkapitels und des bergischen Landes.

In nomine domini amen. Per presens publicum instrumentum cunctis pateat evidenter et sit notum, quod anno nativitatis eiusdem millesimo quadringentesimo quinquagesimo primo indiccione quartadecima, die vero iovis decima octava / mensis marcii hora vesperarum vel quasi, pontificatus sanctissimi in Christo patris et domini nostri domini Nycolai divina providencia pape quinti anno quarto, regni quoque serenissimi et invictissimi principis et domini nostri domini Frederici divina favente clemencia Romanorum regis semper / augusti etc. anno undecimo, reverendissimo in Christo patre et domino domino Theoderico sancte Coloniensis ecclesie archiepiscopo sacri Romani imperii per Ytaliam archicancellario Westphalie et Angarie duce principe electore etc. domino nostro graciosissimo, venerabilibus nobilibus illustribus honorabilibus atque egregiis viris dominis Wernero de Seyne et de Witgensteyne sancti Gereonis Goloniensis et sancti Patrocli Susaciensis Coloniensis dyocesis ecclesiarum preposito, Ludovico de Wertheym scolastico comitibus, Salentino de Ysenburg cappellario barone canonico et Henrico de Tettenheym cellerario et presbitero canonico sancte ecclesie Coloniensis in huiusmodi re et negocio pro parte venerabilium illustrium nobilium honora-1 
yär 18. bilium et egregiorum virorum dominorum decani et capituli prefate ecclesie Coloniensis missis ex una, illustrissimo et excelso principe et domino domino Gerardo duce Iuliacensi et Montensi ac comite in Ravensberge etc., strenuis spectabilibus et egregiis viris dominis Wilhelmo de Nesselrode domino in Steyne dapifero, Iohanne, Luttero et Adolfo dictis Quaden fratribus militibus, Iohanne vanme Huyss marscalco, Iohanne de Nesselrode et Wernero de Bevessen armigeris officiatis ducatus et terre Montensis et dominii Blankenbergensis, prudentibus providis et circumspectis viris Dyderico an der Leyen burgimagistro, Iohanne Palm, Heynone ten Dale iudice, Henkelino van den Eykholte, Sybelone Melsak, Christiano Brakke, Christiano Wyse, Gokelino Sartore, Iohanne an der Leyen, Hennekino Becker, Iohanne up der Borcb, Heydenrico in der Dyrdorp, Christiano ten Dale scabinis, Hermanno up dem Keller, Henrico Malderbret, Petro Anthonii, Rutgero ten Byrken pluribusque aliis opidanis opidi Wipperfurde ducatus Montensis in copioso et magno numero in foro communi dicti opidi congregatis ac communitatem dicti opidi representantibus parte ex altera, in nostrorum notariorum publicorum testiumque infraseriptorum ad hoc specialiter vocatorum et rogatorum presenciat propter hoc personaliter constitutis, antefatus tunc illustrissimus dominus dominus Gerardus dux Iuliacensis et Montensis ac comes in Ravensberge etc. prefatis burgimagistro, scabinis, opidanis et communitati opidi Wipperfurde commisit, precepit atque mandavit alta et intelligibili voce, quatinus nonnullas litteras donacionis prefato reverendissimo in Christo patri et domino domino archiepiscopo Coloniensi pro se, suis successoribus et ecclesia Coloniensi super ducatu Montensi, dominiis sive terris de Blankenberg, de Zynsich et de Remago necnon comitatu Ravensbergensi aliisque terris, castris, opidis, possessionibus ac ipsorum pertinenciis et attinenciis per ipsum dominum ducem et illustrissimam dominam Sophyam de Saxonia ducissam suam conthoralem datas, concessas ac traditas suisque necnon officiatorum et armigerorum suorum subditorumque suorum et plurimorum videlicet burgimagistrorum, scabinorum ac opidanorum opidorum et communitatum Duysseldorpensis, Ghereshemensis, Ratingensis, Lenepensis, Rodensis ante Silvamque sigillis appendentibus sigillatas et aliorum sigillis in cordis sericeis diversorum colorum appensis et appendendis sigillandas ibidem in medium productas exhibitas publice et ostensas in certis pergameni foliis conscriptas que sic incipiunt: "Van godes gnaden wyr Gerard herzoghe zo Guylghe, zo dem Berghe etc. ind greve zo Ravensberghe ind Sophya van Sassen herzoghynne zo Guylghe zo dem Berghe etc. ind grevinne zo Ravensberge syne elighe ghemahel bekennen ind doyn kunt etc." et sic fniuntur: "Gegeven up sent Gregorius dach des hilgen paystes in den jaren unss herren dusentvierhundert ind eyn und funfftzig“ ipsis burgimagistro, scabinis opidanisque communitatis opidi Wipperfurde de verbo ad verbum alta et intelligibili voce ad plenum intellectum perlectas et vocitatas sigillarent et in quantum eos concernerent approbarent et ratificarent et desuper pro firmiori subsistencia ad perpetuan rei memoriam de servando contenta earundem litterarum donacionis perpetuis futuris temporibus litteras speciales eorum sigillo similiter munitas darent et assignarent necnon ipsi reverendissimo in Christo patri et domino domino archiepiscopo Co- 
1451 März 18. loniensi fidelitatem, obedienciam et homagium necnon servare contenta dictarum litterarum donacionis quantum eos concernerent promitterent ac debite fidelitatis obediencie homagii et servandi contenta dictarum litterarum donacionis perpetuis futuris temporibus inviolabiliter quantum eos concernerent pro se, eorum heredibus et successoribus iuramentum iuxta et secundum tenorem cuiusdam cedule vulgaris teutunicalis inserte mox facerent et prestarent. Quiguidem burgimagister scabini et opidani communitatis opidi Wipperfurde de voluntate, commissione, precepto et mandato dicti domini Gerardi ducis sponte et libere eisdem litteris donacionis sum appenderunt et apposuerunt sigillum dictasque litteras donacionis, quantum eos concernere videntur, expresse approbarunt et ratificarunt et desuper pro firma subsistencia ad perpetuam rei memoriam litteras speciales eorum sigillo appendente munitas dederunt et assignarunt et mox similiter sponte et libere eidem reverendissimo in Christo patri et domino domino archiepiscopo Coloniensi fidelitatem obedienciam et homagium ac fidelitatis, obediencie et homagii et servandi contenta dictarum litterarum donacionis quantum eos concernunt pro se suisque successoribus et heredibus inviolabiliter perpetuis temporibus prestare velle iuramentum ad manus suas sacratas singulariter singuli promiserunt et consequenter erectis digitis stipulante et recipiente nobili et illustri domino Gumperto comite de Nuenar hereditario advocato Coloniensi et domino in Alpen vice et nomine prefati reverendissimi in Christo patris et domini domini archiepiscopi Coloniensis ac omnium aliorum quorum interest vel interesse poterit quomodolibet in futurum pro se suisque successoribus et heredibus prefato reverendissimo in Christo patri et domino domino archiepiscopo Coloniensi pro se, suis successoribus et ecclesia Coloniensi debite fidelitatis obediencie homagii necnon servandi contenta litterarum donacionis huiusmodi, quantum eos concernerent, perpetuis futuris temporibus similiter singulariter singuli iuramentum prestiterunt huiusmodi sub tenore et forma cedule teutunicalis que sequitur in hunc modum: "Wyr burgermeyster, scheffen, raed ind gantze ghemeynde der stad Wipperfurde gheloven, hulden ind sweren vor uns, unse erven ind nakomen huyde dis daghes dem hochwirdigen fursten unsem gnedigen leven hern Dyderiche ertzebuschoffe zo Colne hie intgainwirdich, synen nakomen ind gestichte getruwe ind hold zo syn, zo doin ind zo halden zo den ewigen daghen in alre maissen as de gifftbreve ind verschrivunge tuschen dem vurschreven unsem gnedigen herren van Colne ind dem hoch. gebornen fursten ind herren hern Gerarde herzoghen zo Guylghe zo dem Berghe etc. ind greven zo Ravensberghe unsem leven gnedigen heren nu gegeven synd, de wyr ghehort ind myt besegelt hayn, innehaldend ind uyswysend so eid uns des antreffend ys, so uns god helpe ind bilghen sunder arghelyst." Quibus sic peractis prefatus dominus noster dominus archiepiscopus Coloniensis primo et deinde prefati domini capitulares et canonici ecclesie Coloniensis nomine capituli premissa omnia et singula rata et grata habendo ac acceptando loco arrarum sive pro intersigno et perpetuo memoriali huiusmodi sollempnis actus quamplures denarios et monetas in foro publico inter burgimagistrum, scabinos, opidanos et communitatem opidi Wipperfurde predicti proiecerunt, quos omnium consensu prompte et bylariter collegerunt et susce- 
März 18. perunt et quantum quisque potuit collegit et suscepit, rogantes preterea prefatum dominum nostrum archiepiscopum Coloniensem et dominos canonicos et capitulares ecclesie Coloniensis predicte, quatinus ipsis eorum privilegia dignarentur confirmare. Quorum rogatibus annuentes prefati dominus archiepiscopus et domini capitulares et canonici ecclesie Coloniensis nomine capituli eis confirmatorias litteras privilegiorum suorum mox dederunt et assignarunt, de quo ipsi burgimagister, scabini et opidani communitatis predicti opidi Wipperfurde eis plurimas et magnas grates retulerunt. Super quibus omnibus et singulis premissis prefatus reverendissimus in Christo pater et dominus dominus àrchiepiscopus Coloniensis pro se, suis successoribus et ecclesia Coloniensi, domini capitulares et canonici predicti nomine capituli ac pro capitulo et ecclesia Coloniensi ipsis coniunctim et divisim a nobis notariis publicis petiverunt fieri unum vel plura publicum seu publica tot quot fuerint neces: saria instrumentum seu instrumenta. Acta fuerunt hec in opido Wipperfurde predicto sub anno domini, indiccione, die, mense, loco loci, hora, pontificatu regnoque quibus supra, presentibus ibidem nobili et illustri domino Gumperto comite de Nuenar prefato, venerabilibus honorabilibus et egregiis viris magistris Iohanne de Lyns utriusque iuris doctore cancellario prefati domini nostri domini archiepiscopi Coloniensis canonico saneti Andree Coloniensis, Petro de Unkel decano ecclesie sancti Cassii Bonnensis Coloniensis dyocesis, Iohanne de Bek reddituario domini Coloniensis canonico prefate ecclesie sancti Cassii Bonnensis; strenuis et egregiis spectabilibusque viris dominis Scheffardo van me Rode domino in Bornem, Thyderico Beyssel de Ghymmenich marscalco, Iohanne van dem Meynenweghe magistro coquine militibus; Iohanne et Arnoldo de Hoemen burggraviis in Odenkyrchen fratribus, Scheffardo van me Rode domino in Hemersberg, Reynardo de Heide iuniore, Deghenhardo Haze, Dyderico de Plettenberg, Dyderico de Landesberg, Iohanne van der Leyen, Iohanne de Rasveld, Iohanne de Zelijs pincerna ducis Iuliacensis et Montensis, Wilhelmo van me Huyss armigeris; honorabilibus, prudentibus, providis et circumspectis viris Rorico de Bellinghusen secretario domini ducis Iuliacensis et Montensis, domino Rossero pastore in Berka, Emundo de Kodinchoven, Henrico de Bukkenheym, Ertwino de Beke, Conrado de Katzenelnpogen, Jacobo de Lynss clericis; Henrico de Hoyngen advocato in Bonna et petro Verscheyd sculteto in Lynss laycis Coloniensis, Maguntinensis et Treverensis dyocesium testibus ad premissa vocatis specialiter et rogatis.

[Notariatszeichen. $]$ Quia a vero ego Arnoldus van me Lo clericus Myndensis

[S. Arnoldi de Lo.] dyocesis publicus sacra imperiali auctoritate ordinariaque admissione iuratus et approbatus notarius huiusmodi iussioni precepto ac mandato dicti domini ducis, litterarum donacionis lectioni recitacioni earundemque ratificacioni et approbacioni, promissioni et iuramentorum fidelitatis obediencie homagii et servandi contenta litterarum donacionis huiusmodi, protestacioni et recepcioni,

a) Diese erste notavielle Beglanbignng ribht vom Schreiber des Kontextes her. 
1451 Mäı* 18.

[Notariatszeichen.] $\left[\begin{array}{l}\text { Sig. Gerardi de } \\ \text { Lynss notarii. }\end{array}\right]$

acceptacioni, ratificacioni, arrarum proiectioni, collectioni et lectioni, suscepcioni, privilegiorum confirmacioni, peticioni et concessioni aliisque omnibus et singulis premissis dum sic ut premittitur fierent et agerentur unacum honorabili circumspecto viro Gerardo Lynss de Xanctis connotario meo infrascripto testibusque suprascriptis presens interfui, sic fieri vidi et audivi, ideoque presens publicum instrumentum manu mea propria scriptrum exinde confeci, subscripsi et in publicam formam redegi signoque et nomine meis solitis et consuetis consignavi rogatus et requisitus in fidem et testimonium omnium et singulorum premissorum.

b Et ego Gerardus Lynss clericus Coloniensis diocesis publicus imperiali auctoritate notarius, quia premissis omnibus et singulis dum sic ut premittitur fierent et agerentur una cum prenominatis testibus presens interfui eaque sic fieri vidi et audivi, ideo presens publicum instrumentum per honorabilem Arnoldum de Loe connotarium suprascriptum scriptum et subscriptum subscripsi signoque et nomine meis solitis et consuetis signavi rogatus et requisitus in fidem et testimonium omnium et singuIorum premissorum.

Düsseldorf, Königl. Staatsarchiv, Jïlich-Berg eee. 2521. - Original auf Pergament, durch zwei Einschnitte kanzellirt, mit unbedeutenden Rüc7aufschriften 17. Jahrhunderts.

Vgl. J. Hansen, Westfalen u. Rheinland im 15. Jhdt., 2. Bd. Die Münsterische Stiftsfehde (Publikationen a. d. k. preuss. Staatsarchiven Bd. 42, Leipzig 1890), no. 63 \%. 64 .

33.

1454 Juli 13, Burg (an der Wupper). - Herzog Gerhard von Jülich und Berg Graf zu Ravensberg überträgt der Stadt Wipperfürth zum Ersatz für die Mühlengefälle der Honschaft Scharde, welche er der Liebfrauenkirche zu Marienheide wieder zuwendet, seine Rechte auf die Höfe zum Holtz und Wippermannsgut bei Wipperfürtb, verleiht ihr auch zugleich Brau- und Schankgerechtigkeit.

Wir Gerhardt von gottes genaden hertzoge zo Gulich, zo dem Berge ind greve zo Ravensberch doin kundt, also as wy hiebevoren dat gemall unser hundtschafft van Scharde erlassen ind gegeven haven in die moelen zo Gagorden dienende in unser liever vrauwen kirchen zo der Marienheiden ind na der hand dat gemall derselver unser hundtschafft unsen lieven getruwen burgermeister, scheffen, raede ind burgeren unser stadt Wipperfurde vort hain verschreven, so willèn wy dat dat gemall der vurschreven unser hundtschafft by unser yerster gifft bliven ind vortan dienen sall in die vurschreven

b) Das folgende von anderer Hand. 
moele zo Gagarden zo behoeff uneer liever frauwen kirchen vurschreven. Ind umb dat de egenanten unse burger van Wipperfurdt solches nu mit willen hain overgeven, des so bekennen wir offenbarlichen mit diesem brieve vor uns isd unsere erven ind nakomelingen, dat wir in nu darumme ind darfur weder zo staden erfflichen gegeven hain ind geven vestligen in krafft dieses brieffs alle alsulchen recht wir an ind zo den hoeven, erven ind goeden zom Holtze ind Wippermansgude, beide in unsem kirspell van Wipperfurde vurschreven gelegen, haven, also dat dieselven zwein hoeve vurschreven van nu vortan erffligen ind ewenclichen unsen burgeren van Wipperfurde vurschreven dienen sullen glych anderen yren burgergueden; ind die luide daruppe wonhafftich ind gesessen sindt offte werden, sullen in ouch geloefde davon doin, zo yre borgerschaft gehorsame zo syn ind zo bliven as sich dat geburt. Wir hain ouch nu unsen vurschreven burgeren von Wipperfurde erloufft, georlofft ind gegont, dat sy van nu vortan zo erfflichen ewigen zyden binnen unser vurschreven stat gersten off ander bier wie inen clat beqwem syn wirdt, bruwen ind zappen ind mit der gruyss van uns, unsen erven ind nakomelingen sonder allen kroedt ind hinder unbelast ind unbeschwert syn ind bliven sullen. Id en sall ouch nymandts bimmen de vurscbreven unse stat Wipperfurde geyn vremdt uysswendigh bier brengen noch da binnen verzappen, id en geschie dan mit unser burger vurgeschreven orloff ind gudem willen. Alle dese vurschreven sachen, puncte, articule inhalte deses brieves sementlich ind een iglich besonder geloven wir hertzoge vurschreven vur uns, unse erven ind nakomelinge in guden truwen by unser vurstlicher eren unsen lieven getruwen burgermeister, scheffen, raide ind burgeren unser vurschreven stadt Wipperfurde gantz wair, vast, stede ind unverbruchlich, vestligen, erfflichen ind umberme zo den ewigen dagen zo halden, dair umbermee nit weder zo doin noch lassen geschein in geinre hande wyse, hyrinne uisgescheiden alle argeliste, indracht, hindernisse ind geverde. Ind diss zo urkonde der warheit ind gantzer vaster erffliger ind ewiger stedicheit hain wir unse siegell vur uns, unse erven ind nakomelinge mit unser rechter wissenheit ind guden willen an diesen brieff doin hangen ind hain vort gebeischen ind bevolen Werner van Bevessen unsen lieven rait ind getruwen, dat he umb noch merre vesticheit wille alre vurschreven sachen syn siegell mit by dat unse zo gezuige an diesen brieff gehangen hat; das ich Werner van Bevessen vurschreven under mym segell so heran gehangen, bekennen wair is ind gerne gedhain have van heische ind bevelnisse mynes leven gnedigen herren hertzougen vurschreven. Gegeven zor Burch in den iahren unsers herren duysent vierhondert vier ind vunfftzigh auff sent Margareten dag der heilger junffern.

Abschrift 17. Jahthunderts in dem oben unter no. 12 beschriebenen Aktenhefte des Königl. Staatsarchivs zu Düsseldorf Bl. 15-16.

34.

1475 Februar 26. - Die Stadt Köln bittet genannte bergische Städte, dem Entsatzheere vor Neuss den Ankauf von Lebensmitteln zu ermöglichen. 
1475 Febr.26. [An Bürgermeister, Schöffen und Rath zu Ratingen, Kettwig, Gerresheim, Wipperfürth und Lennep.]

Unse fruntliche gruesze etc. Eirbere besundere gude frunde. As unse frunde van geboitz weigen unss alregnedigsten herren des romischen keysers den frunden ind naberen van Nuyss zo troiste ind zo behaltunge alle deser lande zo velde lygen up den Steynen tgen Nuyss, so is unse frundtliche begerde, ir wilt van guder naberschafft den unsen umb gelt veylen kouff van alreley provanden laissen zofoeren, as wir uch des gentzlichen zo getruwen. Dat willen wir gerne umme uch ind die ure weder erkennen ind verschulden ind begeren diss eyne gutliche wederbeschreven antwerde van urre eirbarheit die unse herre got etc. Geschreven up sondach oculi in der vasten anno etc. lxx quinto.

Köln, Stadtarchiv, Kopienbücher Bd. 30 Bl. 24rb.

35 .

1477 Juli 8. - Johann von Goch genannt Nyfftrich, Pfarrer zu Wipperfürth, schliesst unter Zustimmung des S. Apostelstiftes mit Bürgermeister, Richter, Schöffen, Rath, Kirchmeister, Gemeinde und Kirchspielsleuten einen Vertrag über die Verwendung der der neuen Kapelle S. Agatha bei Dierdorf einlaufenden Opfergaben.

In romine domini amen. I unt ind wytlich sij allen lueden, so as byebevoiren bis up datum disses breves eyne capelle yn eere gotz ind sent Agathen, doch yn eyme hultzen gebeuwe yn dem kirspell van Wipperfoirde bij| der Dijrdorp geleegen begriffen ind gebouwet is ind nu zorzijt der gifte dys breiffs yn forder begriffe zo der eeren gotz eyn steynen capelle gebouwet is, die dan noch is a ungeweyet ind nu vort gerne / oevermitz eyndracht ind consent des pastoirs zerzijt zo Wipperfoirde geweyet sulde werden yn eere gotz, sent Agathen, Lucien ind Materns etc., umb dan hijrneist zokoemende unwillen, kijff ind verdreis der opkoemongen derselver capellen an offer ind anderen almissen ind gueder luede gaeven tusghen eynen pastoir zorzyt is off woirde ind den burgeren ind den kirspelslueden zo Wipperfoirde zo verhoeden, so hait die eirsaeme ind eirber her Johan van Goch anders gnant Nijfftrich zorzijt pastoir zo Wipperfoirde sich goetlichen oeverdraegen myt burgermeister, rychter, scheffen, raede, kijrchmeisteren, gemeynden ind kirspelslueden derb stat ind des kirspels zo Wipperfoirde vurgenant, in maessen hyrnae beschreven volget: Item zo dem irsten is der vurgenante her Johan van Goch pastoir zor zijt oeverkoemen myt den vurschreven burgermeister, rychter, scheffenen, raet, kyrchmeisteren, gemeynde ind dem gantzen kirspell zo Wipperfurde, dat die kirchmeister zorzijt sullen ind moegen zo sich nemen yn behoiff der vurschreven capellen zo dem bouwe ind vort zo sent Niclais kirchen bynnen Wipperfoirde zo dem bouwe alle alsulghen gijffte ind almissen die guede luede darzo gevende synt, as nemlichen up sent Aga-
a) roilher, nugebouwet' getilgt.
b) des. 
Juli 8. then dach yn dem wynter, dat weere wilgher kunne dat dat weere, ind dair en sall sich eyn pastoir geyure gerechticheit aene nemen, usgescheiden, so wes an gelde up den altair geoffert wirt off yn eynen sack umb gedrenge zo vermijden, dat geschee vur der myssen, na der missen off bynnen der myssen, yn wat meynongen aeder foegen die offerhande up den altair gescheege, den affer sall ein pastoir zorzijt vur sich ind syne gerechticheit haeven ind behalden. Item weere sache dat sich de zijt ergynge ind die ynnicheit des volkes vergynge, so dat up den altair yn der missen vur off nae off yn dey secke as vurschreven steit neit sees wispennonge an gelde geoffert en wurden, asdan sullen die kirchmeistere zorzijt dem pastoir zorzijt geven sees wispennonge kolsghs, darumb sall der pastoir eyne misse up den selven dach yn der vurschreven capellen bestellen; meer woe der offer sees kolsghe wispennonge wert is up sent Agathen dach, asdan sall sich der pastoir zorzijt dairmyt laessen genoegen. Item der pastoir ind die kirchmeistere zorzyt sullen eyndrechtlichen ind semlichen eynen stock doen machen zo der capellen sent Agathen vurschreven ind dairvur tzwey slosse, der sall eyn pastoir zorzijt eyn sleyssen ind die kirchmeistere dat andere, ind wes dan na dem daege sent Agathen as vurschreven steit geoffert wirt up den altair an gelde, dat sall eyn pastoir zorzijt haeven; ind wes geoffert wirt an wasse, dat sall die kirche alleyne haeven ind behalden; ind wes dairboeven na sent Agathen dage vurschreven geoffert wirt, dat sullen pastoir ind kirchmeistere gelich deilen. Item den stock sullen pastoir ind die kirchmeistere zorzijt eyndrechtlichen up sent Agathen avent off wanne eyn pastoir zerzijt des begert, upsluyssen ind wes dairynne is eyndrechtlichen deylen. - Vort umb dat dyt vurschreven oeverdrach stanthafftich ind volmechtich woirde, so hait der vurschreven her Johan van Goch pastoir zorzijt datselve an die eirwirdigen ind vursichtige heren dechen ind capittell der hilger kirchen zo den heilgen Apostolen bynnen Colne gebracht, die dat myt zo leeven ind zo besteedigen, as sy ouch gedaen haint na ynhalde eyns breves darup begriffen ind gemacht is, die dan hynder burgermeister, scheffenen ind raede zo Wipperfoirde beslossen is; dwilghe heren dechen ind capittell vurschreven zom irsten die vurschreven punten beleyvet haint ind doch dairmyt ynne behalden, off sache wurde, dat yn der capellen sent Agathen vurschreven eynige vicarie off geistlich leyn begyfftet ind besteediget wurde, dat gelichewaill eyn pastoir zorzijt den offer, as vursehreven is, die den altair beroirt, haeven ind behalden sall ind die vurschreven heren dechen ind capittell sullen, so dicke des noet gebuirde, eynen preister zo der vicarien off zo dem geistlichen leyne presenteren yn der wijse des rechten, die dat syn leven lanck haeve ind verwaere. Item so en sall geynich preister yn der vurschreven capellen misse halden buyssen wist ind guden willen eyns pastoirs zor zijt off syns stathelders. Item so ensullen die kirchmeister zorzijt geynen bouw yn der vurschreven capellen doen machen buyssen wist ind willen eyns pastoirs zorzijt zo Wipperfurde. Item so en sall eyn pastoir zorzijt geyn volbert noch willen geven, dairdurch die vurschreven punten yn deile off zo maele gekrenket werden buyssen wist ind willen der vurgenanten heren dechen ind capittell. Doe nu der vurgenanter her Johan van Goch pastoir zorzijt dit 
1477 Juli 8. vurschreven oeverdrach eyn mit den usbehaldenen punten die vurschreven staent der eirwirdiger heren dechen ind capittels vurgenant wederumb gebracht hait ind he zovoeren die alsaemen beleyvet ind bewilliget hait ind dat burgermeister, richter, scheffenen, raet, kirchmeisteren, gemeynde ind kirspelslueden der stat ind des kirspels zo Wipperfurde vurschreven kunt gedaen hait, doe haint die vurschreven burgermeister, richter, scheffenen, raet, kirchmeister, gemeynde ind kirspelsluede dit vurschreven oeverdrach myt allen vurschreven ynhaldende punten gentzlichen beleyvet ind vast ind steede ouch darby zo behalden vur sich ind yre nakoemlinge geloevet, dair nummer weder zo doene, sunder all srgelist. Ind dijs zo urkunde der waerheit soe haint die eirberen ind vursichtigen burgermeister, scheffenen ind raet eyndrechtlichen durch byweesen ind consent des richters daselfs yrer stat secreit vur sich, yre nakoemlinge ind die gantze gemeynde der stat Wipperfurde ind ouch vur dat gantze kirspell, die dair semlichen ind eyndrechtlichen darumb gebeden haint, want gemeynde noch kirspell gheyn besonder siegell enhaint, unden an dissen breiff gehangen a, die dan hynder dat capittell der heilger kirchen der heilger apostelen bynnen Colne zo erfflichem ind ewigem gedechtnisse gelacht is. $O p$ dissen oeverdraege ind besiegelen synt oever ind an gewest die eirberen vromen ind vursichtigen manne Johan Heesprich zorzijt burgermeister zo Wipperfurde, Kirstgen Bracke zorzijt richter ind hoefsamptman daselfs, Heyne zo dem Daele, Hannes an der Leyen, Dreis Becker, Wilhem an der Leyen, Theis Kannengeisser, Zeres an der Leyen, Hannes Becker vur der Portzen, Aelff van Langenberge, Heynman Paes, Herman van Roede, Hannes zom Stalle van dem Voerste ind Hannes Berchvelt, alsaemen scheffenen zorzijt daselffs. Gegeven in den jaren unss heeren duesent veirhundert seven ind seventzich des dynsdaeges na unser liever vrauwen daege visitacionis, dat is nemlich des eichten daeges des maentz julii.

Düsseldorf, Königl. Staatsarchiv, Köln, S. Aposteln no. 253. Original auf Pergament, das kleinere Siegel (Sekret) der Stadt Wipperfürth (wie bei no. 23) an Pressel, wenig verletzt. Gleichzeitige Rückaufschrift: ,Littera concernens capellam sancte Agathe in Wipperforde presentata in capitulo 1477 in vigilia Mathei' [d. i. September 20.]. Inhaltsangabe 17. Jahrlounderts, alte Signatur: No. XX.

36.

1484 Januar 25. - Thys Kannengeisser Bürger zu Wipperfürth wird vom S. Apostelstifte zu dessen Amtmann und Hofrichter bestellt.

Ich Thys Kamnengeisser burger zo Wippervoirde doin kunt, as die wirdigen herren dechen ind capittell der | hilliger Apostelenkirchen in Colne myne lieven herren mir nu yr hoiffsampt zo Wippervoirde bevolen hant na lude $\mid$ ind inhalde eyns brieffs die selven myne lieven herren mir darup gegeven hant, der van woirde zo woirde herna beschreven volght ind luydt.

a) gehangen“ iibe»' ‘lei'Zeile. 
1484Jan.25. alsus: ,Wir dechen ind capittell der hilliger Apostelenkirchen in Colne doin kunt ind bekennen overmitz diesen brieff, dat wir den eirsamen Thijs Kannengeisser burger zo Wippervoirde unsen amptman ind richter unss hoeregerichtz zo Wipperroirde gesatt ind gemaicht hant ind hant yme dat selve unse gerichte ind alle unse gerechticheit zo Wippervoirde ind da umbtrient gelegen bevoelen ran unsen wegen ind in unsen namen zo hanthaven. zo verwaren ind zo regeren, eyme ydern der des hoiffs noit hait recht ind scheffenurdell zo doin ind wederfaren zo laissen na des hoiffs rechte ind gewoinheit, die gude ind hoiffslude up den hoiff gehorende by ailder vrijheit ind by dem hoeve zo behalden, ind weren eynche gude off hoiffslude uns ind dem hoere affhendich woirden, die na all syner macht weder in zo forderen, ouch behulffen zo syn, dat unse rente, dynste a, rechte, kurmode ind hoifftrechten wir ader unse pastoir zo Wippervoirde jars des hoiffs halven bynnen off buyssen Wippervoirde geldende hant, zo geburlichen tzijden betzailt werden ind unverluyslich blyven ind vort zo doin alle dat ghiene dat unss hoiffs amptman zo Wippervoirde van rechte ind guder ailder gewoinheit geburt ind schuldich is zo doin. Ind herup hait uns derselve Thys geburliche geloiffde ind eide gedain, alle punten vurschreven na syser macht ind besten synnen zo halden ind zo vollentzien, beheltnisse uns doch, wannee ind wilche tzyt wir darzo bewegen werden, dat wir dan denselven Thijs des amptz vurschreven entsetzen ind eynen anderen amptman ind richter unss hoiffs vurschreven setzen ind ordineren mogen na unsem willen ind na vermogen unser gerechticheit desselven unss hoiffs vurschreven, uysgescheiden alrekonne argelist ind geveirde. Diss in urkunde der wairheit hain wir dechen ind capittell vurschreven unss capittels siegell ad causas an diesen brieff gehangen. Gegeven in den jaren unss herren duysent vierhondert vier ind eichtzich up sent Pauwels dach conversionis." Also bekennen ich Thijs vurschreven, dat ich vur geloifft ind na lyfflichen gestaifftz eidtz zo gode in den hilligen gesworen hain, dat vursehreven ampt eirbarlichen ind getruwelichen zo myner herren vurschreven nutz ind besten verwaren, hanthaven ind regeren sall ind will, na vermogen des brieffs myne herren vurschreven mir darup oevergeven ind in diesem brieff intersereirt is, uysgescheiden alrekonne argelist ind geveirde. Diss in urkunde der wairheit hain ich Thijs vurschreven myn siegell an diesen brieff gehangen. Gegeven in den jairen unss herren duysent vierhondert vier ind eichtzich up sent Pauwels dach conversionis.

Düsseldorf, Königl. Staatsarchiv, Köln, S. Aposteln no. 259. Original auf Pergament, beschädigt, mit einem Siegeleinschnitt. Gleichzeitige Rïckaufschrift: Littera reversalis schulteti nostri in Wipperfurde data anno domini Ixxxiny. Inhaltsangaben 1\%. Jahrhunderts; alte Signatur: No. XVIII.

a) dyosse. 
37.

Infrascripte sunt proprietates et iura quas habet ecclesia sanctorum Apostolorum Coloniensis in opido et parrochia in Wippervurd Coloniensis dyocesis de curte sua ibidem.

[§. 1. Bestellung und Befugnisse des Amtmannes.] In primis dicta ecclesia sanctorum Apostolorum habet constituere seu ordinare unum officiatum honestum virum opidanum in Wippervurde et ibidem commorantem. Quiquidem officiatus unicuique desideranti a faciet seu exequetur iusticiam de bonis spectantibus ad eandem curtem et eciam quemcumque petentem solventem census ad eandem curtem recipiet et admittet ad suscepcionem bonorumb ipsius curtis.

[\$. 2. Zahl und Zusammensetzung der Schöffen.] Item homines communiter spectantes ad ipsam curtem habent constituere prefato $c$ officiato septem scabinos inter seu infra semet ipsos et non extra, set ad curtem spectantes, quorum quidem scabinorum iuratorum duo erunt de opidanis in Wippervurd, quatuor autem iurati de parrochia in Wippervurd et unus scabinus iuratus erit de Wippervurd.

[§. 3. Gewöhnliche Gerichtstage.] Et talis officiatus debebit qualibet quindena unicuique petenti facere iusticie complementum.

\{\$. 4. Gerichtshegung, uppe leke ind pele nur in Gomeinschaft mit dem landesherrlichen Richter.] Item quandocumque iudicium seu iusticia seu eciam iuris execucio fuerit celebranda in locis appellatis vulgariter ,uppe leke inde pele,; extunc officiatus prefatus per se solum non faciet execucionem iuris set deducet huiusmodi causam ad iudicem superiorem, et in quantum bona, super quibus vertitur causa, fuerint sita infra terminos ipsius opidi in Wippervurd vulgariter dictos ,banmile, extunc deducet causam ad iudicem domini infra opidum; et si bona fuerint sita extra prefatos terminos, extune officiatus una cum scabinis deducet huiusmodi causam ad iudicem seu iudicium extra opidum predictum ante portam et extune prefati duo, videlicet officiatus et iudex, accedent ad locum dictum, leke et pele ${ }^{6}$ et facient execucionem iuris et quicumque subcubuerit in lite, solvet nomine pene domino terre quinque marcas et ad curtem solvet septem solidos et sex denarios, et cum hoc satisfaciet de expensis factis seu habitis in hac causa per personas ad huiusmodi iudicium spectantes.

[\$. 5. Rechtsbelehrung bei dem landesherrlichen Gerichte.] Item in casu quo scabini aliquam causam discutere non possent propter difficultatem iuris, extunc deducet causam ad superius iudicium, et si fuerit infra opidum seu terminos predictos extunc deducet ad d iudicium superius infra opidum, et si fuerit extra opidum seu terminos extunc deducet ad superius iudicium extra, et quidquid scabini diffiniverint in iure, huiusmodi diffinicionem reportabunt scabini curtis ad ipsam curtem et quicumque subcubuerit in lite, solvet et satisfaciet de expensis e factis per scabinos.

a) desiderante. über ater Zeile nachgetragen. b) bonam.

e) expesis. c) Vorher ppf aurchstrichen.

d) ad 
[\$. 6. Vorladung der Hofleute.] Item si officiatus indiguerit aliqua persona spectante ad curtem, illam faciet citari peremptorie seu tribus vicibus, et si citatus contumax effectus fuerit, extune qualibet vice citacionum solvet ad curtem nomine pene septem solidos et sex denarios, et si citatus in contumacia perduraverit et venire recusaret, extunc deducet talem contumaciam ad superiorem iudicem qui faciet eum citari prout supra et extunc tociens quociens contumax effectus fuerit solvet domino terre nomine pene quinque marcas.

[§. 7. Die drei ungebotenen Dinge.] Item officiatus celebrabit iudicium tribus vicibus in quolibet anno sine aliqua intimacione. videlicet feria secunda proxima post epiphaniam domini, feria secunda proxima post a octavas pasche et feria secunda proxima post octavas penthecostes; ad quod iudicium omnes pertinentes ad curtem habentes annos discrecionis tenentur comparere et qui non comparuerit solvet pro contumacia 7 solidos 6 denarios ad graciam (iudicis) nisi habuerit legitimam excusacionem.

[\$. 8. Gerichtliche Auflassung.] Item officiatus admittet unumquemque petentem ad suscepcionem bonorum curtis, salvo semper iure cuinscumque, et prefiget sibi terminum veniendi ad indicium proxima die iuridica et tunc in iudicio admittet eum ad suscepcionem bonorum ipsius curtis et talis admissus dabit officiato pro iure suo sex denarios et dabit scabinis pro iure eorum sex denarios et dabit item ,deme vronen" unum denarium, et extunc officiatus debet tali admisso indicere pacem et omnibus et singulis mandare sub pena banni, ne aliquis tali admisso ad suscepcionem bonorum, ut prefertur, prestet impedimentum set procedat contra eum via iuris tempore et loco optimis et alias ubi de iure debeat fieri.

[§. 9. Aussergerichtliche Auflassung mit nachfolgender öffentlicher Verliündigung.] Item si $\|$ aliquis petet ${ }^{b}$ se admitti extra iudicium ad suscepcionem bonorum ipsius curtis coram duobus scabinis, extunc officiatus faciet graciam petenti et admittet eum et prefati duo scabini presentes facient proximo iudicio publicam relacionem coram omnibus presentibus et astantibus de huiusmodi admissione et publice intimabunt ea que viderunt et audierunt, et eo facto omnes scabini tenentur talia scire equenimiter.

[\$. 10. Verpflichtung des Amtmannes zur Instandhaltung des Gefangenenstoclies.] Item officiatus tenetur truncum captivorum contentum supra forum in Wippervurde tenere in debita structura in finem, quod dominus terre tali trunco, si indiguerit, utifrui poterit et gaudere.

[§. 11. Verpflichtung zur Haltung des Zuchtviehs.] Item officiatus tenetur de iure tenere pro communi bono unum taurum seu bovem non castratum, unum verrem seu porcum masculinum non castratum et unum arietem seu mutonem masculinum non castratum; quiquidem taurus, verres et aries poterint libere et licite trassire per campum hincinde sine infestacione, lesione, percussione et invasione cuiuscumque seu quorumcumque.

[\$. 12. Uebertragung der Hofesgüter mit Ausnahme des rechten Erbes durch den Amtmann.] Item unusquisque debet bona spectancia ad curtem

a) pro. $\quad$ b) petet von anderer Hand am Rande. 
suscipere ab officiato nisi tunc huiusmodi bona ad aliquem per obitum patris sui aut matris sue fuerint devoluta etc.

Köln, Stadtarchiv, Niederschrift aus dem Ende des 14. Jahrhunderts im Liber rubeus fol. 59 no. $15 \%$.

Der unbrauchbare Abdruck bei v. Mering, Gesch. der Burgen etc. Heft 5 S. 60 ff. beruht auf einer Kopie im 12. Bande der Farragines Gelenii. Ein Zusammenhang mit den ,ergänzten Statuten des Apostelstifts vom S. 1429" ist nicht ersichtlich. Die im Jahre 1429 durch den Kardinal Heinrich tit. s. Eusebii getroffenen Bestimmangen beziehen sich ausschliesslich auf die inneren Verluältnisse des Stiftes.

38.

Iuramentum canonici prebendati presentati ad ecclesiam in Legnich aut in Wippervorde.

Ego N. iuro et promitto inviolabiliter a observare exnunc in antea ordinaciones, statuta et consuetudines ecclesie sanctorum Apostolorum que facte, statuta vel observate sunt super incorporacione prefate ecclesie in Legnich (vel in Wippervord) b super decimis et bonis de ecclesia in Legnich prefate ecclesie sanctorum Apostolorum cedendis et per ipsam habendis nec non super non nsu iurium canonicalium et cursu fructuum prebendalium et super dimissione ipsius ecclesie in Legnich et reditu ad premissa et super omnibus aliis et singulis circa ista et super officiacione personali et residencia in ipsa ecclesia in Legnich (vel Wippervorde) ${ }^{\mathrm{b}}$ facienda de quibus singulis plene informatus sum, et specialiter ipsum statutum circa ista factum quod incipit: ,Fredericus' et finit: ,Actum et datum anno domini M . CC.LV. mense marcii.', et quod non procurabo permutacionem dicte ecclesie in || Legnich (Wippervorde) ${ }^{b}$ nec in illam consenciam nisi hoc sit de expresso et libero consensu dominorum meorum decani et capituli ${ }^{1}$, nec redibo ad usum et percepcionem premissorum propter alicuius litis suspicacionem vel mocionem, ymmo si lis michi moveretur non redibo nisi illa evicta; ipsam ecclesiam tenuero in quiete nec aliquid faciam, procurabo vel consenciam fieri quominus ipsum capitulum incorporacione predicta libere uti possit aut per quod quoquomodo defraudari possit in percepcione fructuum prebende currentis aut bonorum suorum apud Legnich (vel Wippervorte) b eroque eis quoad percepcionem huiusmodi promotor fidelis, fraude et dolo in singulis premissis exclusis. Sic me deus adiuvet et hec sancta dei evangelia.

Köln, Stadtarchiv, Evangelienbuch des S. Apostelstiftes, Handschriften $A B$ no. 244, 13l. $240^{b}$ u. 241, Niederschrift aus dem Anfange des 15. Jahrh.
a) inviobiliter.
b) Am Rande.

1) Hierzu am Rande von anderer Hand 15. Jahrh.: ,Nec ipsam ecclesiam aliq o reservabo vel pensione aut alio onere pregravabo. 
39.

(Wachszinsige des Apostelstiftes in Wipperfürth und Umgegend.)

Wippervorde.

\$. Isti sunt homines cerocensuales tenentes solvere iura | capitalia decano et capitulo ecclesie sanctorum Apostolorum | Coloniensis et pastori in Wippervoirde nomine eorum, qui et participes sunt oracionum, vigiliarum, missarum et commendacionum prefatorum dominorum ad Apostolos pront ceteri eorum benefactores.

In Gummersbach.

Elisabeth uxor Telonis to Hemerkusen pueri et progenies.

item pueri Teilonis to Gummeroide.

\Konnegundis to Reynickbusen et fratres et sorores.

DAndreis an dem Oele et progenies.

" pueri to der Eick yn der Roespe.

"Henrich to Winthagen et eius sorores.

"uxor Mercatoris to Winthagen et pueri.

ఎ uxor Hesemans Hoiffstuytz to Gummeroide.

- Wygant to Lutzinckhusen.

" pueri Margrete up dem Hoevell in der Geilpe.

v Henke Krantz in der Geilpe et frater eius molendinarius et soror eorum cum pueris sororis.

D Henke Wever in der Geilpe.

- pueri Henke Wichs in der Geilpe.

- pueri Henonis Norkemans to Kothusen: Hans, Hedenrich et Katherina et eorum pueri.

-Henrich up dem Wege yn der Stronbicke.

\Teile up dem Schonenhoeve.

D pueri Romshagens to Gummeroide.

¿ Peter van Kalsbeke.

\Clais van Ensinckhusen et eius progenies to Gummeroide.

¿ Greet up der Wese, Clais Werneke ind Gerhart up der Wese.

" Henke in der Roespe, Werneke filius eius.

\Brusewint in der Wetten et uxor eius Gert et frater Brusewint Petrus.

\ Henrich van Gummeroide de slichter in Molenbicke.

* Katherina in clem Winckell et pueri.

- Gert uxor Burgers et pueri.

- Henke Becker in der Wetten, Gerdruyt uxor eius et pueri. II

» magister Tilmannus up der Mergenheiden, fratres et soror.

»Peter to der Wipper.

" Mettze van Schenborn.

\Kunna van Eggerinckhusen.

- Elske to Wernschede et eius pueri.

» Peter up dem Danneberge tor Goeten et eins fratres et sorores. 
item Mettze up dem Danneberghe.

" Henke Kuppinck up dem Dannenberge et progenies.

\Kunna van Kalsbeke et progenies.

D Teile van Nunneberge et progenies.

- Grieta up des Strackenhoevell et eius pueri.

- Mager Heyne to Molenbicke.

- Ailke to Stuwelinckhusen et progenies.

- Kothusens pueri et uxor.

- Peter to Stuwelinckhusen et progenies.

- Metize up dem Hagen.

- Else to Kuckucksberge et pueri.

In $\mathrm{Hagen.}$

\Hennes Schulte to Eylepe.

- Henrich Loer to Hagen.

* Steven van Kukelhusen frater Loer.

* Hense van der Bruggen.

* Gese to Haseleye et pueri.

- Hans Ruteman to Eylpe.

- Jutte in den Stuken et pueri.

- Greden soin to Berchem.

- Bele, Munsen wiff, to Dorpmunde et pueri.

- Geze des Jonckers wiff to Oye.

D filia eius morans to Gendena.

D Metta to Alden Hagen quondam uxor Henrici nunc morans to Holthusen et pueri.

In Liberhusen.

»Krevet to Lantenbeke et sui pueri et duo fratres.

In Runderoide.

》 Henke Halm van Ensynckhusen, Elsa uxor eius.

- Hertwyn vain Runderoide.

- Greta uxor Engelberti to Bokelerhusen et pueri.

* Henke Kremer to Valvelde; fratres, sorores et pueri.

D Styna van Valvelde.

- Styna uxor Tyrmans et eius pueri.

Engelbertus up der Aducht.

* Deydorre to Oypelhusen.

In Wippervoirde.

Aleff van Vastenroide et soror eius.

item Henrich Muter et Teilo Knuyst et soror eorum in Rodensait.

- Greta up der Vynckelenberg et Henricus te Elbeshusen frater eius.

- Voolkenrodes geslechte, Ailke uxór Henke Beckers vur der Portzen et soror eius uxor Hennes Zobben et tota progenies.

D Alvert uxor Wollenslegers et frater eius vrygrave zo Lymburg et 
mater eius serviens commendatori in Castro et nepos eius custos Henricus in Hoekishoeven.

item Greta uxor Petri up dem Berge in der Bever.

- Hilla filia eius uxor Gobelini tom Daell.

》 Ailke van dem Steynkenberge uxor Heynemans in der Lutkennae.

\eilo to Bynnerbeyns Goell.

» Hennes Routzenberch et frater eius in curte et pueri eius, quia uxor eius eciam fuit eiusdem iuris.

จ uxor Udalrici in Wippervurde alias Thomas uxor.

\section{In Halver.}

Derick Benkeman, Druda soror eius et pueri.

item Fia van dem Kremendall et soror eius in Brekelvelde.

» Hilbrant tot Bolskeke.

- Gerwyn van Schonenberge.

¿ Greta up dem Keller.

- Heyue die Hover to Halver.

- Heynman up dem Berghe to Kerspe.

- Henke Voege to Hendinckbusen to Wiele.

Köln, Stadtarchiv, Aufzeichnung aus der zweiten Hälfte 15. Jahrhunderts in Liber rubeus Blatt $59^{b}$ no. $157^{a}$, die Stelle über Halver auf einem lkleinen, von gleicher Hand beschriebenen Pergamentblättchen.

\section{0.}

1443. - Aufzeichnung des Pfarrers Volmar von Helden über Einkünfte und Rechte des S. Apostelstiftes in Stadt und Pfarrei Wipperfürth. ${ }^{\text {a }}$

S. $6 \check{0} \quad$ Isti sunt redditus quos habet ecclesia sanctorum Apostolorum in opido et extra | in parochia Wypperwurde quos ego Volmarus de Helden pastor I reduxi de manibus laycorum in quibus ultra memoriam hominum modernorum semper fuerunt et pro reductione illorum non parvos habui labores neque exules(!) persecuciones et parvas habui probaciones preter nomen reddituum quia communiter nominantur iura et redditus Apostolici. Ex eo volo, quod capitulum ecclesie sanctorum Apostolorum de dictis redditibus singulis annis recipiat a pastore (in) Wippervurde ad eorum presencias viginti maldra avene quas dictus pastor absque murmure ac displicencia, attento statu in quo dictam ecclesiam inveni, libenter solvit 1 .

Miïrat7 Hecest avena Apostolica recepta anno domini M.CCCC.XIIII ipso die Gertrudis per me Volmarum de Helden pastorem in Wypperwurde.

a) Ueberschrift 16. J7.: ,De avena Apostoljea.

1) Am Rande von anderer etwas späterer Hand: ,Capitulum nunc nihil consequitur. Et nota quod pastor ibidem habet simile registrum eiusdemque tenoris'. 
In primo Rotgenscheit . . . . . . . . . . 4 molder - sumeren item de alio Rotgenscheyt . . . . . . . . . - $>6$ o

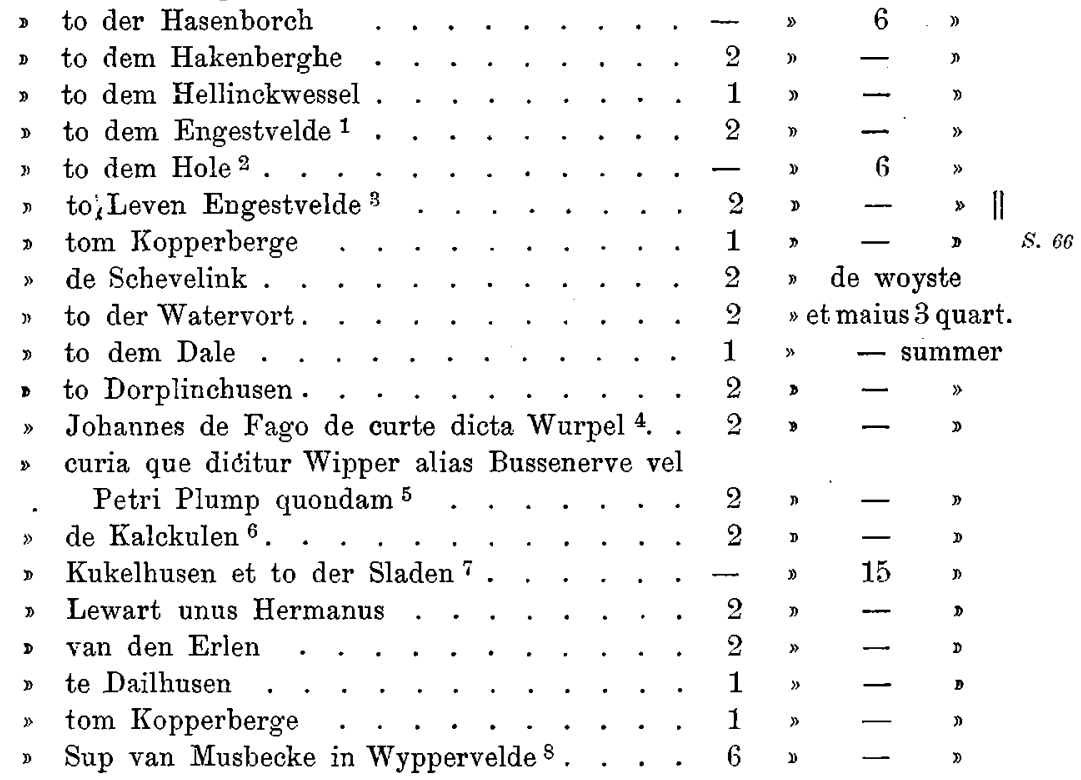

Hii sunt census dominorum Apostolorum sanctorum in s. 67 Colonia qui solvuntur in festo Panthaleonis martiris, recepti anno domini M.CCCC. XLIII et primum in Wippervelde per me 1443.Tuti28 Volmarum pastorem in dicta ecclesia.

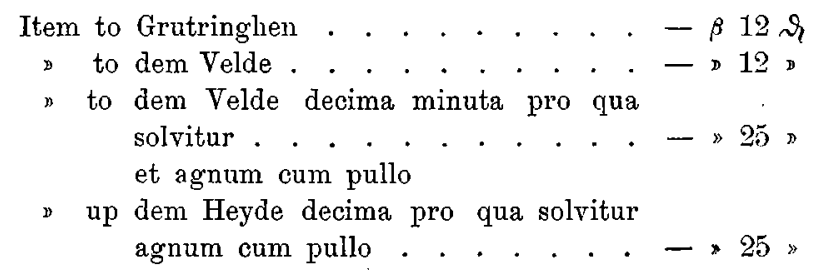

1) Hierzu von der späteren Hand: ,Colonus domicelli Hermanni de Engelsfelde".

2) Ebenso; ,Hans et Teylo Hasenphard'.

3) ,Domicellus Hermannus, et remisi sibi unum maldrum ad 12 annos quia deserta est hereditas ab anno LX ${ }^{0}$ citra etc."

4) Aleff et Hans dictus Buck.

5) filii et filie Heidenrici Dumborn.

6) Gerlacus.

7) Hilbrant et Hermannus Wyse et eorum heredes.

8) alias Musbeke filii et heredes. 
S. 69

S. 69

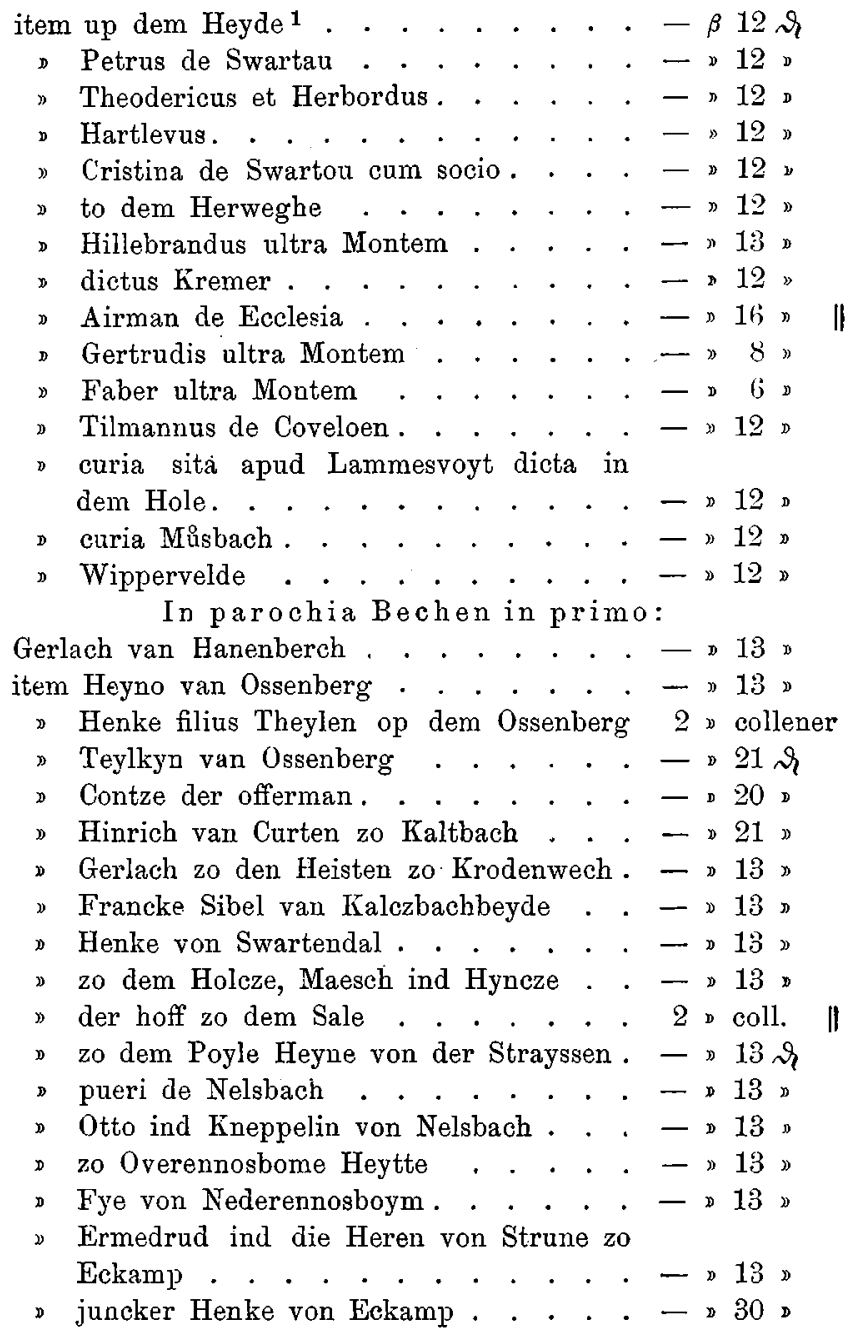

Hii sunt redditus in parrochia Wippervurde et primo in der Bever:

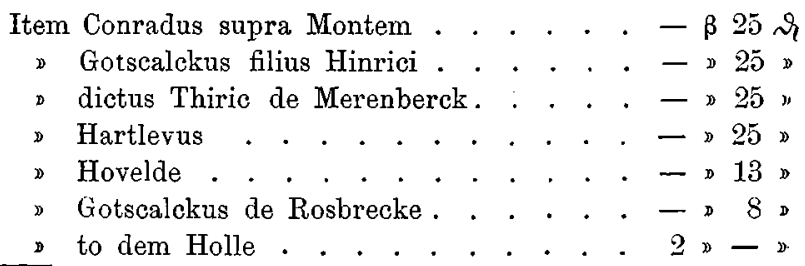

1) Decima pro qua solvuntur $25 \stackrel{2}{\curvearrowright}$ et agnum cum pullo. 
Item omnia predicta bona solvunt in die sancti Martini $12 \Re$. $13,91$.

Item de bonis dictis Votzgud 6 sch. br., et sui vicini supra Montem

Item zo dem Boken. . . . . . . . $-\beta 8$ s

v Lersen gud to den Boken . . . . - 10 ,

Item in predicta parrochia in Scharder hunschup:

Item to Symerinckhusen ...... - . $36 \%$

$\triangleright$ to Symerinchusen. . . . . . . - $>6$ 》

$\supset$ dictus Landerort et Fredericus. . . $3 \frac{1}{2} 》-$ -

$₫$ idem in die Martini . . . . . . . - " 8 ,

„Giselerus de Egwerdinckhusen . . . - 12 \%

- Vulo de Snypperinghen . . . . - - 18 ఎ

\Heynman de Egwerdinckhusen . . . - „12

Item in parrochia Wipperwurde

dictus Amelunt de Scharde . . . . - $\quad 6$ \%

„Thyman et Heynman de Godegarden. - 12 „

bona de Scharde annichilata. . . . - $12 \%$

Giswertus de Godegarden . . . . . - 12 ๖

๖ Thyman de Egwerdinckhusen . . . - 12 »

- Cristina de Scharde . . . . . . . - 12 ”

- in predicta parrochia Sophia de Hale - 8 "

๖ Gotscalckus de Eicholtze . . . . . - 11 ๖ $\|$ s. 11

¿ Heydenricus de Kopperberge . . . - 13 »

¿ Gotscalckus et Greta de Erlen . . . - 10 »

$\gg$ dictus Welp. . . . . . . . . . - „ 8 ॰

Adolphus de Bloymberg . . . . . - 13 ,

DConno de Lenderinchusen: . . . - "16"

Hinricus dictus Kneise . . . . . . - $>7 \frac{1}{2}$ b

- Petrus de Via . . . . . . . . - 12 ,

\Sassenbecke. . . . . . . . . . - $\$ 10 \frac{1}{2}$ ”

- Heydenricus de Schonenberg. . . . - 12 "

"Hertderadus supra Montem . . . . - 10 "

\ Matheus et socius suus. . . . . . - 12 ,

Johannes up dem Bochel . . . . . - , 10 ,

» Johannes de Hole. . . . . . . . - 12 "

》Arman de Watervort . . . . . . - 025

- bona zor Wort. . . . . . . . . - 12 ,

๖ Sifridus de Holte. . . . . . . . - 12 》

》Pilgerimus de Orto . . . . . . . - 15 D $\|$ S. 72

D Johannes de Erlen . . . . . . . - 6 》

\filius Conradi de Schonenberg . . . - 12 ,

» Stillinckhusen . . . . . . . . - > 12 》

„Harderetzhoff . . . . . . . . . - 12 ฉ

\Hinricus monetarius . . . . . - 12 ,

1) Filii Petri in Monte solvunt. 


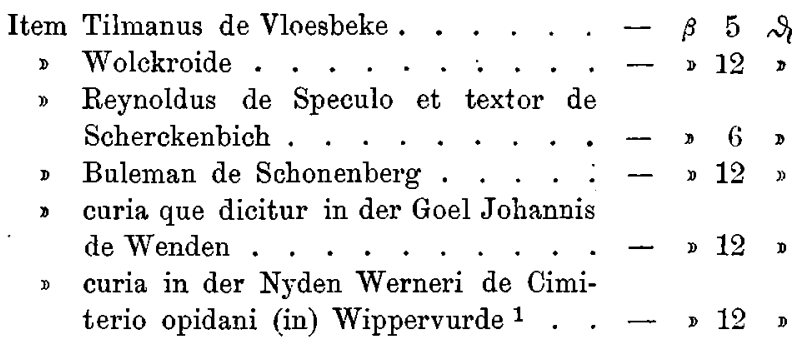

Item recepi a civitate tam de ortis quam domibus et horreis $10 \frac{1}{2}$ marcas colonienses et maurum receptas pro missatico qui alias non solvunt missaticum a.

Item recepi de domo dicta up dem Orde in foro que est Teylonis de Rade sicut stat duo talenta cere.

Item de orto a Iohanne Trappeman 6 alb.

Ista sunt iura dominorum sanctorum Apostolorum in Wyl

Et iste sunt hereditates solvere tenentes in Wyel: b \|

In primo up dem Cleve cum suis hereditatibus cum duobus viris $\mathrm{Hey}^{-}$ denrich et Aleff.

Item zo der Lynden Hassen et sui pueri.

๖ zo der molen Herhusen ind zo der molen Burnhusen hereditates

$\triangleright$ in dem Hynderdal hereditates.

, zo Helmerhusen o

zo Wychershagen ${ }^{c}$ up dem berghe hereditates.

» zo Wiershagen zo der molen d hereditates.

$\checkmark$ zo Aysperelinckhusen.

zo dem Homel Hentze et sui "

zo Bantenberch „

zo Vodenbech

zo der Bruggen „

2 zo Alvershagen

- zo Morkenpissel D

zo Marienhagen Leppechins 》

S. 74

" zo Enscherkay

zo Wreckynckhusen

zo Buttenhusen medietas hereditatume.

Item, quod canonici Bonnenses habent medietatem reddituum, et abbas et conventus Tuiciensis et ecclesia sanctorum Apostolorum medietatem, hoc

Wyll.

a) Vorher. aurchstrichen: massi, missatium.

b) Am Rande von andever Hand: molhen und.

c) Von späterer Hand ist Wychershagen gestrichen und ersetzt aurch: der

e) Von anderer Hand eingeschoben: Item zo Weill erve.

1) Hans et molendinarius ibidem. 
debet sic intelligi, quod ubi dantur duo denarii Bunnensibus, ibi datur unus: denarius ad Apostolos et pariformiter Tuiciensibus. Et Henke van Henderinchusen dictus Vagert (?) fuit famulus ecclesie sanctorum Apostolorum et fuit ultra quinquaginta annos ipse et sui . . (?)

Zahlung des Pfenniggeldes von Häusern, Gärten und Scheunen.

Item nota, quod in opido et circa tam domus quam orti et horria solvunt redditus dictos penninckgelt; ubicunque in domitus incenditur ignis, ibi solvuntur duo mauri; si eciam una domus divideretur in decem focos, tune solveret illa domus 20 mauros, sed si reducerentur in unum, solveret duos mauros ut prius. Et pariformiter unus ortus si divideretur in decem, tunc solveret 20 mauros, sed si reduceretur in unum ortum solveret duos mauros. Eciam de campo arabili citra civitatem fierent centum orti, omnes illi orti solverent ut supra, et si orti illi redierint in terrram arabilem essent liberi a tali solucione.

Hec sunt bona solvencia de curte Berinckrode in die Cuniberti. Not 12. Item Berinckrode . . . . . . . . . $-\beta 12$ \&

๖ Hertghyns Vlosbeke . . . . . . . - > 12 ॥ S.

¿ Overvlosbeke Frankenhoff . . . . . - 12,

¿Bushem . . . . . . . . . . . -12 »

» Berchusen Aleff vam Dal, Clays vam

Holte et Christianus van Schonenberg . - 12 »

》Baltzipen vel Affstol vel Tyre idem . . -, 12 ,

D Bockel Hartleff . . . . . . . . . - 12 ,

» to der Molen . . . . . . . . . . - 12 ,

๖ Overswartau Kratz . . . . . . . - 12 „

$»$ to dem Winckel . . . . . . . . . - $12 \nu$

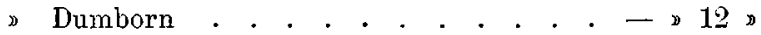

Hee curtes supraseripte spectant ad curtem in Berinckrode et tenentur comparere a ibidem in die sancti Kuniberti sub pena iudicii in civitate.

Scriptum ex registro domini Volmari pastoris in Wipper-s. vorde et eciam habetur in antiquo missali circa canonem etc. $b$

Item nota, quod pastor in Wipperfoirde pro tempore existens pleno iure et sine omni impedimento | tam domini terre quam opidanorum conferre et investire habet altaria beate Marie virginis et / beati Petri, ectlesiam seu capellam curatam sancti Clementis in Wippervelde et hoc multis annis elapsis non est interruptum seu mutatum. Quam domini pastores in Wipperforde, primo dominus Petrus de Wilre contulit altare b. Marie v. domino Alberto et al-
a) comparare.
b) Ton anderer Hand als die vorhergehtonden Verzeichnisse. 
tare s. Petri domino Abraham. Item d. Iohannes de Pavone contulit altare s. Petri d. Mathie. Item Hermannus Boge altare b. (M.) v. d. Henrico de Ruden et $d$. Gobeloni altare b. Petri, et post predicto $d$. Henrico ecclesiam in Wippervelde ; et idem investivit d. Detmarum de Monte Martis ad capellam curatam in Olepe ad presentacionem domicelli ibidem cui competit ius patronatus. Item Rutgerus Vogell contulit altare s. Petri d. Theoderico Lanck et d. Henrico de Swartau ecclesiam in Wippervelde. Item Iohannes de Balve altare b. v. d. Hermanno fratri suo. Item Iohannes Bunteveder altare b. v. Iohanni Tymmerhuyss et ecclesiam in Wippervelde d. Iohanni Vellinckhuyss. Item Gerardus de Bercka altare b. Petri d. Iohanni Vodinckhuyss. Item Volmarus de Hilden, qui ad sedandam a insolenciam aliquorum et hoc ius pastoribus cunctis insinuandum hec manu propria scripsit ex diversis registris et scriptis inventa, inter alia sua iura contulit altare s. Petri d. Alberto Stelteman et ecclesiam in Wippervelde d. Alberto Huishere et investivit ad ecclesiam in Olepe dominos Johannem Breder et Conradum Kar. Et hoc ius non solum approbatur superscripcione ${ }^{b}$ tam longeva, sed clare habetur in fundacionibus dictorum altarium quas consulatus in Wipperforde habet in suis scrineis etc. Item ego Volmarus de Hilden pastor contuli altare s. Petri domino Henrico Verkers de Corbecke presbitero, salvo iure pastoris.

Anno LVII. Ecclesia in Wipperforde habet in certis redditibusc: Primo in avena . . . . . . 103 maldra in siligine . . . . . . . . 13 \% in tritico. . . . . . . . . . 3 D 1 sumbrin. in synodo secundum ius ut supra (?) $42 \mathrm{mk} .-\beta$ item in redditibus in civitate . . 9 \ 6 》 item in redditibus in parrochia. . $30,->$ item de redditibus in Wippervelde 7 item de agris expositis . . . 12 , item de pratis 1 . . . . . . . 9 , 9

Köln, Stadtarchiv, Abschriften aus der 2. Hälfte 15. Jahrh. im Liber Luppelheim S. 65-76.

\footnotetext{
a) sedendam. $\quad$ b) superseripcio. $\quad$ c) Von derselben Hand wie die nüchstworhergehende Aufzeichinung.

1) Am Schlusse der Seite steht: ,Nota! Pastor in Wipperforde sub decanatu Tuiciensi in libro decimarum in $14 \mathrm{~s} .4$ भ. Item taxa pro iure investiture sigillifero in ambitu pro reverendo preposito maiori 40 rader mk., domino officiali ibidem $1 \mathrm{fl}$. aur., notario similiter pro scriptura seu instrumento. Verum d. Tilmanus Witteren composuit et contentavit $9 \mathrm{fl}$. ren. et dal. reg. pro signo etc. anno 1575 ultima augusti. Georgius Meschede decanus annotavit."
} 
41.

\section{(Incendia Wipperfurdae.)}

Nota quod oppidum Wippervoirde infra 80 annos fuita sex vicibus fere combustum 1 .

Primum incendium fuit anno $\mathrm{M}^{0} \mathrm{CCC} 0 \mathrm{XXXIII}$ crastino sancti Mathie et $1333 \mathrm{~F} c b_{r: q}$ totum opidum cum ecclesia fuit consumptum igne demptis b $4^{\text {or }}$ domibus; et hoc incendium dicebatur, Lypartzbrant'.

$2^{\mathrm{m} . \mathrm{c}}$ incendium fuit anno MCCCLII ex fulmine in die corporis Christi 1352 Juni et tunc eciam fuerunt flagellationes.

$3^{\mathrm{m}}$ incendium fuit anno domini M . CCC . LX mo VIII. dictum, Lappen- $186 \mathrm{~s}$ brant' et combusti fuerunt 80 homines quia fuit in nocte.

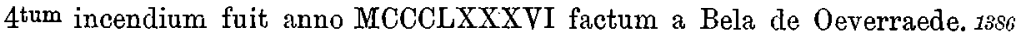

$5^{\text {tum }}$ incendium fuit anno MCCCC ${ }^{\circ}$ IIII in die sancti Andree quando 1fos $x_{00} . *$ Crouwell fecit incendi opidum propter dominum Fredericum archiepiscopum Coloniensem qui vicit opidum anno $1404^{d}$ in die sancti Andree 2 .

$6^{\mathrm{m}}$ incendium fuit anno M. CCCC. XII ${ }^{0}$ factum per Sophiam uxorem 1f12 ort. 1t Wynrici crastino Gereonis.

$7^{\mathrm{m}}$ incendium fuit anno M. CCCC . LXVII . die XXVlI. iunii, et incepit 146\% Juniz7. a domo Boechfelt iuxta portam Coelsche portze in media nocte tandeme et

$\begin{array}{lll}\text { a) Von gleichzeitiger. Hand verbessert aus est. } & \text { b) deptis. } & \text { c) Durch }\end{array}$ Unstellungszeichen sind 2 und 3 in die chronologische Aufeinanderfolge gebracht. $\quad$ a) Die rorlage hat nil 144. . e) Vorher aurchstrichen: continuando.

1) In den lateinischen Chronikenfragmenten 15. Jahrhumderts (133214Ss), die H. Cardauns in den Chron. d. dtsch. Städte, Cöln Bd.2 S. 193 ff. aus einer Würaburger Handschrift veröffentlicht hat, finden sich ohne chronologische Ordnung folgende Nachrichten über die Stadtbrände zu Wipperfürth: ,[1.] Item anno 1332 altera die Matthie apostoli exusta est Wipperfurdis manentibus 4 domibus nuncupatum Bebartzbrandt... [2.] Anno 1352 in festo venerabilis sacramenti fuit incendium magnum in Wipperfurdis per fulminationes... [3.] Anno 1368 exusta est Wipperfurdis, sic quod perierunt 80 homines, nuncupatum Laepperbrant.. [4.] Anno 1386 Wipperfurdis est exusta nuncupatum Belenbrant van Overrode.. [5.] (1405) in nocte s. Andree [Colonienses] oppidum Wipperfurden obsederunt et ceperunt, sed quidam miles in castro versutus dictus Crewell de castris emissis telis lethiferis et ignitis combussit oppidum et sic coacti inimici recesserunt.. [6.] Anno domini 1412 altera s. Gereonis etc. ussit Wipperfurdis dictum Winrichs Feierbrant $[$ d. $h$. Feigin $=$ Sophia s. oben no. 6] . [7.] Anno 1465 in nocte septem dormientium ussit Wipperfurdis appellatum Buircholtzbrant.

2) Die sog. Koelhoff'sche Chronit, Chron. d. dtsch. Städte, Cöln, Bd. s, $S$. 742 berichtet zum J. 1405: „In dem selven jair wunnen die Coelschen Wippervurde, mer up dem slos was ein schutz, Crouwer genoempt, der schois vuirpile van dem slos dat die stat angink ind brant uis. ind asso wart it gewunnen ind verbrant ind die Coelschen mit den burgeren wichen uis der stat." 
consumpsit ecclesiam et domum dotis quam dominus Volmarus pastor reedificavit et combusti sunt 61 domus etc. 1 .

Köln, Stadtarchiv, Niederschrift aus dem Ende 15. Jalhrhunderts im Liber Luppelhein S. $7 \%$.

\section{A n h a n g.}

1.

1302 August 1. - Walram III. Herr von Montjoie und Falkenburg setzt zusammen mit seipen Söhnen Dietrich und Rainald das Recht der Stadt Euskirchen fest.

In nomine sancte et individue trinitatis. Nos Walramus dominus de Monyoye et de Falkenbergh . . Theodericus et Reynaldus liberi nostri cum omni posteritate suc|cessorum nostrorum presentis scripti attestacione et veritate omnibus in perpetuum. Notum facimus universis christifidelibus tam futuris quam presentibus, quod villam nostram Eustkirken | ad maiorem populi benivolenciam nobiscum commorantis ex mera et pura consciencia et libera voluntate nostra tali atque immutabili libertate in perpetuum donari decrevimus: (\$. 1. Befreiung von einzeln aufgeführten Abgaben und Leistungen gegen eine feste Herbstbede von $40 \mathrm{Mar}$ ). Omnes siquidem iussioni atque ordinacioni nostris obedientes tam indigenas quam advenas in hac urbe manere cupientes et habitacionem habentes ab omni exactionis molestia qua quondam premebantur decetero in omne tempus liberos esse concedimus et penitus absolutos; in recompensacionem vero dicte exempcionis et liberacionis cives urbis predicte nobis nostrisque heredibus quadraginta marcas pagamenti in dicta urbe de Eustkirken currentis singulis annis in festo beati Martini hyemalis temporibus perpetuis solvere promiserunt et persolvent. (Befreiung von: a. Frohnund Spanndiensten). Dicti vero cives nulla feriarum opera nobis per ebdomadas facient nisi forte sibi aut rei publice labores et opus exerceant; arma sua, currus et iumenta, cetera quoque vectigalia nobis nequaquam eos prestare cogemus. (b. Beisteuer zur Schwertleite). Item si filius alicuius nostrum habitum induens militarem miles effectus fuerit, nullum ei amminiculum ad cingulum sue milicie ultra id quod volent dare compellentur. (c. Ausstat-

1) Der Bericht über diese siebente Feuersbrunst ist späterer Zusatz. Er gibt das Jahr falsch an. Besser unterrichtet ist der Dortmunder Chronist Joh. Kerlhörde, der zum Jahre 1465 meldet: ,Vigilia Petri und Pauli verbrant Wippervoerde mit der kerken.' S. Chronite des Joh. Kerkhörde, 1405-65 hrsg. v. J. Hansen, Ghron. d. dtsch. Städte Bd. 20 (1888) S. 145. Ebenso der Schreiber der Würzburger Handschrift, oben Anmerkg. 1. Nach den Aufzeichnungen eines Wipperfürther Franziskaners, auf die v. Mering, Gesch. der Burgen, Heft 5 S. 58 sich stïtzt, fand der Brand am Tage, septem fratrum dormientium' statt, also (nach kölner Rechnung) am 27. Juni. 
tungssteuer). Si filia alicuius nostrum matrimonium contraxerit, pro eius coningio nulla servicia vel expensas facere ultra velle ipsorum arctabuntur. (d. Beisteuer zu Grunderwerbs- und Auslösungskosten). Item allodium vel aliud bonum nostrum si redimere vel aliquid aliud a quocumque hominum comparare volumus nullos nobis sumptus in auxilium prebebunt invitj. (e. Heeressteuer bei Heeresfolge über die Alpen oder bei sonstigen längeren Kriegszügen). Vel si nos ipsos aut aliquem nostrum montes Alpium vel mare transire sive in expedicionem aut in longam peregrinacionem ire contigerit, eunti sive redeunti nullum, nisi sponte voluerint subsidium amministrabunt. (\$. 2. Verpflichtung, dem Landeshervn selbst und seinen Verbündeten Zuzilg und Beisteuer zu leisten). Si vero casu agente pro nobis vel pro amico nostro necessitas nos ad arma compellit universi cives nos sive nuncium nostrum, quem eis destinamus ad deducendum, quacunque hora et quocunque nobis placuerit, armis et expensis suis comitabuntur. (\$. 3. Verpflichtung zur Kriegsbereitschaft). Iubemus eciam, ut quilibet ad sui corporis municionem arma sua penes se semper parata habeat pro facultate sua secundum testimonium suorum concivium. (\$. 4. Gerichtlicher Zweikampf). De supervenientibus quoque civibus nemini licebit aliquem civium nostrorum ad singulare certamen monomachye sive duelli proclamare nisi per annum et diem secum in hac urbe concivis commanserit. (\$. 5. Ausweisung fremder Flüchtlinge). Item siquis extraneus metu hostilitatis propter spem defensionis ad bunc locum confugerit, nisi racionabilem causam inimiciciarum suarum et fuge sue possit ostendere, moràm hic facere non permittetur, sed sub nostra protectione et conductu. usque ad terminos nostre iurisdictionis et potestatis ipsum in pace deduci faciemus. (\$. 6. Abzugsfreiheit). Item si aliquis hominum adveniens multarum pecuniarum locuples a aliarum quoque rerum et diviciarum copiosus et. plurimum habundans extiterit, si forsitan casu agente ab hac urbe recedere ac penitus se alienare voluerit, iure civium persoluto clara luce liber et. securus recedet. (§. 7. Freie Verwendung des bürgerlichen Grundbesitzes). Ortos quoque et areas quas indigene cives nostri derelinquunt ad quoslibet usus fructuum eos semper colere concedimus. (\$. 8. Freie Schweinemast im herrschaftlichen Walde). De porcis vero ipsorum qui in nostro pascuntur nemore nullum pro pastura precium exigemus. (\$. 9. Kein Bürger brancht herrschaftliche Gefangene zu herbergen). Item si captivum hominem quicunque familiaris curie in hanc urbem adduxerit nullus civium per vim vel minas cogetur eum in domum suam recipere. (\$. 10. Landesherrlicher Schutz für das über Jahr und Tag besessene Grundeigenthum). Si vero aliquis civium nostrorum in iurisdictione nostra terram comparaverit quam per annum et diem quiete et pacifice possederit, eam sibi defensare tenemur quousqueinsticia mediante ammoveatur vel amore. - Hec itaque decreta tum pro libertate urbis nostre Eustkirken cum pro commoditate civium eiusdem loci nos. Walramus mediantibus pluribus fidelibus nostris viris honestis in perpetuum conservanda iuramento affirmavimus. - Amplius preter hec ad nostre partis utilitatem et honoris iusticiam scriptis et rebus indultis huius-

a) locuplex. 
modi pro nobis iura non inmerito adiungi et conservari volumus: (§. 11 . Anfall erblosen Gutes an den Landesherrn). Si aliquis civium seu vir sive mulier de indigenis vel advenis sine prole vel herede de hac vi[ta decedere contigerit] a res eius et bona ad manum nostram omnia transibunt. i§ 12. Verpflichtung der Bürgerschaft zur Instandhaltung der Festungswerke). Item si aliqua pars fossati, aggeris aut valli urbem ambientis dilapsa fuerit et universa civitas secundo et tercio commonita operandi necnon reparandi diligenciam non adhibuerit, quadraginta solidorum pagamenti in dicta urbe currentis pena multabitur qui ad nos venient persolvendi; si vero unus vel duo per contumaciam se subtraxerint quinque soljdos dicti pagamenti fisco nostro persolvent. (\$. 13. Verpflichtung zu* Instandsetzung der öffentlichen Wege). Plateas et vias in urbe et ad urbem necessarias a sculteto secundo et tercio commoniti, si non communiter construxerint, quinque solidos dicti pagamenti nobis persolvent; si vero aliquis ab hac opera contumaciter se subtraxerit pena viginti denariorum punietur. (§. 14. Pachtzahlung für ein vom Landesherrn auf dem Markte zu errichtendes allgemeines Kaufhaus unbeschadet der städtischen Freiheiten). Item si forsitan in foro rerum venalium domus tabernaria diversorum officiorum sumptibus et expensis nostris constructa fuerit, a singulis officiis annuam pensionem recipiemus salva nichilominus urbis libertate, quam in hoc facto nequaquam lesisse reputabimur. (\$. 15. Jährliche Reloognition von jeder Hofstatt ausser allen alten Rechten, Zinsen und Gerichtsgefällen). Igitur pro hac libertate quam indulsimus dicte urbi firmiter a nobis conservanda de singulis areis in urbe per singulos annos in festo sancti Remigii sex denarios dicti pagamenti et duos capones in festo beati Martini nobis persolventb, salvis eciam nobis iuribus et censibus nostris antiquis cum emergenciis iusticie nostre. - Ut igitur predicta in perpetuum firmiter rata et inviolata permaneant presentis paginam scripti sigillis nostris una cum sigillis virorum honestorum Iohannis de Haasdail ac Godefridi de Pomerio militum munimus corroboratam. Nos vero Iohannes ac Godefridus milites predicti ad requisicionem reverendi domini nostri Walrami domini de Monyoye et de / Falkenborgh, Theoderici et Reynaldi suorum filiorum predictorum, sigilla nostra presentibus litteris apposuimus in memoriam et testimonium premissorum. Datum et actum anno / domini M. trecentesimo secundo in die beati Petri ad vincula.

Köln, Stadtarchiv, Haupt-Urk.-Arch. no. 6r\%. - Original auf Pergament mit fünf Siegeleinschnitten, beschädigt.

Moderne Abschrift auf dem Bürgermeisteramte zu Euskirchen, beglaubigt 1863 Juni 12 durch den Kölner Stadtarchivar L. Ennen.

Gedruclit: Katzfey, Geschichte der Stadt Mïnstereifel Bd.2 (Köln, 1855) S. 56 ff., mit zahlreichen Fehlern und Lücken.

Ver"zeichnet: Mittheilungen a.d. Stadtarchiv v. Köln, Heft 4, S. 46.u.6\%\%.

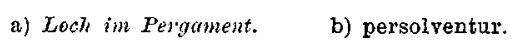


2.

1322 April. - Reinold Herr von Montjoie und Falkenburg und seine Gemahlin Maria ertheilen ihrer Stadt Euskirchen ein Markt- und Gewerbe - Privilegium.

Reynoldus dominus de Montjoie et de Valkenborch ac Maria eius collateralis scabinis et universis oppidanis nostris dilectis de Euskirchen salutem cum affectu. Attendentes fidelitatem quam invenimus in vobis et obsequia graciosa nobis impensa ac impendenda, vobis ista privilegia indulgemus, ut ex eis oppidum nostrum de Euskirchen melioretur et ditetur. (\$. 1. Wochenmarkt.) Scientes, quod de cetero omni septimana sit liberum iorum in predicto oppido nostro loco consueto qualibet feria quarta nunc quarta proxime ventura post diem beate Walburgis incipiendo duraturum toto tempore eterno 1322 Mai 5 . cum omnibus libertatibus que in aliis foris inveniuntur et articulis infrascriptis. Damus enim pacem treugas ac firmum conductum omnibus venientibus ad forum predictum cum bonis suis veniendi et redeundi absque dolo, ita quod nec arrestari poterunt nec teneri aliquo modo, exceptis illis qui sunt exclusi a gracia nostra ac nobis ad os iudicati et homicidis qui hoc fecerunt in terra nostra. (§.2. Jahrmarlt.) Insuper statuimus, ut singulis annis ipsa die beati Cornelii sint nundine annales libere durature, per dictas nun-Sept. 14 . dinas subsequentes concedentes eodem modo pacem, treugas ac bonum conductum omnibus venientibus cum bonis suis ad predictas nundinas quamdiu duraverint et per unum diem ante ac per unum diem post, exceptis illis, qui prius de foro septimanali sunt exclusi. (\$. 3. Vergünstigungen für die Handwerker.) Preterea damus et concedimus omnibus exercentibus officia seu opera manualia, qui nunc morantur in predicto oppido nostro et qui intrant ad morandum seu habitandum, quod de suis officiis plena gaudeant libertate ad decem annos immediate subsequentes, incipientes a prima die fori predicta et erunt quiti ac liberi de bonis suis mobilibus seu de parato bono eorum tempore predicto; sed si hereditatem emerint, de illa solvent medietatem eius quod alii cives de Euskirchen solvunt et dant proporcionaliter de sua hereditate; predictis autem decem annis transactis solvent et dabunt integraliter sicut alii cives. Item omnes exercentes officia intrantes predictum opidum nostrum ad morandum liberi sint et quiti, ut predictum est, pistoribus et braxatoribus exceptis qui solvent sicut alii pistores et braxatores qui nune intus morantur. (\$. 4. Marktpolizeiliche Bestimmungen.) Preterea statuimus ad securiorem libertatem fori et opidi nostri predicti, ut quicumque inchoaverit litem cum aliis ex qua forefactum oritur, quod ille dabit quinque marcas coloniensis pagamenti pro emenda. Insuper emptores mercimoniorum seu bonorum quorumcumque in predicto foro possunt illa ducere, portare ac pellere ubicumque voluerint ad placitum eorum. Item volumus, quod universa blada et legumina mensurentur cum mensura iurata et combusta seu signata signo opidi nostri predicti, et transgressor huius mandati dabit sexaginta solidos dicti pagamenti pro emenda. Preterea statuimus, ut in die fori predicti nullus aperiat saccum suum bladi vel alterius 
leguminis nisi prius sonita sit nola seu campana ad hoc deputata, et qui contra hoc fecerit etiam dabit sexaginta solidos pro emenda. (§. 5. Einsetzung einer eigenen Lebensmittelpolizei.) Ceterum ad premissa volumus et mandamus, ut officiatus noster et scabini de Euskirchen qui sunt et qui pro tempore fuerint, quibus ad hoc damus potestatem, constituant duos viros ad hoc bonos magistros dictos curmeistre qui secundum exigenciam temporis faciant per penam ad hoc aptam vinum, cervisiam, panem, carnes et huiusmodi victualia racionabiliter vendi sicut in aliis locis invenitur. Et ut premissa omnia a nobis et nostris heredibus successoribus firmiter et inviolabiliter observentur, fecimus nostra magna sigilla presentibus appendi in testimonium omnium premissorum. Datum anno domini millesimo trecentesimo vicesimo secundo feria secunda post diem pasce.

Düren, Stadtarchiv, Or. Perg. m. Bruchst. eines Siegels.

Gedruckt: H. J. Werners, Beilage zum Verwaltungsbericht der Stadt Düren 1879/80, S. 1. 